\title{
Verticillium wilt of olive: a case study to implement an integrated strategy to control a soil-borne pathogen
}

\author{
Francisco Javier López-Escudero • \\ Jesús Mercado-Blanco
}

Received: 12 July 2010 /Accepted: 22 October 2010 /Published online: 10 November 2010

(C) The Author(s) 2010. This article is published with open access at Springerlink.com

\begin{abstract}
Olive (Olea europaea L.) is one of the first domesticated and cultivated tree species and has historical, social and economical relevance. However, its future as a strategic commodity in Mediterranean agriculture is threatened by diverse biotic (traditional and new/emerging pests and diseases) and abiotic (erosion, climate change) menaces. These problems could also be of relevance for new geographical areas where olive cultivation is not traditional but is increasingly spreading (i.e., South America, Australia, etc). One of the major constraints for olive cultivation is Verticillium wilt, a vascular disease caused by the soil-borne fungus Verticillium dahliae Kleb. In this review we describe how Verticillium wilt of olive (VWO) has become a major problem for olive
\end{abstract}

Responsible Editor: Hans Lambers.

F. J. López-Escudero

Departamento de Agronomía, Universidad de Córdoba,

Campus Universitario de Rabanales,

Edificio Celestino Mutis (C4),

14071 Córdoba, Spain

J. Mercado-Blanco $(\bowtie)$

Departamento de Protección de Cultivos,

Instituto de Agricultura Sostenible,

Consejo Superior de Investigaciones Científicas (CSIC),

Apartado 4084,

14080 Córdoba, Spain

e-mail: jesus.mercado@ias.csic.es cultivation during the last two decades. Similar to other vascular diseases, VWO is difficult to manage and single control measure are mostly ineffective. Therefore, an integrated disease management strategy that fits modern sustainable agriculture criteria must be implemented. Multidisciplinary research efforts and advances to understand this pathosystem and to develop appropriate control measures are summarized. The main conclusion is that a holistic approach is the best strategy to effectively control VWO, integrating biological, chemical, physical, and cultural approaches.

Keywords Defoliating and non-defoliating pathotypes · Integrated disease management . Microsclerotia $\cdot$ Molecular detection - Olea europaea L. - Olive cultivars $\cdot$ Pathogen diversity $\cdot$ Disease recovery phenomenon $\cdot$ Resistance $\cdot$ Soil solarization . Vascular disease $\cdot$ Verticillium dahliae $\cdot$ Verticillium wilt control
Abbreviations
AFLP Amplified fragment length polymorphism
ATMT Agrobacterium tumefaciens-mediated trans- formation
CLSM Confocal laser scanning microscopy
D Defoliating
DI Disease incidence
MS Microsclerotia
ND Non-defoliating 
PCR Polymerase chain reaction

RAPD Random amplified polymorphic DNA

VCG Vegetative compatibility group

VWO Verticillium wilt of olive

\section{History, importance and cultivation range of olive}

Olive (Olea europaea L.), belonging to the Oleaceae botanical family, is a long-living and legendary tree with more than economical importance. The oil extracted from its drupe is part of human culture and history, being used for preparing food, oil lamp, medicine and cosmetics, or for sacred rituals. Abundant archaeological evidences demonstrate the significance of this tree, its fruit and oil in the history and culture of different Mediterranean peoples. Thus, it is cited in the Bible and the Koran, repeatedly mentioned by Homer in the Odyssey, and frequently present in Greek mythology.

Olive is one of the most ancient cultured plants and the only species within the Oleaceae family with edible fruit. Domestication took place around 6.000 5.000 B.C., probably from wild olives (O. europaea L. subsp. sylvestris). Due to the presence of abundant latent buds in the wood, olive is easy to propagate and this may have contributed to its cultivation at ancient times (Zohary and Spiegel-Roy 1975; Caballero and del Río 2008a). The origin and domestication of olive is debated among historians, but it likely originated from the region surrounded by the south of the Caucasian range, the Persian high plateau, and coastal Syria. It is assumed that its expansion throughout the Mediterranean Basin took place from the Anatolian peninsula, Cyprus, Crete and Egypt, at first by the Greeks and Phoenicians, later by the Carthaginians, Romans, and Arabs. Therefore, olive is linked to the history of some of the most ancient Mediterranean civilizations. Later, at the time of the large transoceanic voyages in the 15th and 16th centuries, it spread to the Americas, and more recently, it was introduced and cultivated in South Africa, China, Japan and Australia (Civantos 2008).

Olive cultivation is concentrated between latitudes $30^{\circ}-45^{\circ}$ at both the northern and southern hemispheres in Mediterranean-type climatic regions. Thus, $97 \%$ of the global cultivation area (approximately 10.5 millions ha) is located in the Mediterranean Basin, $0.8 \%$ in the Americas, $1.5 \%$ in Asia and $0.01 \%$ in Oceania (FAO
2008). Olive is nowadays a crop with a huge economical, social and ecological importance within the Mediterranean Basin. For instance, olive cultivation acreage in Spain, the world's largest olive-oil producer, is $2.6 \times 10^{6}$ ha (FAO 2008). A summary of the main olive producing countries in the world is presented in Table 1. Olive oil, the main product from olive trees, is an important fat source. It is a principal component of the so-called Mediterranean diet, and the benefits of its consumption have been frequently highlighted. Diverse studies have demonstrated that olive oil is salutary due to its lipid profile rich in monounsaturated fatty acids, particularly oleic acid, and the presence of other minor components (PérezJiménez et al. 2007).

Olive is cultivated in a wide variety of soils and can tolerate a broad range of physicochemical conditions. For instance, olive is drought-resistant, heat tolerant, and well-adapted to a wide range of soil $\mathrm{pH}(5.5-8.5)$. Similarly, olive has high tolerance to salinity (Aragüés et al. 2010) and to an excess of boron and chlorine (Navarro and Parra 2008). However, olive trees are sensitive to poorly oxygenated soils which may occur for example after persistent flooding. Flood tolerance is cultivar-dependent and it is associated with the capacity to produce adventitious roots near the soil surface (Aragüés et al. 2004). In general, flood tolerance is lower in young trees and during the active growing phase of the tree (Sánchez-Hernández et al. 1998; Navarro and Parra 2008).

Traditional olive orchards in the Mediterranean Basin have variable tree densities which depend on topography and water availability (Fig. 1). For instance, orchards with low tree densities (20 trees/ha) can be found in Tunisia (Fig. 1a). However, traditional dry-land olive plantations can frequently support plant densities up to 100 tree/ha, a common situation in Mediterranean Basin countries such as Greece, Portugal or Spain. In these countries the presence of high-sloped dry land orchards (100-150 trees/ha) is not unusual (Fig. 1b), a situation that may favor heavy erosion. During the last two decades, olive orchards with higher tree densities have been progressively established in Greece (200 trees/ha), Italy (100-400 trees/ha) or Spain (75-250 trees/ha), either under irrigation or dry-land regimes (Navarro and Parra 2008) (Fig. 1c). Finally, establishment of high-tree-density orchards (up to 2,000 trees/ ha) with drip-irrigation systems is becoming relevant in some regions. This new concept of olive growing is 
Table 1 Importance of olive cultivation worldwide and distribution of Verticillium wilt of olive

\begin{tabular}{|c|c|c|c|c|c|}
\hline \multirow[t]{2}{*}{ Country /zone } & \multicolumn{2}{|c|}{ Olive fruit production $^{\mathrm{a}}$} & \multicolumn{2}{|l|}{ Area $^{\mathrm{a}}$} & \multirow[t]{2}{*}{ First report of Verticillium wilt of olive } \\
\hline & Tons $(\times 1000)$ & $\%$ from total & $\mathrm{Ha}$ & $\%$ from total & \\
\hline Spain & $6.222,10$ & 34,41 & 2.600 .000 & 23,98 & Caballero et al. 1980 \\
\hline Italy & $3.512,66$ & 19,42 & 1.211 .776 & 11,17 & Ruggieri 1946 \\
\hline Greece & $2.444,23$ & 13,52 & 800.000 & 7,38 & Zachos 1963 \\
\hline Turkey & $1.464,24$ & 8,10 & 774.370 & 7,14 & Saydam and Copcu 1972 \\
\hline Tunisia & $1.183,00$ & 6,54 & 3.000 .000 & 27,67 & - \\
\hline Morocco & 765,38 & 4,23 & 547.600 & 5,05 & Serrhini and Zeroual 1995 \\
\hline Syria & 495,31 & 2,74 & 600.498 & 5,54 & Al-Ahmad and Mosli 1993 \\
\hline Portugal & 375,00 & 2,07 & 379.400 & 3,50 & - \\
\hline Egypt & 318,00 & 1,76 & 50.000 & 0,46 & - \\
\hline Algeria & 220,00 & 1,22 & 270.000 & 2,49 & Bellahcene et al. 2000 \\
\hline Libya & 165,00 & 0,91 & 148.000 & 1,36 & - \\
\hline Argentina & 160,00 & 0,88 & 52.000 & 0,47 & - \\
\hline Palestine & 141,00 & 0,78 & 93.000 & 0,85 & - \\
\hline Jordan & 94,06 & 0,52 & 60.531 & 0,55 & Manluk et al. 1984 \\
\hline Lebanon & 76,00 & 0,42 & 58.600 & 0,54 & - \\
\hline EEUU & 58,97 & 0,33 & 12.141 & 0,11 & Snyder et al. 1950 (California) \\
\hline Australia & 57,12 & 0,32 & 10.500 & 0,09 & Morschel 1961 \\
\hline Peru & 52,44 & 0,29 & 9.456 & 0,08 & - \\
\hline Iran & 40,00 & 0,22 & 23.000 & 0,21 & Sanei et al. 2004 \\
\hline Croatia & 34,52 & 0,19 & 14.346 & 0,13 & - \\
\hline France & 22,66 & 0,13 & 18.853 & 0,17 & Vigouroux 1975 \\
\hline Malta & - & & - & - & Porta-Puglia and Mifsud 2005 \\
\hline Israel & 29,50 & 0,16 & 16.000 & 0,14 & Levin et al. 2003a \\
\hline WORLD & 18.083 .800 & 100,00 & 10.839 .026 & 100.00 & \\
\hline
\end{tabular}

${ }^{a}$ Data from the Food and Agriculture Organization of the United Nations (FAO) for 2008. (http://faostat.fao.org/site/567/default. aspx\#ancor). $-=$ Non available data

known as hedgerow, super-intensive olive orchard system, and may modify the traditional landscape of olive growing areas in the near future (Fig. 1d). The impact of olive cultivation systems on incidence and severity of the most relevant olive pests and diseases has received scant attention. However, some reports are warning on the vulnerability of trees to certain diseases when higher vegetation densities are created (Trapero et al. 2009a). Thus, increased incidence of attacks by air-borne fungi such as Fusicladium oleaginum (formerly Spilocaea oleagina) (olive peacock spot), Pseudocercospora cladosporioides (olive cercosporiose) and Colletotrichum spp. (olive anthracnose) have been reported. Trapero et al. (2009a) also report on the increase of Pseudomonas savastanoi pv. savastanoi (olive knot) incidence in hedgerow olive orchards, probably due to damage caused by harvesting machines. The possible impact of the high-treedensity cultivation systems on diseases caused by soil-borne pathogens has, to our knowledge, not been studied.

One of the major constraints for olive cultivation is Verticillium wilt, a vascular disease caused by the soil-borne fungus Verticillium dahliae Kleb. General aspects on the Verticillium genus and Verticillium wilts and their control have been excellently reviewed elsewhere (Hiemstra and Harris 1998; Pegg and Brady 2002; Barbara and Clewes 2003; Fradin and Thomma 2006; Robb 2007; Klosterman et al. 2009. In this review we describe how Verticillium wilt of olive has developed into a major problem for olive cultivation during the last two decades, identifying 
Fig. 1 Olive orchards showing different tree densities, topography and irrigation regime: traditional low tree density olive orchard in North of Tunisia, a region with a rainfall regime below $200 \mathrm{~mm}(\mathbf{a})$; traditional dry-land orchard in a high slope area (100-150 trees/ha) (b); Intensive (7x $5 \mathrm{~m})$ irrigated olive plantation (c); and a high-treedensity orchard (hedgerow system, 2.000 trees/ha) of cultivar Arbequina (d). Orchards in $\mathbf{b}, \mathbf{c}$ and $\mathbf{d}$ are located in Southern Spain. Picture 1 (a) was kindly provided by Dr. Luis F. Roca
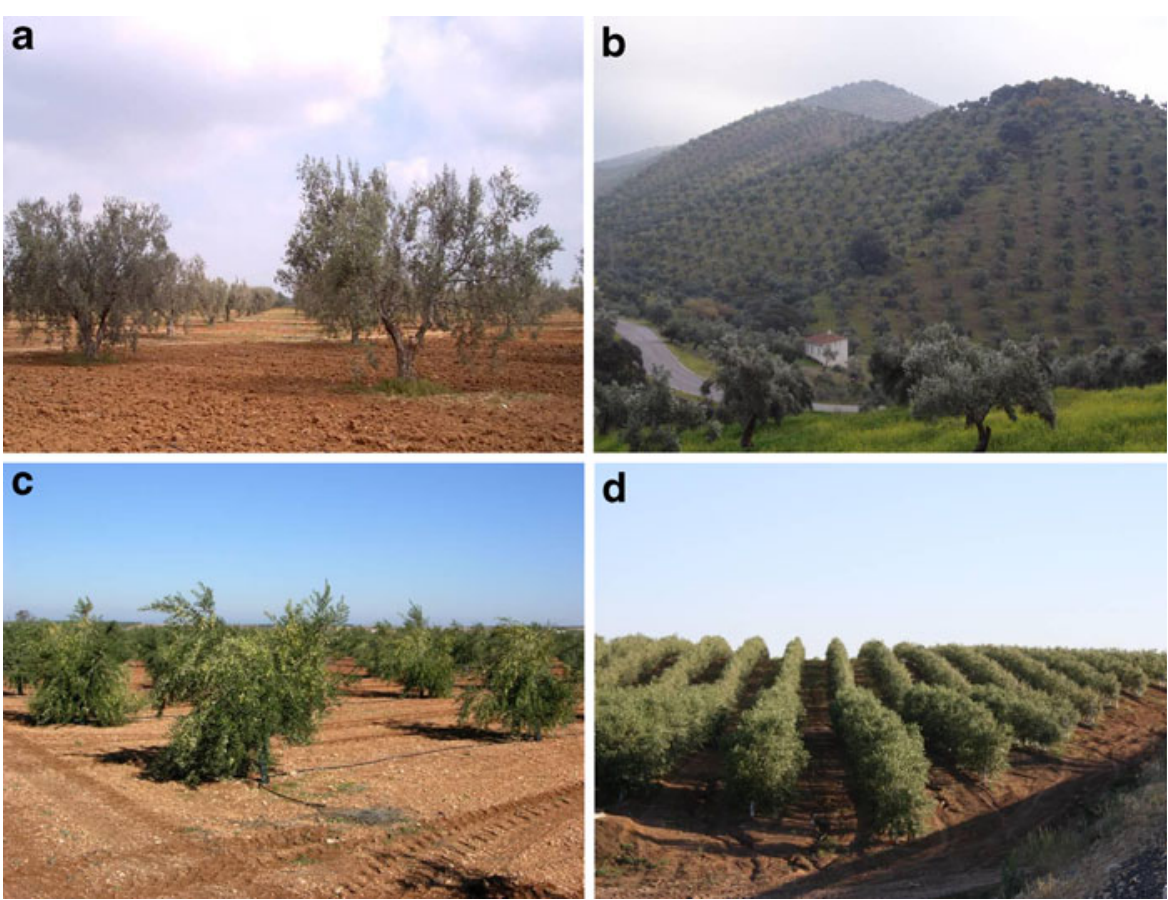

epidemiological factors that might have contributed to its expansion. A second part will focus on the description of an integrated disease management strategy to effectively control this disease. We summarize efforts carried out to understand this pathosystem and to develop appropriate control measures. This ranges from unraveling the genetic, molecular, and pathogenic diversity of the pathogen to implementation of adequate cultural practices, and from the development of molecular procedures to detect the pathogen both in planta and in soil to studies on the potential use of biological control. Other important topics include the evaluation of pathogen resistance of different genotypes and the management of soils before the establishment of new orchards.

\section{Current importance of Verticillium wilt of olive}

Verticillium wilt of olive (VWO) is considered the most serious biotic threat to this commodity. This disease has been detected in almost all regions where olive is cultivated, causing serious concern to growers, nursery companies and the olive-oil industry. The disease was described for the first time in Italy (Ruggieri 1946), and since then, the list of olive- growing regions where VWO has been reported is continuously enlarged (Table 1).

Adequate assessment of the actual economic losses caused by VWO in olive orchards is complicated. There are diverse reasons for this related to the nature of the disease and characteristics of this tree crop. Olive trees usually undergo repeated infections, either in the same season or in successive ones, from $V$. dahliae propagules present in soil, and these recurring infections may (or may not) kill the entire tree. It is more common, however, that a tree is only partially affected by the disease during a given growing season, with variable severity of wilting symptoms (i.e. die-back of individual branches, partial leave defoliations or inflorescence necrosis) limiting or stopping tree growth and production. Olive flowering only takes place in 1year old shoots. Therefore, if these shoots are affected by the disease, the expected production of the tree will be lost in the following season. Nevertheless, affected trees may eventually overcome the disease as a result of producing new tissues around previous necrotic lesions, and recovered branches of affected trees can reach normal yield levels in following growing seasons. To increase the complexity of assessing the impact of VWO, olive has a long juvenile period before entering in production, and during this time, the entire tree has higher probability to be killed by the 
pathogen. Finally, the longevity of olive, it can be productive for many decades, poses difficulties for an exact assessment of the economic value, and losses resulting from VWO.

A lack of broad and systematic surveys may be providing an incomplete depiction of the expansion and importance of the disease. Nonetheless, partial surveys on VWO incidence and resulting crop losses have been performed. For example, Thanassoulopoulos et al. (1979) reported a VWO incidence of $2-3 \%$ ( $1 \%$ tree mortality), and harvest losses of $1 \%$ of the national Greek production. In Spain, 1980-1983 surveys showed that the disease was present in Southern provinces near the Guadalquivir valley with $38.5 \%$ incidence in the 122 adult orchards inspected (Blanco-López et al. 1984). Surveys in the period 1994-1996 detected significant disease (39.5\% incidence in 112 newly-established orchards) in locations situated far from areas were VWO was first detected (Sánchez-Hernández et al. 1998). Since then, an increasing incidence and severity of VWO attacks has being reported in different olive-growing areas of Spain (Jiménez-Díaz et al. 2009; Rodríguez et al. 2009a). Al-Ahmad and Mosli (1993) estimated a loss of $1-2.3 \%$ due to the fact that $0.9-4.5 \%$ of surveyed olive trees were affected in Syria. In Morocco, Serrhini and Zeroual (1995) found that VWO affected $10-30 \%$ of trees in $60 \%$ of the olive orchards they inspected. VWO is also relevant in Algeria, and surveys have shown that the disease is present in most of the olive growing areas, affecting up to $90 \%$ of the orchards that were examined, with a mean disease incidence [DI] of 12\% (Bellahcene et al. 2000). Levin et al. (2003a) have estimated a reduction of $75-89 \%$ in the production of susceptible olive cv. Picual in irrigated Israelian orchards. A survey in the Apulia region (Southern Italy) revealed that $16 \%$ of surveyed olive fields were infested with $V$. dahliae, and, more importantly, the pathogen was found in $50 \%$ of olive nurseries analyzed (Nigro et al. 2005). Finally, a recent inspection covering $90 \%$ of the total olive acreage in Turkey revealed that $V$. dahliae was prevalent in $35 \%$ of all olive orchards inspected and that DI reached 3.1\% (Dervis et al. 2010). Reports are also confirming the presence of the disease in non traditional olive cultivating countries such as Australia (Sergeeva and Spooner-Hart 2009) or Argentina (Pérez et al. 2010). VWO seems to be a minor problem so far in these regions, nonetheless adequate actions should be promptly considered to avoid further spread of the disease. The overall picture that emerges from these surveys is that VWO is expanding due to overlapping triggering factors, some of which are poorly understood. Epidemiological aspects related to this expansion will be discussed later.

\section{Symptomatology and aetiology of Verticillium wilt of olive}

Symptomatology: Verticillium wilt of olive syndromes

Two VWO syndromes have traditionally been distinguished in olive: namely, an acute form ('apoplexy') (Fig. 2a) and a chronic form ('slow decline') (Fig. 2b and c) (Jiménez-Díaz et al. 1998). The 'apoplexy' syndrome is characterized by rapid outbreaks involving severe wilting of main and secondary branches which occurs mainly in late winter to early spring under Mediterranean Basin conditions. Leaves first become chlorotic, then turn light-brown and undergo progressive rolling inward, remaining attached to the branches. The final result is a rapid and extensive dieback of twigs and branches (Fig. 2a). When apoplexy occurs in young plants the death of the entire tree is very common (Blanco-López et al. 1984; RodríguezJurado et al. 1993; Jiménez-Díaz et al. 1998; LópezEscudero and Blanco-López 2001). The 'slow decline' is characterized by heavy defoliation (green or dull-green leaves in this case) of branches (Fig. 2b), foliar chlorosis and mummification and death of inflorescences (Fig. 2c), beginning in spring and slowly progressing to early summer. Defoliation usually affects some of the tree shoots, and it is characteristic that still-green leaves may remain attached at the distal end of the shoots (Fig. 2b).

Affected branches, or even the main trunk of the tree, often show a purple hue or long and slightly-sunken necrotic lesions that correspond with the longitudinal distribution of the infected xylem vessels. All or some of the symptoms of any of the VWO syndromes can coincide in one infected tree, although this will depend on the length of the period conducive for the disease. For instance, mummification of fruits (Fig. 2d) at different growth and maturation stages can develop from spring to fall in areas where adequate climatic conditions are present. 
Fig. 2 Olive orchard showing trees severely affected by the apoplexy syndrome of Verticillium wilt of olive (see text for details). The rapid and extensive die-back of twigs and branches can affect the tree partially (a). Symptoms of the slow decline syndrome: defoliation of green or dull-green leaves (b), and necrosis of inflorescences (c). Mummification of fruits on a wilted tree (d)
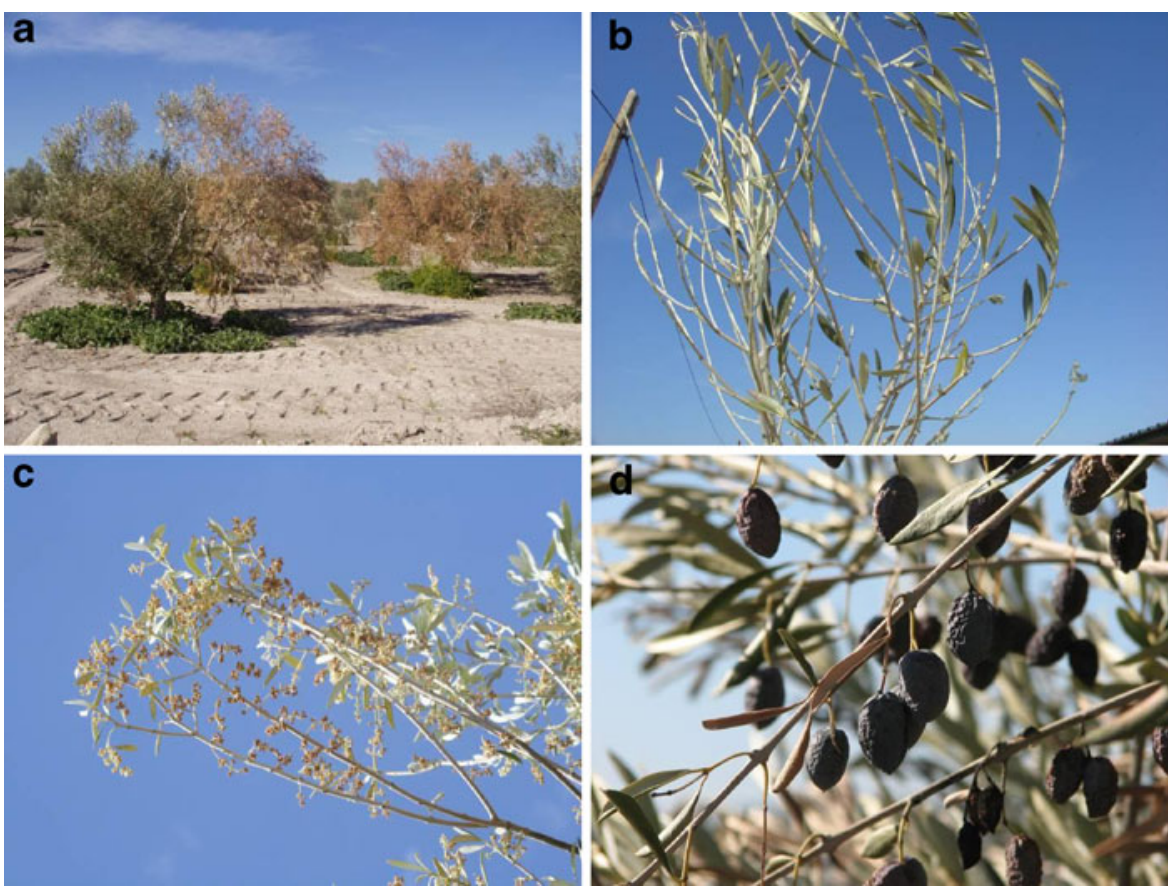

Infected trees that have not died due to the disease, may recover. Such trees are able to produce new vascular tissue that can completely enclose old necrotic xylem vessels, enabling new vegetative growth in affected stems and branches (Tjamos et al. 1991; López-Escudero and Blanco-López 2001). Similarly, diseased but recovered plants usually produce suckers at the basis of the trunk. Understanding this phenomenon of natural recovery may be of relevance to develop an effective integrated disease management strategy.

It is worth mentioning here that VWO symptoms severity depends, among other factors, on olive cultivar susceptibility, pathogen inoculum potential (density) in soil, and environmental conditions. Moreover, some VWO symptoms are less specific than those observed in other woody hosts that are susceptible to $V$. dahliae. Thus, some VWO symptoms can be confounded or overlapped with others caused by different (a)biotic stresses. For instance, aerial and non-specific symptoms caused by Phytophthora spp. in olive should be particularly emphasized (Sánchez-Hernández et al. 1998). This oomycete causes root rot of olive trees which is a specific symptom with diagnostic value. However, there are no specific aerial symptoms associated with root rot. Phytophthora infection leads to a widespread blight that can affect the entire tree crown, and that may quickly kill young olive plants
(Sánchez-Hernández et al. 1998). Olive root rot caused by Phytophthora spp. may lead to flaccidity and desiccation of leaves and shoots, leaf yellowing and defoliation, a symptomatology that is nearly indistinguishable from the 'apoplexy' syndrome caused by $V$. dahliae attacks. Thus, surveys conducted in olive groves in Andalucía (southern Spain) aimed to identify the aetiology of the so-called olive "dry syndrome", identified $V$. dahliae and Phytophthora megasperma as the causal agents of this syndrome in respectively $36.2 \%$ and $33.3 \%$ of the inspected fields (SánchezHernández et al. 1998). This ambiguity dictates the development of pathogen isolation and identification methods in order to provide a correct diagnosis (see below).

The causal agent: taxonomy, general features and host range

The aetiological agent of VWO is the soil-borne fungus Verticillium dahliae Kleb. (Klebahn 1913) (Ascomycota; Sordariomycetes; Phyllachorales). It is a hemibiotrophic, haploid species for which no sexual state has been identified to date (Pegg and Brady 2002; Barbara and Clewes 2003; Fradin and Thomma 2006; Klosterman et al. 2009). This pathogen is microscopically characterized by the presence of 
hyaline conidiophores and production of conidia from the tips of phialides borne in whorls of erect conidiophores (namely verticils) (Fig. 3a). Colonies of $V$. dahliae are of moderate growth rate in culturing media and display a wide range of morphologies (López-Escudero et al. 2003). The cells of the hyphae, phialides and conidia so far examined are mononuclear, but the tip of the hyphae can have up to 15 nuclei. Verticillium dahliae differentiates morphologically from other phytopathogenic species within the genus Verticillium (i.e. V. albo-atrum) by the formation of typical melanized, resistant resting structures (microsclerotia, [MS]) (Fig. 3b). These MS originate from hyphal swelling and subsequent lateral budding which leads to the formation of cell clusters (Hall and Ly 1972; Perry and Evert 1984). Microsclerotia are produced in dead or dying tissues of infected plants at the end of the parasitic phase of $V$. dahliae life's cycle (see below).

Verticillium dahliae is one of the most important species within the genus Verticillium because of its ample distribution and its broad host range. Indeed, this pathogenic fungus causes severe vascular wilt diseases in many economically-important herbaceous and woody crop species. Also many forest tree species are susceptible to $V$. dahliae infections (Sinclair et al. 1987; Hiemstra and Harris 1998; Pegg and Brady 2002, and references therein). Finally, because of the epidemiological implications, it is worth mentioning the susceptibility of a large number of weeds to this pathogen (Thanassoulopoulos et al. 1981; Vargas-Machuca et al. 1987; Yildiz et al. 2009).

Diversity of Verticillium dahliae infecting olive

\section{Morphological and physiological variability}

Verticillium dahliae shows a wide morphological and physiological diversity: broad differences in shape and color of colonies develop in different culture media and variable types of conidiophores and MS can be found (Pegg and Brady 2002 and references therein). However, morphological criteria cannot solely be used to establish a suitable distinction among subspecific groups which may display, for instance, differential pathogenicity or virulence. Thus, diverse studies have indicated that morphology of MS produced by $V$. dahliae on different culture media might be correlated with the virulence of the isolate. For instance, López-Escudero and BlancoLópez (2005c) reported significant differences in the average length/width ratio among MS produced by different isolates on modified sodium polypectate agar (Butterfield and DeVay 1977), a common culture medium used to assess pathogen inoculum density in soil (see below). Indeed, MS produced by highly-virulent isolates were elongated and showed an average length/width ratio of 4.06 , whereas those
Fig. 3 Characteristic erect conidiophores (verticils) of Verticillium dahliae bearing conidia at the tips of phialides (a). Typical melanized microsclerotia (b). Microphotographs were obtained from cultures grown on potato dextrose agar (PDA) plates. Bar represents $50 \mu \mathrm{m}$ in both images
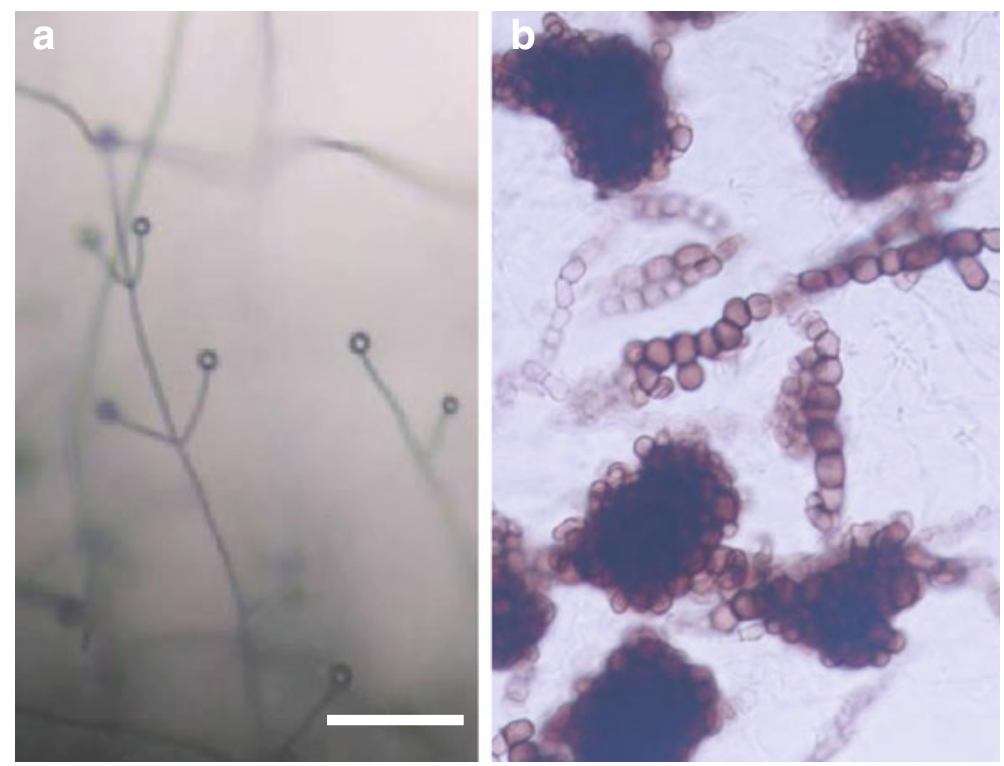
produced by mildly-virulent isolates were more rounded and showed an average ratio of 2.92 . Verticillium dahliae isolates causing a defoliating syndrome in cotton and olive can detoxify the benzylisoquinoline alkaloid sanguinarine, and have a growth optimum temperature of $24-27^{\circ} \mathrm{C}$, whereas isolates that do not induce defoliation in these hosts are not able to detoxify this compound and their optimum temperature ranged between 21 and $24^{\circ} \mathrm{C}$ (Bejarano-Alcázar et al. 1996).

\section{Pathogenicity groups}

Severity of VWO attacks depends on the virulence of the $V$. dahliae pathotype that infects the tree. Thus, $V$. dahliae isolates infecting olive are traditionally classified into defoliating (D) and non-defoliating (ND) pathotypes, according to their ability to cause the complete fall of green leaves (Rodríguez-Jurado et al. 1993). Interestingly, differential virulence displayed by isolates infecting cotton (Gossypium hirsutum L.) was also described in olive (Schnathorst and Sibbett 1971a). Thus, an isolate recovered from cotton or olive displays cross virulence in both crops. The $\mathrm{D}$ pathotype is highly virulent and causes severe symptoms including wilt, chlorosis, defoliation, drastic weight and height reduction and, eventually, death of the tree (Blanco-López et al. 1984; Rodríguez-Jurado et al. 1993; López-Escudero and Blanco-López 2001; Birem et al. 2009). The ND pathotype causes nearly the same symptoms in olive as D-pathotype infections, although at milder (defoliation of green leaves) or moderate (die-back, chlorosis or necrosis) levels. Similarly, it induces reduction in weight and, to a lesser extent, in height under favorable environmental conditions (López-Escudero and Blanco-López 2001; López-Escudero et al. 2004, 2007a; Martos-Moreno et al. 2006). Differences in virulence seem to be consistent among olive cultivars (López-Escudero et al. 2004, 2007a; Martos-Moreno et al. 2006; Dervis et al. 2010).

The broad host range and apparent low host specificity suggests that $V$. dahliae populations contain low pathogenic and genetic diversity. However, $V$. dahliae virulence variability is apparent by the aforementioned presence of the D and ND pathotypes infecting both cotton and olive. Isolates of the D pathotype are more virulent than ND isolates (Schnathorst and Mathre 1966a; Bejarano-Alcázar et al. 1996, 1997; LópezEscudero and Blanco-López 2001, 2007a). Consequent- ly, olive and cotton cultivars tolerant to the less virulent pathotype (ND) are severely affected by the more virulent one (D), and epidemics caused by the latter start earlier and develop faster and more severely.

Therefore, understanding the genetic and pathogenic diversity of $V$. dahliae populations is of relevance for the effective implementation of an integrated disease management strategy. For instance, the successful use of resistant cultivars in a given geographical area can be compromised by the variability of the pathogen population structure (i.e., presence of different races or pathotypes) found in that region. Thus, the optimal use of resistant genotypes and/or the efficient application of additional disease control measures need of an appropriate knowledge on the structure, history, and evolutionary potential of the pathogen populations (McDonald and Linde 2002).

\section{Genetic diversity: Verticillium dahliae vegetative compatibility groups}

As mentioned above, $V$. dahliae is a strictly asexualreproducing fungus. Therefore, the genetic structure of its populations is determined by the genotypic diversity which is influenced by parameters such as: size of the population (density of inoculum), genetic drift, mutational rate, distribution and dissemination of the pathogen by infected planting material, plant residues and/or pathogen-infested soil, migration (flow) of genotypes, mortality rate, or the mode of asexual reproduction (McDonald and Linde 2002). Moreover, the only possible way for $V$. dahliae to exchange genetic material between populations is through hyphal anastomosis (fusion of hyphae) and subsequent heterokaryosis (fusion of nuclei). Therefore, two isolates which can anastomose their hyphae and form a stable heterokaryon are considered compatible and belong to the same vegetative compatibility group (VCG) (Leslie 1993; Katan 2000b). Verticillium dahliae VCGs are mostly identified using spontaneous nitrate-nonutilizing (nit) mutants. If two isolates belong to the same VCG, their nit mutants will anastomose and produce wild-type growth in complementation assays (Korolev and Katan 1997). Isolates belonging to a VCG have the potential to share the same "pool" of genes and would be genetically separated from other individuals belonging to a different VCG thanks to socalled incompatibility mechanisms (Leslie 1993). Thus, $V$. dahliae isolates from different VCGs are 
thought to be genetically-isolated populations, potentially varying in a number of ecological, physiological and virulence traits (Katan 2000b). The study of VCGs has traditionally served to explore genetic diversity in $V$. dahliae populations from the perspectives of geographical origin and/or plant host provenance of isolates. Currently, VCG1 (A and B), VCG2 (A and B), and VCG4 (A and B) (Chen 1994; Daayf et al. 1995; Dobinson et al. 2000; Joaquim and Rowe 1990, 1991; and Korolev et al. 2000, 2001; Strausbaugh et al. 1992; Zhengjun et al. 1998) are fully accepted. The differentiation into subgroups A and B is based on the frequency and vigor of nit mutant complementation (Joaquim and Rowe 1991; Strausbaugh 1993). Other VCGs, either less prevalent or localized in well-defined geographical areas, have been reported as well (namely VCG3, VCG5, VCG6, VCGBr or VCGBa) (Bhat and Subbarao 1999; Bhat et al. 2003; Joaquim and Rowe
1990; Strausbaugh et al. 1992; Jiménez-Díaz et al. 2006). Regarding to $V$. dahliae isolates infecting olive, only representatives of VCG1A, VCG2A, VCG2B, and VCG4B have so far been identified (Pérez-Artés et al. 2000; Cherrab et al. 2002; Tantaoui et al. 2002; Tsror and Levin 2003; Bellahcene et al. 2005b; Sanei et al. 2005; Collado-Romero et al. 2006; Dervis et al. 2007, 2010) (Fig. 4).

Association between genetic and molecular diversity and its correlation with host specificity, virulence and geographical distribution

The possibility to find a correlation between $V$. dahliae VCGs and differential virulence in relevant crops would be valuable for disease prediction and breeding for resistance (Katan 2000b). So far, however, contradictory results have been reported and no definitive

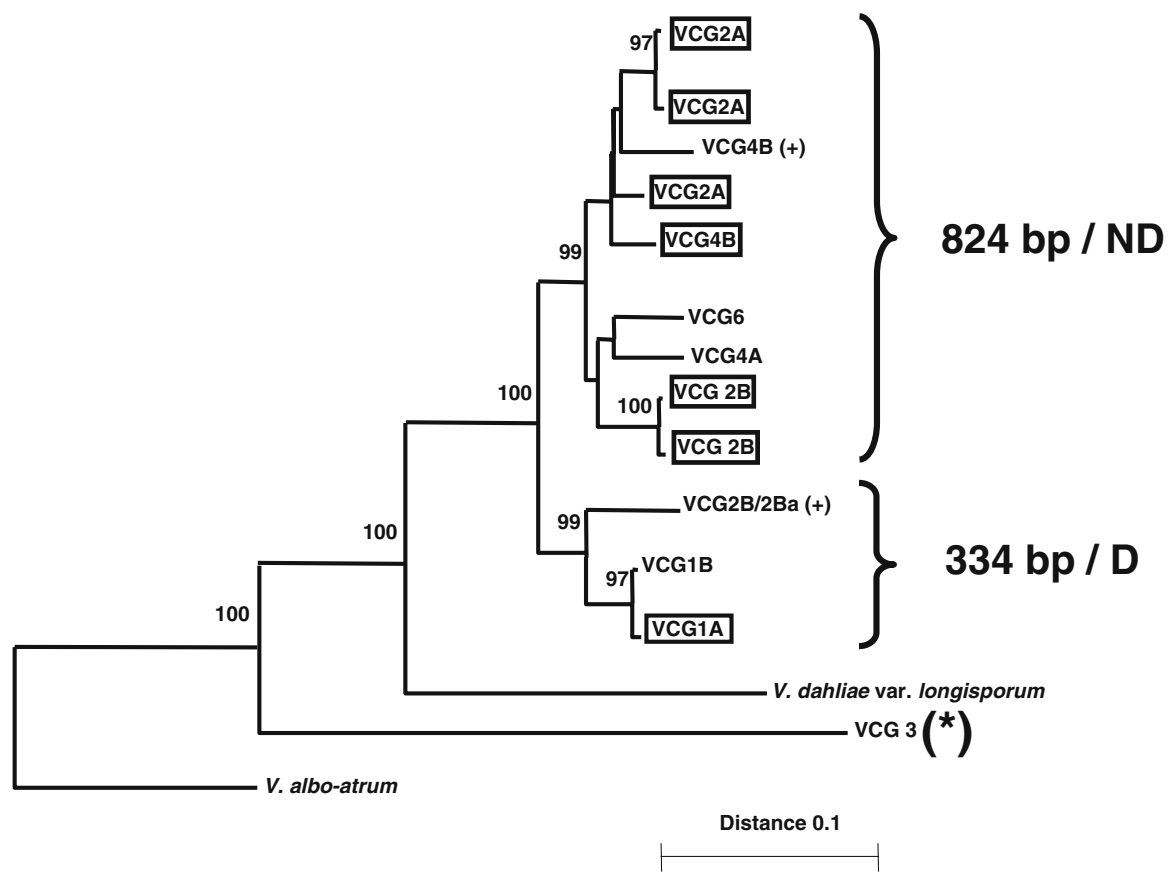

Fig. 4 Simplified phenogram of genetic distance (simple matching method) derived from neighbor-joining (Saitou and Nei 1987) analysis of some 580 AFLP fragments from a broad collection $(>200)$ of Verticillium dahliae isolates (representatives of $V$. albo-atrum and $V$. dahliae var. longisporum were also included in the analysis). Only bootstrap values above 95 are shown (1,000 replicates). Vegetative compatibility groups (VCG) from which olive isolates have been reported so far are boxed. The ' $824 \mathrm{bp} / \mathrm{ND}$ ' notation means $V$. dahliae isolates which can be identified by the 824-bp PCR marker amplified in non-defoliating (ND) olive and cotton isolates. The '334 bp/ ND' notation means $V$. dahliae isolates which can be identified by the 334-bp PCR marker amplified in defoliating (D) olive and cotton isolates (see text for details). The 334-bp PCR marker is also amplified in VCG3 isolates $(*)$; however, this group has not been reported to infect olive. $(+)$, Subgroups exclusively found to infect artichoke in Spain (Jiménez-Díaz et al. 2006). For details in AFLP-based phenetic and phylogenetic analyses of $V$. dahliae VCGs, consult Collado-Romero et al. 2006, 2008, 2010 
conclusions can be drawn. Indeed, some studies point to a worldwide, prevalent distribution of VCG1, VCG2, and VCG4, suggesting a limited VCG diversity. Other investigations suggested that some VCGs may prevail on a crop in a given geographic area (Joaquim and Rowe 1991; Strausbaugh 1993; Katan 2000b; Subbarao et al. 1995; Dobinson et al. 1998; Elena 2000; Korolev et al. 2000; Bhat et al. 2003; Hiemstra and RatajGuranowska 2003). On the other hand, considering VCGs as fully genetically isolated groups may be a strict statement. In fact, the existence of weak complementation and formation of heterokaryons between isolates belonging to different VCGs (or certain subgroups), or even between different Verticillium species, has been described (Daayf et al. 1995; Hiemstra and Rataj-Guranowska 2003; Joaquim and Rowe 1990; Strausbaugh et al. 1992). This may suggest the existence of a continuum of genetic variation surpassing the genetic barrier of the VCG. This can be further supported by recent findings suggesting that parasexuality within the genus Verticillium can be an important mechanism to enhance genetic variability. Thus, the appearance of interspecific hybrids may contribute to diversity and evolution, and more importantly, could be of outstanding significance for the emergence of novel traits such as new (or modified) host adaptation and/or enhanced virulence to host genotypes (Collado-Romero et al. 2010).

Examing Verticillium wilts from a disease control perspective, the relationship between pathogenicity and the presence of a particular $V$. dahliae genetic group (VCG) linked in a geographical context or host plant can be crucial. However, a clear-cut association between isolates of a particular VCG and their pathogenicity or virulence in a given host plant is not always easy to ascertain. Thus, some studies support the correlation between VCG assignment of isolates and their differential virulence displayed in a given plant (Joaquim and Rowe 1990; Bhat and Subbarao 1999; Tsror et al. 2001; Korolev et al. 2001), whereas others conclude that different isolates from the same VCG show different degrees of virulence in a same crop (Elena 1999; Korolev et al. 2000, 2001). Interesting examples pointing to an association between genetic groups and host specificity are: i) the predominance of isolates assigned to VCG4 in potato (Solanum tuberosum L.) infections in the United States and Israel (Joaquim and Rowe 1991; Strausbaugh et al. 1992; Korolev et al. 2000); ii) the aforementioned association of the highly-virulent, D-pathotype isolates of cotton (Gossypium hirsutum L.) with their assignment to VCG1A described in various areas such as Central Asia, China, Israel, Peru, Spain, Turkey and USA (Daayf et al. 1995; Korolev et al. 2001; Zhengjun et al. 1998; Korolev et al. 2008; Dervis et al. 2008), in what may constitute an example of dispersal of isolates from an original focus of infected cotton genotypes; or iii) the prevalence of VCG2A and 2B isolates infecting artichoke (Cynara scolymus L.) in a defined artichokecultivating region of eastern-central Spain, with VCG2B being the most virulent in this host (JiménezDíaz et al. 2006). Studies regarding to olive-infecting $V$. dahliae isolates, are indicating the following scenario: 1) highly-virulent isolates, inducing severe syndromes in olive, generally belong to the D pathotype; 2) all olive D-pathotype isolates have so far been assigned to VCG1A in all countries where this group/pathotype has been reported (Pérez-Artés et al. 2000; Collado-Romero et al. 2006; Dervis et al. 2010); and 3) olive isolates assigned to other VCGs (namely, VCG2 and VCG4) have been characterized as ND pathotype either by pathogenicity testing or by PCR-based molecular pathotyping (Fig. 4). However, a correlation has not always been reported between VCG and pathogenicity in olive isolates (Tantaoui et al. 2002), or a continuum of virulence has been found within the VCG1A/D pathotype group, revealing that severity of symptoms caused by some D isolates was not significantly different to that induced by ND isolates in artificial inoculation experiments (Dervis et al. 2010). Thus, despite VCG assignment provides useful information on the diversity of $V$. dahliae populations, it could be insufficient to correlate genetic diversity with traits such as level of virulence or host specificity. Therefore, more refined tools such as molecular methodologies are necessary. They provide higher resolution than VCG analysis to unravel the complex structure of $V$. dahliae populations.

The diversity and the structure of $V$. dahliae populations have also been studied using different neutral molecular markers that are best suited to make inferences on migration and drift genotype. For strictly asexual-reproducing fungi, these markers also assist in estimating the variability in ecologicallyimportant characters (i.e., pathogenicity, virulence). Thus, characterization and genetic differentiation of $V$. dahliae (and/or other Verticillium spp.) isolates has been carried out by restriction fragment length 
polymorphism (RFLP) (Carder and Barbara 1991; Typas et al. 1992; Carder et al. 1994; Okoli et al. 1994; Dobinson et al. 2000), random amplified polymorphic DNA (RAPD) (Messner et al. 1996; Koike et al. 1996; Zeise and von Tiedemann 2002; Bhat and Subbarao 1999), and amplified fragment length polymorphism (AFLP) (Collins et al. 2003; Fahleson et al. 2003; Radišek et al. 2003; ColladoRomero et al. 2006). Analysis and comparison of DNA sequences such as the intergenic spacer (IGS) and internal transcribed spacer (ITS) regions of genes encoding ribosomal RNA, as well as repeated DNA sequences, have also been used to study variation within $V$. dahliae (Morton et al. 1995a, b; Subbarao et al. 1995; Dobinson et al. 1998; Pramateftaki et al. 2000).

Olive-infecting $V$. dahliae isolates have been studied using RAPD (Cherrab et al. 2000; Pérez-Artés et al. 2000; Lachquer and Sedra 2002; Bellahcene et al. 2005a; Nigro et al. 2005), AFLP (Collado-Romero et al. 2006), and PCR-specific markers (Pérez-Artés et al. 2000; Bellahcene et al. 2005a; Mercado-Blanco et al. 2003b; Collins et al. 2005; Nigro et al. 2005; ColladoRomero et al. 2006; Dervis et al. 2010). RAPD fingerprints have provided variable results, for instance, this approach was successful in correlating the geographical origin of a collection of olive-infecting Moroccan isolates, but not their colony morphology (Cherrab et al. 2000). On the other hand, RAPD fingerprinting showed that olive-infecting $V$. dahliae isolates in Algeria showed limited diversity, which correlated with the presence of only one VCG, and solely the ND pathotype (Bellahcene et al. 2005a). Previously, no correlation was found between RAPD markers, the geographic origin or the host plants of the isolates examined, although four RAPD groups were described (Lachquer and Sedra 2002). Finally, RAPD fingerprinting indicated a low level of genetic diversity in $V$. dahliae olive-infecting population in the Apulia region (Italy). No correlation was found among pathogen isolates, olive cultivars and geographical location, and PCR analysis showed that all isolates (with the exception of one inconclusive result) belonged to the ND pathotype (Nigro et al. 2005).

Early studies on molecular variability of $V$. dahliae populations infecting cotton and olive in southern Spain unraveled the presence of different D- and ND-specific RAPD patterns from which SCARs ("sequence characterized amplified regions") markers were subsequently identified (Pérez-Artés et al. 2000). These studies already revealed significant molecular diversity in $V$. dahliae cotton/olive-infecting populations. Indeed, specific RAPD fingerprints were found in all the examined D-pathotype isolates which were assigned to VCG1A, therefore distinguishing this group as genetically homogeneous. However, the rest of isolates evaluated (characterized as ND pathotype) showed greater diversity than the previous group and no specific RAPD pattern could be associated to the different VCGs (VCG2A, 2B or 4B) to which these isolates were assigned (Pérez-Artés et al. 2000). More recently, the molecular variability amongst $V$. dahliae VCGs infecting artichoke, cotton and olive from diverse regions of the Mediterranean Basin was assessed by AFLP, which offers a much higher resolution than RAPD fingerprinting, and by PCR markers analyses (Collado-Romero et al. 2006) (Fig. 4). The aim of this study was to explore associations between molecular patterns (AFLP and PCR markers) and phenotypic features (virulence), vegetative compatibility diversity, and geographical origin of host plants. The results demonstrated that $V$. dahliae isolates within a VCG subgroup were similar at the molecular level, and that clustering of isolates correlated with VCG subgroups regardless of host source and geographic origin. An important conclusion to be drawn from this study was that VCGs are clonal groups, each one genetically differentiated and/or isolated from the others. As for olive-infecting isolates concerns, a group exclusively found in artichoke (namely VCG2 $\mathrm{B}^{334} / 2 \beta^{334}$ cluster) was molecularly similar to isolates of VCG1A group (which harbors cotton and olive-infecting D pathotype; Fig. 4). Interestingly, VCG1A isolates from artichoke and cotton induced a severe (defoliating) syndrome in cotton but not in artichoke, with this VCG being the most virulent group to cotton over any other group. In contrast, isolates of VCG1A were the least virulent to artichoke, whereas VCG2B and VCG4B isolates were the most virulent ones in this host (Jiménez-Díaz et al. 2006). Indeed, molecular (AFLP and PCR-based pathotyping) and VCG diversity of isolates showed a variable pattern of correlation with regards to virulence in different hosts.

RAPD analyses, as stated above, showed low molecular variability among VCG1A/D-pathotype isolates (cotton and olive) originating from southern Spain. However, the use of AFLP fingerprints and PCR-based pathotyping in a wider collection of 
isolates revealed molecular differences between VCG1A/D pathotype isolates from Spain and isolates of the same group from Greece and Turkey. This would support the idea that new strains of $V$. dahliae VCG1A might develop in different geographic areas or, alternatively, that they may have spread from a common focus. Moreover, the lack of a 462-bp sequence in VCG1A isolates from Greece and Turkey, which is a consistent PCR marker of Spanish cotton and olive D isolates (Mercado-Blanco et al. 2003b) would support each of these two possibilities (Collado-Romero et al. 2006). Interestingly, the absence of the 462-bp PCR marker has been further confirmed in three VCG1 cotton-infecting isolates in Israel, however no further information on the subgroups was reported (Korolev et al. 2008). In addition, this maker was absent in all VCG1A/D pathotype olive-infecting isolates in Turkey so far examined (Dervis et al. 2010). Despite this, the VCG1A/D-pathotype isolates from Turkey, infecting olive are molecularly different from their Spanish relatives, yet pathogenicity tests did not revealed any significant differences in virulence among them (Dervis et al. 2010).

Molecular tools have also served to study the evolutionary relationships among $V$. dahliae VCG (sub)groups. Using parsimony analysis of AFLP fingerprints and sequences of six DNA regions (actin, $\beta$-tubulin, calmodulin, and histone-3 genes, the ITS 1 and 2 regions of the rDNA, and a $V$. dahliae-specific polymorphic DNA sequence) from a broad collection of isolates has provided interesting conclusions (Collado-Romero et al. 2008, 2010). A low number of polymorphisms in gene sequences was found among isolates of different VCGs, and individual gene genealogies provided very little resolution at the VCG level. However, evolutionary relationships among $V$. dahliae VCGs (that is, at the intraspecific level) were resolved by phylogenetic analyses of AFLP fingerprints, multiple gene genealogies, and the combined data of AFLP fingerprinting and multiple gene genealogies. Thus, two main lineages were identified. One including VCG1A (which harbors olive D pathotype isolates), VCG1B, and VCG2 $\mathrm{B}^{334}$, and another comprising two closely related subgroups of VCGs (where olive ND isolates are allocated): VCG2A and VCG4B (subclade 1) and VCG2B ${ }^{824}$, VCG4A, and VCG6 (subclade 2) (Fig. 4). This study demonstrated that $V$. dahliae VCG subgroups were monophyletic except for VCG2B that appeared to be polyphyletic. An additional interesting conclusion from this study was that limiting the parsimony analysis either to AFLP fingerprints or DNA sequences would have obscured intra-VCG differentiation, and that the dual approach represented by the independent and combined analyses of AFLP fingerprints and DNA sequences was a highly valuable approach (Collado-Romero et al. 2008).

In summary, all these studies have provided fundamental knowledge on the structure of $V$. dahliae populations, including those isolates infecting olive. Moreover, relevant association between VCG and molecular diversity has been found, although correlation with host specificity or pathogen virulence is sometimes difficult to establish and/or interpret. In addition, these results offer a valuable practical perspective as well: the availability of molecular tools for in planta and in soil pathogen detection (see below). Indeed, from the variety of molecular markers identified, proper selection can be made from those ones clearly associated with specific groups or linked to a particular phenotypic trait (i.e., pathotype). Thus, specific DNA sequences can be identified to design VCG-specific or pathotype-specific primers to be used in PCR-based detection and diagnosis procedures of $V$. dahliae isolates infecting olive or any other host (Pérez-Artés et al. 2000; Mercado-Blanco et al. 2003b; Collado-Romero et al. 2006, 2009) (Fig. 4).

\section{Verticillium wilt of olive disease cycle}

The aforementioned MS are the survival structures in soil during the non-parasitic phase of the life cycle of $V$. dahliae. In addition, they represent the main dispersal form as well as the primary infectious propagules (Wilhelm 1955; Schnathorst 1981). MS are produced in dead or dying tissues (especially in leaves, branches and herbaceous stems) of infected plants during the late stages of the parasitic phase of the pathogen's life cycle. Eventually, MS are incorporated into soil upon plant debris degradation. During the time MS are not associated with a plant root host, these quiescent structures can withstand the adverse physical, chemical and biological conditions usually found in soils, remaining viable for up to 15 years (Wilhelm 1955). In contrast, $V$. dahliae 
hyphae and conidia lose their viability in soils in a short period of time (Green 1969; Schreiber and Green 1962). MS can therefore endure dormancy whilst waiting for favorable environmental conditions and/or the presence of root exudates from their main hosts that stimulate their germination. They can also germinate and infect alternative hosts and it is worth noting the existence of numerous tolerant hosts as well as $V$. dahliae-asymptomatic carriers, which actually represent potential reservoirs for the increase in both density and dispersal of pathogen inoculum (Pegg and Brady 2002). During the non-parasitic phase, the dispersal of MS occurs through a number of natural (soil movement by water, air, irrigation, etc) and human (machinery, etc) means that will be reviewed later on. The effectiveness of some of these dispersal mechanisms may explain the wide distribution of the pathogen in specific olive growing areas.

Recent insightful molecular work has provided interesting information on MS development process. Thus, a class II hydrophobin gene ( $V D H 1)$ has been demonstrated to play an essential role in the persistence of $V$. dahliae in soils, since it is needed for wildtype MS development and for enhanced tolerance of conidia to desiccation (Klimes and Dobinson 2006). However, this gene was not implicated in normal Verticillium wilt progress in tomato (Lycopersicum esculentum L.) plants. More recently, $V D H 1$ gene has been suggested to mediate MS development from conidiophores as well (Klimes et al. 2008). A mitogen-activated protein (MAP) kinase gene $(V M K 1)$ was also associated with pathogenicity and MS formation. Indeed, disruption of $V M K 1$ gene via Agrobacterium tumefaciens-mediated transformation (ATMT) in lettuce (Lactuca sativa L.) and tomato $V$. dahliae isolates provoked reduction in virulence in several host plants. Similarly, mutants of this gene showed reduced conidiation and MS formation (Rauyaree et al. 2005). These studies are truly relevant in unraveling molecular mechanisms of MS morphogenesis. This will eventually provide important knowledge on $V$. dahliae propagule survival and pathogenic-related mechanisms which should open novel avenues to develop effective Verticillium wilt control measures.

The parasitic phase of $V$. dahliae biological cycle begins with the germination of MS in the soil, a process stimulated by the presence of root exudates from either susceptible or non-susceptible plants.
Germination gives rise to the formation of infective hyphae which penetrate the roots, grow within xylem vessels, producing mycelium and spores and finally spreading to the aerial part of the plant aided by the transport of the spores in the xylem transpiration stream (Pegg and Brady 2002). When colonization is widespread, expression of symptoms is triggered (wilting and drying of shoots, defoliation, inflorescence dehydration, etc.). At late stages of the disease MS are formed in dead or dying plant tissues and pathogen biomass could be formed outside the fading vascular tissue. The incorporation and subsequent decomposition of plant debris, particularly of infected leaves (Wilhelm and Taylor 1965; Tjamos and Botseas 1987; Tjamos and Tsougriani 1990), facilitates MS release into soil, closing the parasitic phase of $V$. dahliae and contributing to the increase of the number of infective propagules within (Navas-Cortés et al. 2008). Dormant MS will remain in soil until suitable conditions favor germination and and the formation of new infections and start a new parasitic phase (Pegg and Brady 2002).

A number of microscopy studies have examined the interaction of Verticillium spp. with various plant species, including olive, although mainly focused on anatomical aspects of the colonization process (for instance, Garber and Houston 1966; Perry and Evert 1983; Gerik and Huisman 1988; Rodríguez-Jurado 1993; Zhou et al. 2006). Recently, the combination of biotechnological tools (construction of fluorescentlytagged $V$. dahliae derivatives) and powerful microscopic methodologies (confocal laser scanning microscopy [CLSM]), which allow direct in vivo observations of tissue samples, made it possible to examine in a very detailed way the $V$. dahliae colonization process in herbaceous hosts. Thus, the infection and colonization process of oilseed rape (Brassica napus L.) (Eynck et al. 2007) and lettuce (Vallad and Subbarao 2008) have been elegantly described.

The use of fluorescent tagging in conjunction with three-dimensional tissue sectioning and CLSM has been implemented to examine the infection and colonization processes of the susceptible olive cultivar Arbequina by $V$. dahliae (Prieto et al. 2009). An EYFP (enhanced yellow fluorescent protein)-tagged derivative (VDAT-36I) of an olive-infecting D pathotype isolate was produced by ATMT. Interestingly, these processes were examined under non-gnotobiotic 
conditions, using nursery-produced olive plants with fully developed root systems and therefore harboring abundant and diverse naturally-resident microorganisms (Mercado-Blanco et al. 2001). This provided an experimental design resembling conditions much closer to natural environments rather than those present in gnotobiotic systems frequently utilized in this type of study. Results have shown that inner colonization of olive root tissues predominantly takes place through a passive entry mechanism, facilitated by the presence of micro or macro root injuries (Prieto et al. 2009). This scenario has been suggested as the most likely occurring in plant root systems growing under natural soil conditions (Pegg 1985; Pegg and Brady 2002). Ingress of infective hyphae into the olive root system by naturally-produced injuries (for instance, caused by nematodes), or man-made damage (produced by cultural practices) has been previously suggested to favor $V$. dahliae invasion, although pathogen entrance through intact rootlets or at the site of emergence of lateral roots was not discounted as a possible route of entry (Rodríguez-Jurado 1993). Indeed, CLSM imagery showed that entry of $V$. dahliae into root epidermal cells by an active mechanism, or at the points of emergence of lateral roots (Fig. 5), could also take place although to a much lesser extent than entrance by available root breakages (Prieto et al. 2009). An interesting finding was the detection of VDAT-36I MS on the olive root surface just a few days after artificial inoculation. Production of MS on olive roots under this experimental set-up took place much earlier than that observed in oilseed rape (Eynck et al. 2007). About 1 week after inoculation, abundant VDAT-36I biomass on/in root tissues was visualized by CLSM. Then, VDAT-36I hyphae reached the root vascular tissue after root cortex cells were actively invaded by fungal biomass at both inter- and intracellularly levels (Prieto et al. 2009). In fact, if the pathogen was able to penetrate the cortex tissue, little hindrance to final invasion of xylem vessels was observed in the susceptible cv. Arbequina. This has also been scored in the lettuce- $V$. dahliae pathosystem (Vallad and Subbarao 2008). Once in the root vascular system, pathogen colonization of above-ground vascular tissues of trees can be very rapid, and may eventually reach the leaf petioles (Tjamos and Botseas 1987; Rijkers et al. 1992). Indeed, $V$. dahliae can progress throughout the entire length of the plant using a

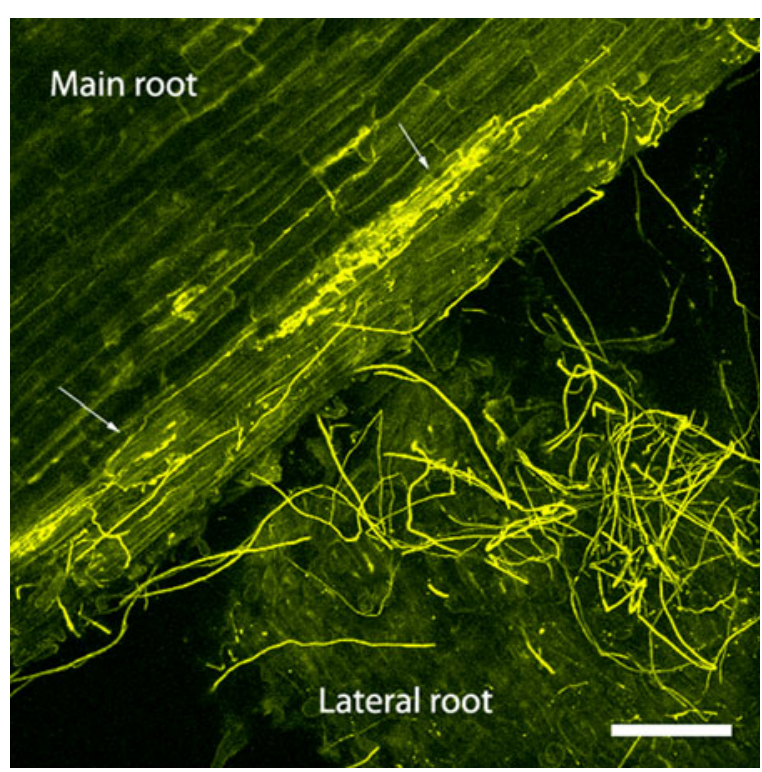

Fig. 5 Confocal laser scanning microscopy (CLSM) image showing the profuse colonization by Verticillium dahliae VDAT-36I at the zone of emergence of a lateral root in olive cv. Arbequina (see text for details). Image is a projection of 45 adjacent confocal optical sections. The focal step size between confocal optical sections was $4 \mu \mathrm{m}$. Image was taken six days after dipping the entire root system in a conidia suspension of VDAT-36I. Hyphae can be easily detected by their strong yellow fluorescence. Events of colonization of epidermal cells can be seen on the main root (arrowed). Bar represents $20 \mu \mathrm{m}$. For further details on the $V$. dahliae-olive bioassay and CLSM imagery, consult Prieto et al. (2009). This picture was kindly provided by Dr. Pilar Prieto

cyclical process consisting of proliferation of hyphae, production of spores, passive transport by the transpiration stream, and new conidia germination cycle (Pegg and Brady 2002). Contrasting to hyphal growth, production of conidia seems to be favored within xylem vessels of trees, likely due to a specific physical-chemical environment providing low level of oxygen and negative potential pressure (Ioannou et al. 1977; Duncan and Himelick 1988). This rapid colonization process precedes the development of symptoms of VWO (Rodríguez-Jurado 1993), and it has been described for a number of woody hosts as well (Hiemstra 1998, and references therein). The final stage in the colonization process of isolate VDAT-36I was verified by CLSM, confirming the rapid progression of the pathogen to the above-ground tissues, exclusively confined within the xylem vessels of both stems and leaf petioles (Prieto et al. 2009). 
The spread of $V$. dahliae biomass within the vascular tissues may be hampered by various physical (deposition of callose and lignin materials, entrapment and vascular occlusion by tyloses, or gel plugs formation in infected vessels) and/or biochemical (for instance, phytoalexins and toxic substances production) defensive mechanisms deployed by the host (reviewed by Mace et al. 1981; Beckman 1987; Tjamos and Beckman 1989; Hiemstra 1998; Pegg and Brady 2002; Fradin and Thomma 2006). Also, anatomical features of the xylem vessels (i.e., size, number or distribution) may play an important role in the resistance of some olive cultivars to infection, as earlier reported in the alfalfa (Medicago sativa L.) $/ V$. albo-atrum interaction (Pennypacker and Leath 1993). In the case of olive/ $V$. dahliae interaction, complete obstruction of aerial xylem vessels was not observed by CLSM, since only living, fluorescentlytagged fungal biomass could be detected (Prieto et al. 2009). However, full occlusion of vessel cells by accumulation of polysaccharide-type materials has been visualized by electron scanning microscopy in the susceptible cv. Picual upon pathogen infection (Baídez et al. 2007). These authors have also shown how $V$. dahliae mycelium propagated and passed from one element to another through the xylem vessel pit membranes. Similarly, this methodological approach showed the obstruction of the xylem lumen by the formation of tyloses and aggregates originated from the degradation of external material of the vessel walls as consequence of adhesion of pathogen hyphae to them. In addition, some phenolic compounds (i.e. quercetin, luteolin or rutin) present in olive were suggested to act as phytoanticipins and/or phytoalexins of olive's natural defense or resistance mechanisms (Baídez et al. 2007). Recently, Markakis et al. (2010) have reported the involvement of verbascoside in defense mechanisms of Greek olive cultivars against $V$. dahliae.

As discussed above, heavy colonization of olive tissues by the pathogen clearly precedes disease symptoms development, as observed by both microscopy (Rodríguez-Jurado 1993; Prieto et al. 2009) and molecular studies (Mercado-Blanco et al. 2001, 2002, 2003a). However, little is known on mechanisms responsible of the wilting syndrome or on host defense responses in olive upon $V$. dahliae infection with the exception of those reported by Baídez et al. (2007) and by Markakis et al. (2010). Nevertheless, physiological alterations as a consequence of pathogen invasion may have a strong influence on photosynthesis, nutrient translocation, water transport, and/or respiration as described in other hosts (Abeles et al. 1992; Resende et al. 1996; Sadras et al. 2000). Indeed, Birem et al. (2009) have recently reported significant reductions in water consumption and chlorophyll production in leaves of artificiallyinoculated 'Picual' (susceptible) plants compared to plants of cv. Frantoio (resistant). This was associated with the progress of the wilt symptoms. Furthermore, ethylene levels in leaf petioles were significantly higher in 'Picual' than in 'Frantoio' plants.

Overall, however, a large gap on fundamental knowledge of both $V$. dahliae pathogenic and virulence mechanisms operating in VWO and defense responses triggered in resistant olive cultivars to $\mathrm{D}$ and ND pathotypes invasion is still waiting to be filled.

\section{Factors contributing to the importance and distribution of Verticillium wilt of olive: epidemiology}

There are a number of key factors contributing to the current VWO importance, distribution and expansion which can be influential either on the pathogen, the host and/or the environment: use of infested (or lack of pathogen-free) soils and/or infected planting and propagation material, pathogen dispersal efficacy, predominant growing of susceptible cultivars, fertilization and irrigation misuse, inadequate soil and crop management practices, climatic and edaphic factors, etc.

It has been traditionally assumed that the incidence and severity of VWO attacks is usually higher in young, newly-established orchards (510 year-old trees), from reports in Greece (Thanassoulopoulos et al. 1979), Spain (Blanco-López et al. 1984), Syria (Al-Ahmad and Mosli 1993) and Morocco (Serrhini and Zeroual 1995). It is also worth mentioning that the current expansion of the disease, particularly in Spain and Turkey (LópezEscudero et al. 2009b; Dervis et al. 2010), has been associated with changes from traditional to new habits in olive growing (for instance, dripirrigation, intensive culturing, etc.). However, it is known that VWO attacks in older (greater than 
50 years-old) trees can take place as well (Wilhelm and Taylor 1965; López-Escudero et al. 2009b), the symptoms observed in these cases being less severe and transient (Cirulli and Montemurro 1976; Thanassoulopoulos et al. 1979; Blanco-López et al. 1984). More recent surveys are further confirming that VWO is rapidly expanding to new areas and also affecting traditional orchards and even very old trees (Sánchez-Hernández et al. 1998; Rodríguez et al. 2008; López-Escudero et al. 2009b). On the other hand, we would like to emphasize that, from an epidemiological perspective one of the most relevant factors is the existence and dispersal of highlyvirulent isolates (D pathotype) in important olivegrowing areas. A well-studied example is the Guadalquivir Valley in Southern Spain, where populations of D-pathotype isolates were initially restricted to marshes at the lower valley (surveys performed in the $80 \mathrm{~s}$ ). Since then, D isolates have continuously spread to olive-growing areas distant from that initial focus (Bejarano-Alcázar et al. 1996; López-Escudero and Blanco-López 2001; MercadoBlanco et al. 2003b; Navas-Cortés et al. 2008; Rodríguez et al. 2008). Indeed, recent surveys have shown that D isolates were recovered from wilted trees in higher percentage $(67.7 \%)$ than ND ones (32.2\%) in Andalucía (Southern Spain), the largest olive cultivation area in the world (López-Escudero et al. 2009b). Moreover, Moraño-Moreno et al. (2008) reported percentages of up to 81 and $12 \%$ of D and ND propagules, respectively, in water used for olive and cotton groves irrigation. Remarkably, an overwhelming prevalence of $\mathrm{D}$ pathotype/ VCG1A isolates has been also reported after a recent survey performed in all important olive-cultivation regions of Turkey (Dervis et al. 2010). This suggests that several triggering factors, some favoring the efficient pathogen dispersal and others favoring the disease progress, can be synergistically contributing to explain the current distribution and importance of VWO.

Factors favoring persistence, increase and dispersal of Verticillium dahliae infective propagules

Previous cultivation of $V$. dahliae-susceptible crops in soils where olive orchards are being established has been identified as one of the major causes for VWO onset and spread (Zachos 1963; Wilhelm and Taylor 1965; Cirulli and Montemurro 1976; Thanassoulopoulos et al. 1979; Blanco-Lopez et al. 1984; Al-Ahmad and Mosli 1993; Serrhini and Zeroual 1995). This is because many of these crops (cotton, potato, tomato, alfalfa, or even olive itself) increase the pathogen population in soil in a very efficient way (Evans et al. 1966; Pegg 1974; Tjamos and Botseas 1987; Tjamos and Tsougriani 1990; Bejarano-Alcázar et al. 1996). Moreover, it has been already mentioned that $V$. dahliae is able to infect a broad range of plant species, existing cross-pathogenicity between olive-infecting isolates and those from other hosts (Snyder et al. 1950; Saydam and Copcu 1972; Cirulli and Montemurro 1976). Thus, pathogen propagules released in soils from infested plant debris of previous herbaceous crops, or disseminated from neighboring fields where susceptible crops are cultivated (Fig. 6a), can eventually provoke high incidences of VWO in olive orchards in the same or nearby plots. For instance, VWO incidence in orchards located less than $10 \mathrm{~km}$ from the Guadalquivir River (Andalucía, southern Spain) was significantly higher in plots
Fig. 6 Dispersal of infective Verticillium dahliae propagules (microsclerotia) within and among olive orchards may be favored by several inadequate cultural practices: pruning and grinding plant debris from affected trees (a), and/or transfer of infested soil from neighboring plots cultivated with other hosts (cotton in the image) (b)
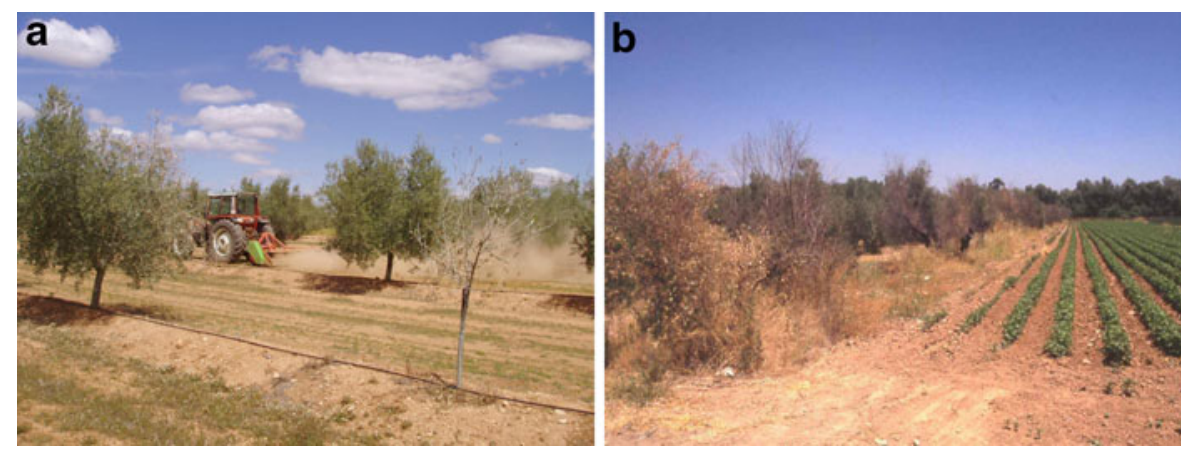
traditionally dedicated to grow diverse susceptible vegetables crops before being replaced by olive. The proximity of neighboring $V$. dahliae-susceptible crops to olive orchards was positively associated with VWO presence (DI $=21.5 \%$ of surveyed orchards), but not when non-susceptible crops surrounded olive orchards (DI $=11.9 \%$ of investigated fields) (López-Escudero et al. 2009b).

VWO attacks are also favored by the capacity of $V$. dahliae MS for prolonged survival in soil, where are incorporated at the end of the parasitic phase along with infected plant debris (Wilhelm 1955). Likewise, the pathogen can persist, and even increase its inoculum potential, in soils by means of colonizing a large number of herbaceous and woody crops as well as wild flora species. Related to this, many susceptible weeds are broadleaf genera frequently found in olive groves (i.e., Anagallis, Lamium, Malva, Matricaria, Medicago, Senecio, Solanum, Veronica, etc.) thus contributing to the proliferation and dispersal of the pathogen in the soil (Thanassoulopoulos et al. 1981; Vargas-Machuca et al. 1987; Heale 1988; Ligoxigakis et al. 2002; Uremis 2005; Yildiz et al. 2009). Although monocot species, both cultivated and weeds, are not considered $V$. dahliae hosts, surface root colonization in oat, barley, corn or wheat has been reported (Benson and Ashworth 1976; Levy and Isaac 1976). Therefore, their contribution to enhance the number of infective pathogen propagules in olive plantations cannot completely be ruled out since some monocot species (mainly barley and wheat) are used as cover crops (see below).

The use of infected planting material (grafts, buds, shoots or cuttings) (Thanassoulopoulos 1993) has been described as one of the major means of $V$. dahliae dissemination. Obviously, a mandatory initial step for an effective VWO control is the implementation of certification programs aimed to produce pathogen-free olive plants (see below). It is also interesting to mention here one study suggesting that $V$. dahliae seed-transmission can also operate in olive, a situation which has been reported in herbaceous hosts (Toit et al. 2005; Vallad et al. 2005). Indeed, V. dahliae was detected in olive seeds by PCR-based assays (Karajeh 2006). However, spreading of the pathogen to new orchards by vertical transmission would be negligible, since olive is almost exclusively propagated by rooted cuttings. Nevertheless, $V$. dahliae-infected seeds/fruits may constitute an additional source for pathogen inoculum increment in soil and for its dispersal to new areas.

The spreading of both soil particles and plant debris carrying $V$. dahliae infective propagules can be facilitated by a number of short- and longdistance means (Fig. 6), enabling MS to reach pathogen-free areas. Indeed, MS present in infested soil can be dispersed within and among olive orchards by wind (Easton et al. 1969), transport of plant residues from affected crops to pathogen-free areas (Schnathorst and Sibbett 1971a, b), or use of cultivating machinery (Al-Ahmad and Mosli 1993; Serrhini and Zeroual 1995), which, in addition, can cause root damage and thus facilitate infection by the pathogen (Tjamos 1993). Similarly, the spread of contaminated plant tissues debris, particularly leaves (Wilhelm and Taylor 1965; Tjamos and Botseas 1987; Tjamos and Tsougriani 1990; Navas-Cortés et al. 2008), or by pruning operations (Fig. 6b) (LópezEscudero et al. 2008) has been documented.

The dispersal of $V$. dahliae propagules by irrigation water has been earlier demonstrated in several herbaceous crops (Easton et al. 1969; Xiao et al. 1998). Moreover, Thanassoulopoulos et al. (1981) early suggested that water runoff after heavy rains or copious irrigation regimes could facilitate the movement of $V$. dahliae propagules in olive plantations soils. Our own results illustrate the epidemiological implications of irrigation systems on $V$. dahliae propagule dissemination in olive fields. López-Escudero and Blanco-López (2005b) first obtained indirect evidences on the important role of irrigation water (dripping irrigation system) in VWO incidence and severity in affected olive groves. Indeed, they found that pathogen inoculum density in wet soil zones around drippers, and its increments over time, were significantly higher than that found in areas outside the influence of soil moisture. On the other hand, the presence of $V$. dahliae MS along the entire irrigation engineering system (i.e., from main water channels and reception tanks of pumping stations to the sand filters and storing water ponds located at the farmer plot) of an irrigation community in Southern Spain were recently evaluated. The study concluded that the irrigation structure examined was indeed providing $V$. dahliae-infested irrigation water (propagule numbers were variable but reached up to $0.94 \mathrm{MS} \mathrm{m}^{-3}$ ) to a large area devoted to olive cultivation where VWO is present (López-Escudero et al. 2009a). 
Factors favoring disease onset, progress and severity

A) Agronomical factors: irrigation, fertilization, tree density and soil management

Verticillium wilts losses are particularly high under irrigation regimes in many hosts, including olive (Ruggieri 1948; Cirulli 1981; Schnathorst 1981; Blanco-López and DeVay 1987; Pegg and Brady 2002). However, this fact has been shown to be contradictory in some cases (Xiao and Subbarao 2000). Thus, the trend to shift from dry-land to irrigated systems experienced during the last decades in different olive cultivation areas may have contributed to the expansion of VWO to zones where the disease was not previously reported or was just a minor problem (Dervis et al. 2010). This may be particularly true with the application of large water doses or high irrigation frequencies, or at times which could be especially conducive for $V$. dahliae infection (Blanco-López et al. 1984; López-Escudero and Blanco-López 2005b; López-Escudero et al. 2009b). In fact, drought-resistant cultivars in several crops (i.e., cotton) are not affected by Verticillium wilt when rain fall precipitation is the only available water source, and disease appears when irrigation is introduced (Schnathorst 1981). The effect of irrigation in the onset and development of VWO has been repeatedly reported in Mediterranean countries. Thus, DI values in non-irrigated and irrigated orchards reached $9 \%$ and $21 \%$, respectively, in Morocco (Al-Ahmad and Mosli 1993); 4.5 and $13 \%$ in Syria (Serrhini and Zeroual 1995); 17\% and $40 \%$ in Southern Spain (Blanco-López et al. 1984); or, in a more recent survey, $18.3 \%$ and $20.3 \%$ in the three major olive growing provinces within this latter area (López-Escudero et al. 2009b). Finally, irrigation in combination with high-tree densities seem to favor VWO incidence (Rodríguez et al. 2008).

At first instance, irrigation provides a long-distance dispersal mean for $V$. dahliae propagules. As an example, the D pathotype was more frequently found in olive trees growing in irrigated $(79 \%)$ than in dryfarming $(43 \%)$ orchards, whereas the presence of ND isolates was the same under both irrigation regimes (López-Escudero et al. 2009b). Conversely, an inadequate irrigation management may also constitute an important disease predisposing factor in irrigated areas, as demonstrated in a particular case of saline conditions in Israel (Levin et al. 2003a, b, 2007) (see below). Also, irrigation water can significantly increase pathogen inoculum densities in soil compared to a deficient irrigation regime, as reported in cauliflower (Brassica oleracea L. var. botrytis) (Xiao et al. 1998). The same effect was observed in damp soil zones under the influence of drippers around olive trees (López-Escudero and Blanco-López 2005b). The nature of this phenomenon is not well known and may be due to the arrival of new inoculum by the irrigation water, to an increase of pre-existing inoculum favored by humidity, or to the positive effect of irrigation on disease onset and/or development (López-Escudero and Blanco-López 2005b). In addition, roots growth increases in a wet soil profile, therefore increasing the probability of root-pathogen contact (Huisman 1982; Fernández et al. 1991; Xiao and Subbarao 2000; López-Escudero and BlancoLópez 2005b).

The influence of fertilization on vascular wilt diseases has been studied in a wide range of crops (Pegg and Brady 2002; Huber and Thompson 2007; Datnoff et al. 2007). However, most of the available information on this issue is related to herbaceous plants, and little is known for woody species, including olive. Nutrition affects plant growth and its defense mechanisms against pathogens attacks, particularly inappropriate nitrogen $(\mathrm{N})$ fertilization (Datnoff et al. 2007). In the case of Verticillium wilts, the use of low $\mathrm{N}$ inputs is associated with lower DI and severity (Pegg and Brady 2002). For olive, it is widely assumed that excessive $\mathrm{N}$ fertilization, particularly associated with high irrigation doses or with watering frequencies favoring rapid vegetative growth, can increase the incidence and severity of $V$. dahliae infections, as reported for cotton (El-Zik 1985). However, information is contradictory in many cases, and studies have shown that results depend on the dose or on the $\mathrm{N}$ chemical form applied. For instance, it has been found that $\mathrm{N}$ fertilization in the form of ammonia reduces the number of $V$. dahliae propagules in soil and, furthermore, increases the biological activity of pathogen's antagonists (Pegg and Brady 2002). On the other hand, other soil factors, such as $\mathrm{pH}$, cation exchange capacity, moisture etc., play an important role in the reaction of the plant to fertilization. To the best of our knowledge, no studies on the effect of other nutrients in VWO incidence have been carried out. However, in 
hosts such as cotton and pistachio (Pistacia vera L.), an increase of Verticillium wilt incidence has been associated with K deficiency (Pegg and Brady 2002, and references therein). In summary, the influence of fertilization on VWO incidence and severity is largely unknown and, in our opinion, studies on this issue should be encouraged.

The influence of high tree densities on Verticillium wilts onset and incidence over time has been seldom studied. López-Escudero et al. (2009c) have recently evaluated whether modern olive cultivation systems, either intensive ( $>200$ tree/ha) or super-intensive (2,000 tree/ha, arranged in hedgerows), may have consequences on VWO occurrence. Results have shown that tree density seems not to influence VWO incidence under field conditions. In fact, the only relevant effect observed when a susceptible cultivar was present was a reduction in the time period elapsed between orchard establishment and appearance of first disease symptoms. Therefore, it is likely that factors such us cultivar susceptibility, virulence of pathogen isolates present in soil and their distribution, soil management, or the interaction among any of them, are more decisive than tree density by itself.

The adoption of an overzealous soil management system may also pose phytopathological risks for an olive orchard, with tilling being reported as an important mechanism for $V$. dahliae dispersal within and among cultivated plots in herbaceous and woody hosts (Hiemstra and Harris 1998; Pegg and Brady 2002). Additionally, it is postulated that tilling can cause root damage thus facilitating root infection by the pathogen in cotton (Schnathorst and Mathre 1966b) or olive (Tjamos 1993), which in particular produces numerous superficial absorbent secondary roots that may favor root penetration by the pathogen. This effect was also informed by other authors who reported positive correlations between incidence of VWO and the use of chisels and discs (Serrhini and Zeroual 1995) for soil cultivation, or even the number of soil discings (Al-Ahmad and Mosli 1993). On the other hand, non-tilling systems should be supplemented with an exhaustive control of weeds by herbicides to avoid the increase of pathogen inoculum sources (see above). As an alternative, the use of cover crops has emerged as a suitable practice for soil and water conservation in olive cultivation (Gómez et al. 2009; Rodríguez-Lizana et al. 2008). This soil management practice can be a feasible way to reach sustainability in many olive-cropped soils since it may protect against erosion, improve soil structure and increase organic matter contents. Nevertheless, non-cropped weed cover should be avoided since, as mentioned above, many broadleaf weeds frequently found in olive growing areas can be used by $V$. dahliae to survive and multiply. Similarly, inert covers made of pruning debris from diseased olive trees are completely discouraged, since they constitute a primary source of pathogen inoculum spreading (Bejarano-Alcázar 2008; López-Escudero et al. 2008).

The use of soil amendments has an important role within a sustainable agriculture framework (Hamblin 1995), and it is commonly used in small olive plantations in combination with reduce-tilling (van Bruggen 1995; López-Escudero et al. 2008). Additionally, it has proved as an effective eradicative control measure of soil-borne pathogens, either in a direct way (by killing resting and/or infective pathogen propagules), or by indirect means (i.e., inducing favorable conditions to microbial antagonists) (see below). However, an adequate traceability of some organic amendments would be recommended, since they may alone constitute an inoculum source for pathogen spreading. For example, transmission of $V$. dahliae MS by manure from sheep fed on $V$. dahliae-infected cotton debris, which was used as organic amendment at the time an olive orchard was planted, has been demonstrated (López-Escudero and Blanco-López 1999). It is also important to mention that, regrettably, olive growers in some areas have occasionally used olive plant debris (mainly leaves and chopped pruning residues) as organic amendments or even as inert coverts (López-Escudero et al. 2008) (Fig. 6b). Obviously, this practice must be avoided in areas were VWO is prevalent.

B) Environmental factors: temperature, edaphic features and biotic interactions

Despite temperature is one of the most important variables in epidemiology studies, its influence in Verticillium wilts onset and development has been scarcely studied. Optimum temperature for $V$. dahliae ranged from 22 to $25^{\circ} \mathrm{C}$ which coincides with the most favorable temperature for the development of many Verticillium wilts (Garber and Presley 1971). Severity of VWO attacks is favored by air temperatures of $20-25^{\circ} \mathrm{C}$ during spring days, followed by summers with broader thermal amplitude but with day 
peaks not higher than $30-35^{\circ} \mathrm{C}$ (Wilhelm and Taylor 1965; López-Escudero and Blanco-López 2001). However, if during summer days temperatures are above $25^{\circ} \mathrm{C}$ for a prolonged period of time, both pathogen colonization and symptom development normally stop. All these observations and results have served to standardize temperature conditions in controlled-growth chambers to promote VWO epidemics in a number of studies (for instance, MercadoBlanco et al. 2001; López-Escudero et al. 2004).

Similarly, little is known about the influence of edaphic factors on the presence and increase of $V$. dahliae in soil, or on Verticillium wilts onset and development. However, the effect of factors such as $\mathrm{pH}$ changes in soil upon the application of (in)organic amendments to control Verticillium wilt diseases in several herbaceous hosts has been studied to some extend (Lazarovits et al. 2000; Pegg and Brady 2002; Goicoechea 2009). Verticillium dahliae normally occurs in neutral to alkaline soils ( $\mathrm{pH}$ 6-9), since acidic pH's (below 5.5) are inhibitory to pathogen growth and MS production and survival. Moreover, toxic effects to the pathogen caused by the accumulation of $\mathrm{Mn}$ and $\mathrm{Al}$ in host plant tissues at low $\mathrm{pH}$ could subsequently suppress mycelial growth. The reduction of $\mathrm{Ca}$ levels in soils, or the increase of $\mathrm{K}$ or $\mathrm{Mg}$ (for instance, by the application of certain organic amendments), diminish disease severity as well (Pegg and Brady 2002). However, the individual effect of these parameters on the pathogen and the disease could be masked by the interaction with factors such as soil texture, rate of organic matter mineralization, soil microbiota activity, etc. (Gamliel et al. 2000; Lazarovits et al. 2000; Goicoechea 2009).

Most of the studies indicate that natural saline soils or salinity induced by the recycling of salt-rich irrigation water increase the incidence and severity of wilt diseases in potato, tomato, alfalfa or sugar maple (Acer saccharum Marshall) (Pegg and Brady 2002 and references therein). This effect is enhanced in combination with drought stress. It is also notable that some of these studies postulate that increasing salinity can trigger mechanisms of breakdown of resistance of the cultivar used. For instance, VWO was strongly exacerbated in olive cultivars Barnea, Picual and Souri when planted in a sandy-loam saline soil with a high salt content $\left(\mathrm{Na}^{+}: 250-440 \mathrm{Meq}\right.$; $\mathrm{Ca}^{++}$and $\mathrm{Mg}^{++}$: 40-180 Meq; B: 0.0-10 $\mathrm{mg} \mathrm{l}^{-1}$ ) and irrigated with saline water with a salt concentration of $4.2 \mathrm{dS} \mathrm{m}^{-1}$ (Levin et al. 2003a, b, 2007).
Soil texture seems to have a variable effect both on the pathogen and on the disease in several hosts, a likely consequence of the aforementioned complex interactions taking place between soil itself and diverse factors such as organic matter abundance, $\mathrm{pH}$, temperature, moisture, availability of nutrients and/or presence and diversity of fungistatic soil microflora (Pegg and Brady 2002; Goicoechea 2009). Our investigations have also explored whether VWO incidence could be correlated with the soil type where olive orchards are established (López-Escudero et al. 2009b). Thus, field surveys carried out in the main olive growing area in the world (Guadalquivir Valley, southern Spain) have shown that DI was significantly lower (mean percentage $12.9 \%$ ) in olive orchards established in Alfisol than that scored in orchards established in Entisol, Inceptisol or Vertisol soils (USDA Soil Taxonomy). In these cases, mean percentages of wilted trees were similar (Fig. 7).

Finally, a relevant but not well-studied aspect with poses important epidemiological consequences as well as altering the correct implementation of VWO control measures is the interaction between $V$. dahliae and other olive soil-borne pathogens. For instance, olive root rot disease, mainly caused by the oomycetes P. megasperma and Phytophthora inundata (Sánchez-Hernández et al. 1998), has recently experienced an important increase concomitant with the augment of VWO in new olive plantations. Both species are frequently found in soils and their infections, associated with flooding conditions or excessive irrigation, occur at high frequencies. It is interesting to remark that both Phytophthora spp. and $V$. dahliae can survive in soils in the form of resistant structures (oospores and MS, respectively), coexist in the same field, and therefore can simultaneously infect the same tree under appropriate conditions (Sánchez-Hernández et al. 1998; Sánchez-Alcalá 2005). In this context synergistic interactions may take place between both pathogens, thus influencing the development of any of the two syndromes. In relation to this special attention should be given to the possibility that infections by Phytophthora spp. may cause a change in the resistance level of $V$. dahliaeresistant olive cultivars, therefore increasing their susceptibility to VWO or even breaking their resistance to $V$. dahliae.

Another biotic concern is the root-knot nematode Meloidogyne javanica that may cause considerable 


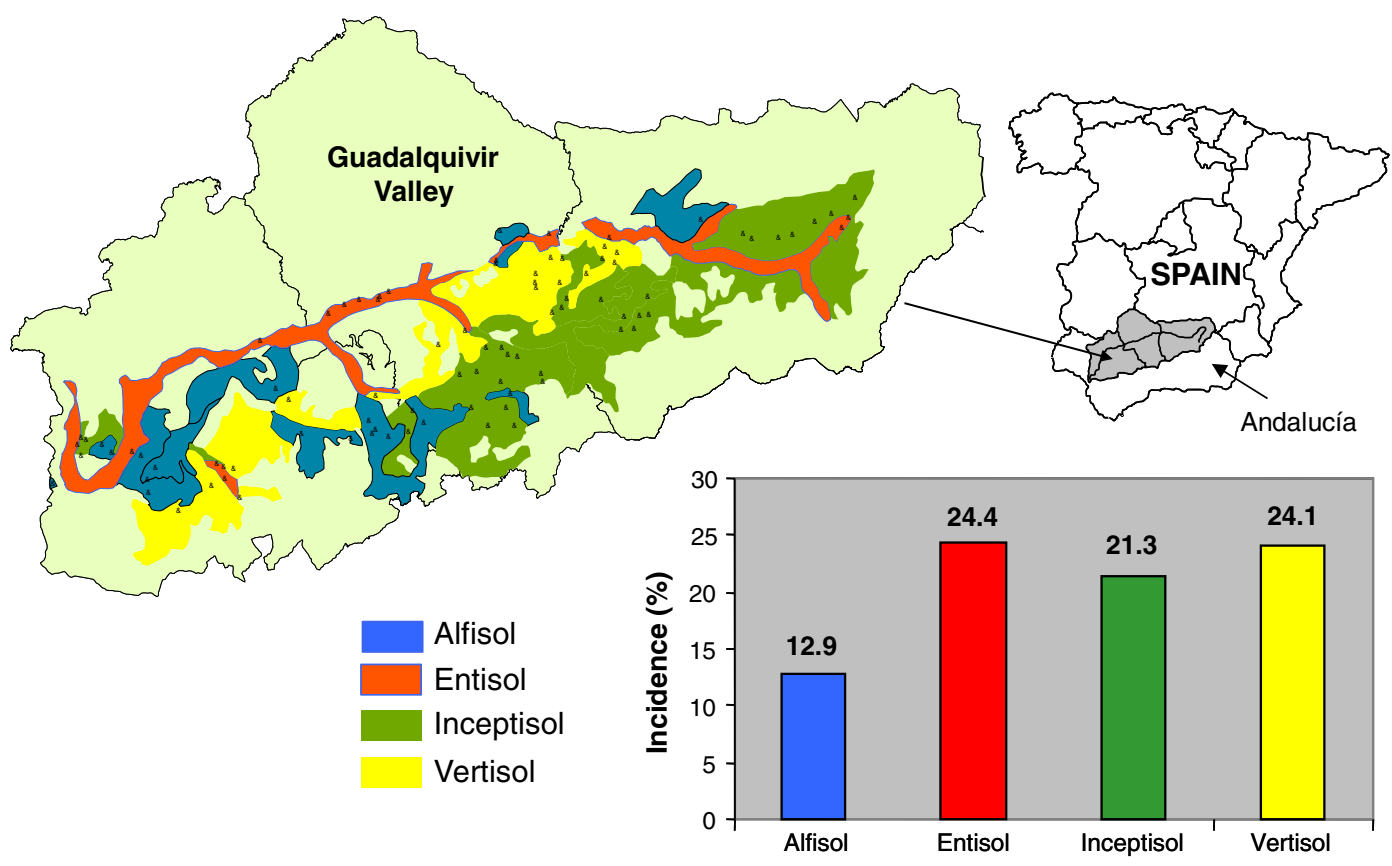

Fig. 7 Influence of the soil type on Verticillium wilt incidence in the Guadalquivir Valley, Andalucía (southern Spain)

damage to olive groves in olive growing areas where V. dahliae is also present (Saeedizadeh et al. 2003, 2006). However, variable observations have been reported for other nematodes (i.e. Meloidogyne spp. and Pratylenchus spp.) which also interact with olive (reviewed by Castillo et al. 2010, and references therein). The study by Saeedizadeh et al. (2003), carried out under greenhouse conditions, demonstrated that seedlings co-inoculated with $V$. dahliae and $M$. javanica experienced a significant growth reduction compared to plants inoculated with any of them, separately. It was also remarkable that galling and nematode population were higher in plant roots potted in a sandy soil than those ones planted in loamy soil. Interestingly enough, fungal colonization in roots and stems was higher in seedlings grown in loamy soil, and wilting symptoms were much severe in plants grown in loamy soil than those in sandy soil (Saeedizadeh et al. 2003).

To conclude this epidemiological section, a recent study may illustrate how some of the previouslydescribed factors may explain the progress of VWO epidemics, although under very precise conditions. Indeed, temporal and spatial analyses of the disease in an olive orchard (about 400 trees/ha, approximately 4 ha, susceptible cv. Arbequina, drip-irrigated, flat plot, nontilling) was carried out during 5 years at Southern Spain
(Navas-Cortés et al. 2008). Assessment of $V$. dahliae isolates infecting the trees was performed by PCRbased and DNA fingerprinting tools as well, to track inoculum sources and spread of pathogen genotypes (D and ND pathotypes) throughout the orchard. Main conclusions of this study were: 1) VWO epidemics in a newly-established, high tree-density, irrigated olive orchard could occur within a relatively short period of time; 2) $V$. dahliae D and ND pathotypes infecting olive trees have different disease spatial patterns; 3) Infections by the $\mathrm{D}$ isolates are more concerning since they can spread rapidly by windblown infected leaves that fall early and numerously from diseased trees; 4) Actions should be taken to avoid sources of primary pathogen inoculum (i.e. propagules in infected planting material and/or infested soil from neighboring fields); 5) Dispersal of inoculum (infested soil and/or infected fallen leaves) by human activities was considered highly relevant; and 6) The dispersal of $V$. dahliae propagules by surface water can be considered of minor importance, and just restricted to surface rain, under a situation of drip irrigation in a flat terrain (Navas-Cortés et al. 2008). It is tempting to speculate whether scenarios like this one, where diverse triggering and overlapping factors are interacting, could serve to describe VWO epidemics in other types of olive orchards, or even in larger areas (i.e., at a regional 
scale). However, multiple and variable orchard-specific factors (agronomical, topographical, edaphic, climatic, pathogen population structure, cultivar susceptibility, etc.) may differentially operate in each particular case, and extrapolation of these results should therefore be done with the necessary caution.

\section{Control of Verticillium wilt of olive: an integrated disease management strategy}

Verticillium wilts, including VWO, are very difficult diseases to control. Diverse factors contribute to this fact and some have already been presented in this review. For instance: 1) the capacity to produce and disseminate MS able to endure in soil for prolonged periods of time; 2) the broad range of hosts which can be colonized even without causing symptoms, thus enhancing the pathogen survival capacity in soil; 3 ) the lack of effectiveness of fungicides due to the pathogen location within the xylem vessels during its parasitic phase; or iv) the presence of genetic variability in $V$. dahliae populations residing in soil where olive is established, which explain the existence of differential virulence (D and ND pathotypes). In woody and long-living hosts such as olive, the prolonged exposure time to infections must be added as a determinant factor.

Therefore, VWO may be seen as a paradigm of a plant disease whose effective control requires the implementation of an integrated disease management strategy, where none of the available control measures is sufficiently effective when applied individually. This strategy should be based in the development and application of both preventive (before-planting) and palliative (post-planting) control measures (Tjamos 1993; Blanco-López and Jiménez-Díaz 1995; Tjamos and Jiménez-Díaz 1998) (Fig. 8). It is evident that prior to establishing a new olive orchard, preventive measures are undoubtedly the most effective and plausible ones from an economic perspective. These actions are basically aimed to pathogen exclusion (i.e., use of healthy plant material and free-pathogen soils) and/or pathogen eradication (i.e., biological, physical, cultural or chemical practices to reduce the number of propagules in the soil). Thereafter, from the time an olive orchard is established, it is particularly encouraged to use physical, biological and cultural methods to: 1) reduce the (pre)existing pathogen inoculum (i.e., soil solarization, organic amendments, destruction of pruning debris, etc); 2) avoid that inoculum cause new infections (i.e., using resistant cultivars); and 3) impede that pathogen propagules spread within and among neighboring orchards (i.e., reducing tillage). It should be stressed that many control actions recommended ahead of planting should also be of application after planting. For example, soil solarization (see below) can be performed before establishing a new orchard, but also carried out when healthy plants will be planted to replace dead trees which have succumbed to VWO. Similarly, the use of microbial antagonists could be at the production stage (nurseries) or as a palliative measure in the field, etc. We will now review some of the pre- and post-planting measures that should be implemented to control VWO. These actions are sustained on the available knowledge on the pathogen, the pathosystem, and the epidemiological factors contributing to the disease so far described.

Pre-planting measures to control VWO

Use of pathogen-free propagation and planting material: development of Verticillium dahliae in planta detection procedures

The possibility that $V$. dahliae persists in symptomless plants alerts about the precautions that must be taken to ensure that healthy propagation and/or planting material is used to establish new olive orchards in pathogen-free soils. Therefore, the early, rapid and reliable in planta detection of the pathogen (particularly of the D pathotype because of its alarming spread) would be of importance for the management of VWO. Thus, the production of pathogen-free certified olive plants in nurseries is a key control measure to avoid pathogen dispersal to new areas. In addition, this should be bound to the use of healthy (pathogen-free or de-infested) soils (see below).

Pathogen-free qualification of olive plants by means of traditional isolation procedures suffers from the inconsistency of recovering $V$. dahliae from affected woody tissues (Blanco-López et al. 1984). Moreover, isolation of the pathogen from plant tissues is timeconsuming and, in the case of VWO, does not provide information about the pathotype (D and/or ND). Alternative diagnostic methods have therefore been developed to overcome these limitations. Thus, molecular detection and differentiation of Verticillium spp. is generally performed by PCR-based procedures. For 
Fig. 8 Strategy for an integrated control of Verticillium wilt of olive. Based on Blanco-López and JiménezDíaz (1995) and Trapero and Blanco-López (2008)

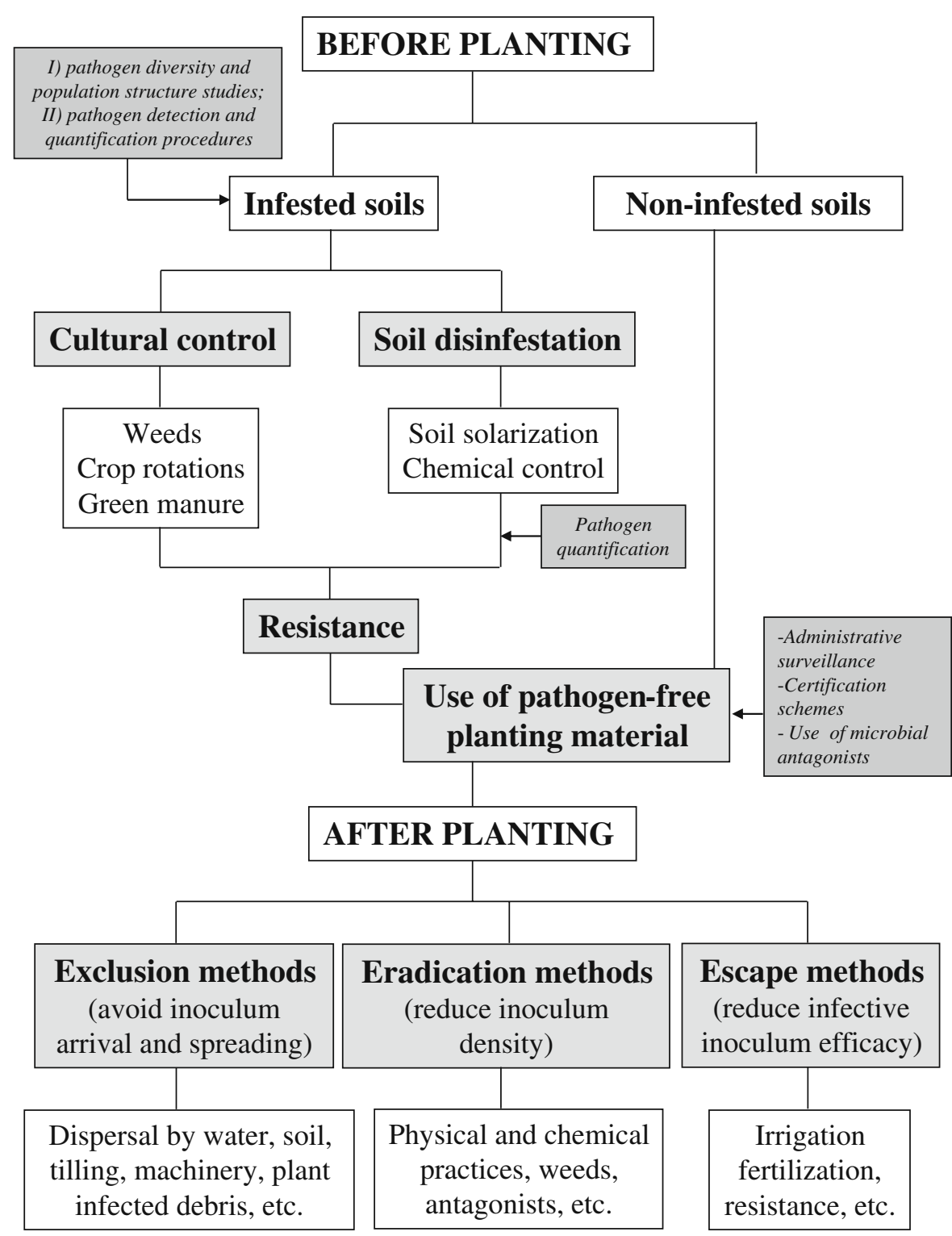

instance, $V$. dahliae-specific PCR primers derived from the mitochondrial small rDNA gene region were designed to differentiate $V$. dahliae isolates from diverse Ascomycetes genera and also from its close relative $V$. albo-atrum ( $\mathrm{Li}$ et al. 1994). Other PCR primers based upon ITS rDNA sequences or RAPDs markers have been designed for the specific differentiation, and in some cases detection and quantification, of Verticillium wilt pathogens in diverse herbaceous host plants and soil samples (Nazar et al. 1991; Robb et al. 1993, 1994; Moukhamedov et al. 1994; Morton et al. 1995a; Heinz et al. 1998; Li et al. 1999; Heinz and Platt 2000). However, the differentiation of $V$. dahliae D and ND pathotypes was never addressed in these studies. The availability of pathotype-specific PCR primers (Pérez-Artés et al. 2000) raised the possibility to develop detection procedures for the early, rapid and specific molecular diagnosis of $V$. dahliae isolates, especially aimed at nursery-produced olive plants. Nested-PCR protocols, necessary to accurately detect the presence of very low quantities of pathogen DNA in samples of total genomic olive DNA, are already available for the in planta differential detection of the ND (Mercado-Blanco et al. 2001) and D (Mercado-Blanco et al. 2002) pathotypes. The tuning up of these molecular detection procedures 
was performed in artificially-inoculated plants. Detection of each $V$. dahliae pathotype DNA was effective from the very earliest moments after inoculation; that is, positive pathogen DNA detection was achieved in symptomless plants, much earlier than first VWO symptoms developed. Interestingly, olive plants inoculated with the ND pathotype which developed VWO but became symptomless 7 months after inoculation (i.e., they showed the recovery phenomenon, see below), were positive to the presence of pathogen DNA when examined by the nested-PCR assay (Mercado-Blanco et al. 2001). These results confirmed that asymptomatic plants may constitute a reservoir of $V$. dahliae propagules, as previously discussed in this review. On the other hand, the availability of a specific molecular detection procedure for the $\mathrm{D}$ pathotype is of much help to avoid spread of the most damaging pathotype to new areas, especially if they are free of $V$. dahliae. This is of particular relevance now, since the crop is expanding into Australia and South American countries, which currently import large amounts of rooted, nursery-produced olive plants (S. Ruano, A. Trapero-Casas, personal communications).

Subsequent refinements of nested-PCR protocols have been accomplished. Thus, an improved duplex, nestedPCR procedure was developed eliminating occasional ambiguities observed when detecting D isolates, and reducing time and cost for an effective detection of $\mathrm{D}$ and ND $V$. dahliae in olive tissues (Mercado-Blanco et al. 2003b). The duplex, nested-PCR procedure is based on the simultaneous amplification of both the previously described ND PCR markers (Mercado-Blanco et al. 2001) and a D-associated PCR marker designed from a $V$. dahliae species-specific genomic sequence (Carder et al. 1994), which has been revealed as highly polymorphic in subsequent studies (Collins et al. 2005; Collado-Romero et al. 2006; Collado-Romero et al. 2010). The procedure was effective in the rapid, unequivocal and simultaneous detection of the two infecting $V$. dahliae pathotypes in both artificiallyinoculated, self-rooted olive plants and naturallyinfected adult trees of different cultivar, age and growing conditions (Mercado-Blanco et al. 2003b). Therefore, the improved molecular detection protocol enabled to discover that both pathotypes can infect and colonize the same olive tree under natural conditions. This finding poses important epidemiological consequences and may be of interest for the implementation of additional control measures. Finally, $V$. dahliae (no pathotype differentiation) has also been successfully detected in olive seeds by nested-PCR assays using PCR primers designed from the ITS region of nuclear rDNA genes (Karajeh 2006).

Besides being informative on the pathotype present in infected olive tissues, all PCR-based procedures so far developed for $V$. dahliae detection always yielded more consistent and sensitive results compared to traditional microbiological isolation methods. This was confirmed by a comparative study between the nested-PCR strategy, in this case using PCR primer pairs which did not differentiate between D and ND pathotypes (Li et al. 1994), and the traditional pathogen isolation method in culturing media from olive tissues (Morera et al. 2005). It is worth mentioning here the recent development of a multiplex-nested-PCR procedure which can differentiate among $V$. dahliae VCGs simultaneously infecting artichoke plants (Collado-Romero et al. 2009). This procedure is applicable to olive and many other plants which can be infected by any $V$. dahliae subspecific group(s). Obviously, despite these molecular procedures were originally aimed to qualify nursery-produced olive plants, they also have a huge value in VWO diagnosis of adult olive trees under field conditions.

All previous molecular detection methods are qualitative and provided essential information to assess the sanitary status of planting material, or for specific and accurate disease diagnostics in established, commercial orchards. However, they do not provide information on differences of pathogen biomass present in plant tissues or on the relation between susceptibility of host genotypes and/or virulence of isolates. Thus, for Verticillium wilt diseases, quantitative measurement of the pathogen in infected tissues is necessary to characterize the disease reaction of host genotypes to specific strains of the pathogen. Quantification of Verticillium spp. DNA in several infected herbaceous hosts has been previously performed by PCR-based quantitative procedures (Hu et al. 1993; Heinz et al. 1998; Dan et al. 2001). However, real-time quantitative PCR (RT-qPCR) technology enables the quantification of nucleic acids in unknown samples by a direct comparison to standards amplified in parallel reactions (Morrison et al. 1999; Deepak et al. 2007). It is more accurate and less time consuming than conventional, end-point quantitative PCR because it monitors PCR products before reaction components become limiting. Currently, RT-qPCR technology is 
commonly used in plant pathology for the precise detection and quantification of pathogens in infected plants and infested soils (reviewed by Schena et al. 2004b; Ma and Michailides 2007), and it has been used to quantify $V$. dahliae DNA as well (Schena et al. 2004a; Atallah et al. 2007; Gayoso et al. 2007). RTqPCR has also been successfully implemented to quantify the biomass of $V$. dahliae $\mathrm{D}$ and ND pathotypes in infected olive plants (Mercado-Blanco et al. 2003a; Markakis et al. 2009). These studies not only provided accurate quantification of $V$. dahliae DNA in infected olive tissues, but also served to test whether severity of VWO and virulence of pathotypes are correlated with the amount of pathogen DNA present in plant tissues. This was achieved by performing time-course infection bioassays of susceptible and resistant olives genotypes, and by monitoring pathogen colonization in root and stem tissues by means of RT-qPCR.

Using this approach Mercado-Blanco et al. (2003a) reached four interesting conclusions. 1) The amount of pathogen DNA quantified in an olive genotype correlated with its susceptibility to Verticillium wilt. Thus, pathogen biomass (either D or ND pathotype) in roots and in stems was higher in the most severely diseased genotype ('Picual', highly susceptible) and lesser in 'Arbequina' (susceptible) and 'Acebuche-L' (resistant) plants. These two latter genotypes also produced fewer diseased plants, although all roots were infected as demonstrated by nested-PCR assays. 2) Overall, differences in the amount of pathogen DNA measured in planta were influenced more by the olive genotype than by the virulence of the infecting pathotype. This suggested that the extent of pathogen colonization does not clearly determine the virulence phenotype. Thus, with regard to $V$. dahliae persistence in the infected olive tissues, the more susceptible was the olive genotype and the more virulent was the $V$. dahliae pathotype in the interaction, the longer the time period was for which significant amounts of pathogen DNA were measured in plant tissues. 3) Maximum amounts of pathogen DNA in roots of plants of all olive genotypes and stems of 'Picual' occurred before maximum disease expression. Thereafter, pathogen DNA in root decreased sharply ('Arbequina' and 'Acebuche-L' plants) or varied slightly along several weeks after inoculation ('Picual' plants). This has been recently confirmed by the increase of pathotype D biomass observed by CLSM in roots of artificially-inoculated 'Arbequina' plants
(Prieto et al. 2009) (see above). Similarly, the gradual decrease in pathogen DNA corroborated earlier work suggesting that pathogen biomass may decrease once the disease is fully developed (Rodríguez-Jurado 1993). Therefore, evidences of the cyclical colonization pattern observed in herbaceous hosts upon V. alboatrum infection ( $\mathrm{Hu}$ et al. 1993; Heinz et al. 1998) were not observed in olive. It might well be that putative cycles of colonization in olive may require a time period longer than the extent (100 days) of bioassays performed in this study. 4) Finally, and from a practical perspective, RT-qPCR has revealed as an outstanding tool to assess the reaction of olive genotypes to $V$. dahliae pathotypes. An earlier recommendation on the necessity of accurate in planta quantification of $V$. dahliae biomass during breeding programs for resistance to Verticillium wilt in potato (Dan et al. 2001) is of application in VWO as well. The RT-qPCR approach can definitively assist in pursuing such an aim.

Recently, a similar approach was carried out to correlate the relative amount of DNA of $V$. dahliae D and ND pathotypes to VWO susceptibility in the Greek cultivars Amfissis (susceptible) and Kalamon and Koroneiki (resistant) (Markakis et al. 2009). Overall, results confirmed main conclusions reached in the RT-qPCR study with Spanish olive genotypes. Thus, for example, it was demonstrated that the D and ND pathotypes were present at a significantly higher level in susceptible 'Amfissis' plants than in resistant 'Kalamon' and 'Koroneiki' genotypes. However, some differences were also found. Interestingly, the amount of pathogen (both DNA and percentage of positive isolations) in roots was lower than in stems and shoots, and declined in plant tissues over time regardless the olive cultivar examined. This was in contrast to the lower pathogen DNA content found in stem tissues compared to that in root tissues reported by Mercado-Blanco et al. (2003a). This discrepancy was attributed to the different infection methods used (root system dipping in conidial suspension of Spanish cultivars vs. transplant to MS-infested soil for Greek ones) and to the distinct duration of bioassays and sampling time-points strategies (about 100 days, although numerous sampling time-points for the Spanish cultivars vs. over a year but only three sampling times for the Greek bioassay). Markakis et al. (2009) also observed a steady decline in the amount of DNA over time in all cultivars examined, 
as overall reported by Mercado-Blanco et al. (2003a). This observation was attributed to defense mechanisms operating in olive (for instance, occlusion of infected vessels, inactivation of the pathogen in the xylem, increase of certain phenolic compounds, etc) within the framework of the recovery phenomenon (Markakis et al. 2009).

\section{Use of healthy soils}

The use of soils infested with $V$. dahliae propagules must be obviously avoided, especially if the D pathotype is present and susceptible genotypes are considered to be planted. It is should be stressed that soil's health is the first prerequisite to achieve a healthy crop (Cook 1993). Therefore, planting decision should be based on a proper knowledge of the phytosanitary status of the soil (evaluation of pathogen presence, history of phytopathological problems) besides its fertility and proper agronomical features (Jiménez-Díaz 1998). When selecting a site for new plantation a few precautions should be taken into account. For instance, it is advisable to avoid fields in close proximity with $V$. dahliae-susceptible crops, or to avoid soils where susceptible hosts are known to have been previously cropped. But most importantly, it is highly recommended to assess the presence of pathogen propagules in soil, either by traditional microbiological isolation procedures (Harris et al. 1993; López-Escudero and Blanco-López 2001), or by molecular detection assays (Pérez-Artés et al. 2005).

\section{A) Estimation of Verticillium dahliae inoculum potential in soil}

Traditional microbiological methods used to quantify $V$. dahliae $\mathrm{MS}$ in soil has been thoroughly reviewed by Harris et al. (1993). These techniques involve the plating of a defined amount of soil, previously processed by diverse methods (i.e. suspension, sieving, centrifugation etc), onto plates of semi-selective culturing media (Harris et al. 1993). Each viable pathogen propagule, either as a single MS or as a cluster of them, free or attached to soil or plant debris particles, will germinate and produce a recognizable $V$. dahliae colony. Indeed, MS produced from mycelium form a typical star-shaped distribution upon incubation (López-Escudero et al. 2003). Colonies are then counted and the result is expressed as propagules per gram of soil.
None of the available media seems to be completely selective for $V$. dahliae, and growth of other soil-borne microorganisms is generally observed (Butterfield and DeVay 1977; Harris et al. 1993; Termorshuizen et al. 1998; López-Escudero et al. 2003). Moreover, it should be mentioned that precision in detection and quantification of $V$. dahliae in soil is particularly aimed to: 1) disease risk assessment, predicting the onset and development of future VWO epidemics, and 2) evaluate the effectiveness of control measures for pathogen eradication in soil. Therefore, several studies have evaluated advantages and disadvantages of available selective media and propagule isolation procedures (Termorshuizen et al. 1998; Goud and Termorshuizen 2003; Goud et al. 2003; LópezEscudero et al. 2003). Remarkably, these studies conclude that results obtained upon the implementation of the available detection/quantification methods are greatly influenced by: 1) diverse soil features, such as texture, (i.e. average size of pathogen propagules when the process includes sieving); 2) the amount of soil distributed on a plate which could influence competition and/or antagonism events taking place in vitro among the culturable soil microorganisms present in the soil sample; and/or 3) the variability and abundance of the culturable soil microbiota (Harris et al. 1993). One of the most common techniques for $V$. dahliae quantification in soil is based on the wet sieving method (Huisman and Ashworth 1974). This procedure separates the $35-150 \mu \mathrm{m}$ soil fractions in water. Subsequently, aliquots of this suspension are plated onto several media, such as the previously-mentioned modified sodium polypectate agar medium (Butterfield and DeVay 1977). Other techniques are based on dryplating procedures which seem to be less variable at higher inoculum levels than the wet sieving. The latter is less sensitive but more effective than the former when the number of MS in the soil sample is low (Harris et al. 1993; Goud and Termorshuizen 2003).

As mentioned above, dry and wet plating methods have traditionally been used for the detection and quantification of $V$. dahliae in soil. Nevertheless, plating methods are time-consuming, inconsistent, soil-dependent and usually not informative about $V$. dahliae pathotypes present in the soil sample (Harris et al. 1993; Goud and Termorshuizen 2003; LópezEscudero and Blanco-López 2005c). Thus, PCRbased techniques have been effectively used for the molecular detection (Mahuku et al. 1999; Volossiouk 
et al. 1995) and quantification (Krishnamurty et al. 2001; Mahuku and Platt 2002; Debode et al. 2009; Peters et al. 2009) of Verticillium spp. in soil. Success in the detection procedure always depends upon efficiency in extracting PCR-quality DNA from soil samples. One of the main barriers for the efficient and consistent amplification of target DNA extracted from soil samples is the presence of humic acids and related compounds originated from degradation of organic matter (García-Pedrajas et al. 1999). These compounds are known to be powerful inhibitors of Taq polymerases (Tsai and Olson 1992). Therefore, diverse methods have been designed to prevent copurification of such inhibitors from soil samples, or to avoid their inhibitory effects on PCR (Volossiouk et al. 1995; García-Pedrajas et al. 1999; Heinz and Platt 2000).

Differential molecular detection of $V$. dahliae pathotypes in soil has been accomplished by PCRbased procedures as well (Pérez-Artés et al. 2005). Indeed, the same specific primer pairs used for the in planta detection of D and ND pathotypes by nested PCR has been employed to detect both pathotypes in artificially- and naturally-infested soils. An efficient DNA extraction method from $V$. dahliae MS in infested soils was designed. The procedure included the use of acid-washed sand during the grinding process, which facilitated the mechanical disruption of MS in the soil sample, and the addition of skimmed milk that avoided the co-purification of Taq-polymerase inhibitors along with DNA (Pérez-Artés et al. 2005). The need of an adequate physical disruption of MS in soil during the grinding process and regardless the soil texture (clay or sandy) has been reported when extracting DNA from different fungal structures present in soil (García-Pedrajas et al. 1999; Faggian et al. 1999). In addition, accurate detection of $V$. dahliae pathotypes from DNA extracted directly from soil samples required a nested-PCR strategy. This could be explained either by the presence of inhibitors in the soil extract or by very low amounts of target DNA in the reaction mixture. Although the nested-PCR procedure proved effective in naturally-infested soils, only a low percentage of samples from a given sampling area yielded successful amplification of the expected diagnostic DNA (Pérez-Artés et al. 2005). A likely uneven spatial distribution of $V$. dahliae propagules in soil (Bejarano-Alcázar and JiménezDíaz 1997) may explain this result, what advices that
PCR-based detection procedures must be used in conjunction with an adequate soil sampling strategy.

B) Strategies for soil disinfestation

Besides procedures for isolating and quantifying $V$. dahliae propagules in soil, which provide useful information for disease risk assessment, soils chosen to establish new olive orchards could be previously sanitized by different approaches. Before-planting strategies for soil disinfection are based on the application of physical, cultural, biological or chemical practices to reduce pathogen inoculum in soil. It is important to remark that complete eradication of the pathogen is very difficult, and soil re-infestation can take place from pre-existing, non-eliminated propagules after disinfection treatment. An additional aspect to be considered is the high cost of some of these control measures that makes them advisable only at low scale (i.e. for well-defined focus where the pathogen has been particularly detected, Fig. 9a), or for crop areas where the cost of a selected eradication practice is acceptable (i.e. super-intensive hedgerow olive orchards).

Soil disinfestation prior to orchard establishment can be accompanied by cultural and biological-based practices. For instance, a delay in planting the olive orchard combined with crop rotation and/or cultural interventions such as cropping of non-susceptible species, or their sowing and subsequent burying of green manures such as Sudan grass (Sorghum halepense var. sudanense) have been widely advised. These practices increase the antagonistic microbiota (see below) and have shown some effectiveness in controlling $V$. dahliae (Devay and Pullman 1984).

Soil solarization is one of the most effective physical control methods to reduce inoculum density of soilborne pathogens such as V. dahliae (Katan 1987; Katan 2000a; Goicoechea 2009). Soil covering with transparent polyethylene films, combined with abundant watering, makes it possible to heat soil by sun irradiation to temperatures lethal for many soil-borne pathogens and weed seeds. Temperatures reached by soil solarization normally range from 35 to $60^{\circ} \mathrm{C}$ (depending on soil type and depth) and these are enough to kill $V$. dahliae MS (Katan 1987). It has been effectively implemented to control Verticillium wilts of herbaceous and woody hosts before sowing or planting (Pegg and Brady 2002, and references therein). However, it is interesting to emphasize that temperatures above $70^{\circ} \mathrm{C}$ can produce 


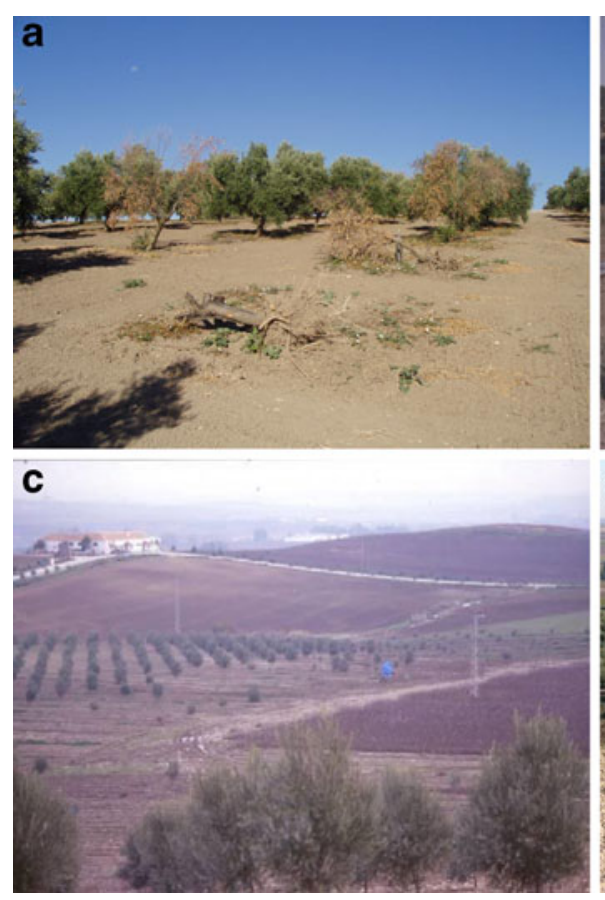

Fig. 9 Control of the disease in affected focus inside olive orchards should be stressed by removing and destroying wilted plants (a). Soil solarization, applied in individual trees, tree lines, or affected spots after replacing dead trees, is very effective in reducing pathogen population in soil (b). A steady and adequate implementation of an integrated disease control strategy can be successful to overcome Verticillium wilt of

detrimental effects on soil microbiota and may result in eradication of beneficial microorganisms (i.e. rhizobia, mycorrhizal fungi, and antagonists [Katan 2000a; Goicoechea 2009]). Another limitation of this physical method is that its efficacy depends on particular environmental and soil conditions, such as physical soil features and irrigation. Moreover, the survival of $V$. dahliae MS at deep layers in the soil profile can constitute a source of infective propagules years after soil solarization treatment(s) (Katan 1981; Tjamos et al. 1991; López-Escudero and Blanco-López 2001).

Soil solarization is a common pre-planting practice in modern agricultural systems, predominantly for highvalue herbaceous hosts such as artichoke, cotton, strawberry, etc. In some of these crops (i.e., cotton) it has been successfully combined with tolerant cultivars (Melero-Vara et al. 1995). In others (i.e., artichoke), soil solarization was combined with reduced dosage of some of the most common chemical biocides used in intensively-managed crops (methyl bromide, chloropic-
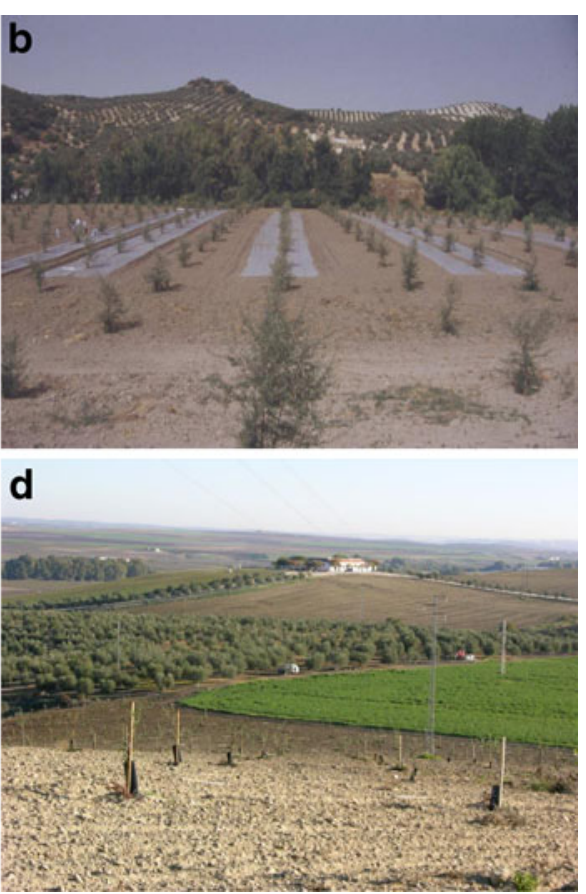

olive over the years. Bottom pictures show the same experimental plot at Southern Spain where a high Verticillium dahliae inoculum density in soil caused elevated tree (cv. Picual) mortality in 1998 (c). Ten years later, after replacing with resistant cultivars Frantoio, Oblonga and Empletre and rigorous disease control measures, the disease incidence and severity has significantly decreased (d)

rin, etc) (Tjamos and Paplomatas 1988). The high levels of solar irradiation in most of the olive growing regions would make soil solarization an adequate control action to reduce MS viability. Indeed, it has been used to diminish VWO symptoms in established orchards (see below). Nevertheless, to the best of our knowledge, soil solarization as extensive before-planting practice in commercial olive orchards has not been used, probably due to its high cost. However, it has been successfully applied in combination with low doses of metamsodium to disinfest new plots for planting at olive germoplasm collections sites (Caballero and Del Rio 2008b). These chemical treatments combined with soil solarization may be also very effective and economicalcost justified for soil disinfestations at specific spots of olive orchards affected by VWO (see below).

Soil-borne pathogens disinfestation by chemical treatments has been a common before-planting practice in intensive agriculture of numerous herbaceous crops. The efficacy of soil fumigants or combinations 
of them (Metam-sodium, 1,3-dichloropropene, chloropicrin, or methyl bromide, which is being internationally phased out under the Montreal Protocol) against $V$. dahliae has been recently reviewed by Goicoechea (2009). This and other classical reviews (i.e. Katan 2000b) on the subject strongly emphasize the need of searching for alternatives to the use of these noxious chemicals, within a sustainable agriculture framework (Hamblin 1995). The final goal would be the implementation of a control strategy based on chemical treatments, either alone or in combination with some of the aforementioned physical and cultural methods, but always employed at reduced dosages. For instance, the combination of diverse soil amendments with low dosages of biocides has been minutely documented, and its use particularly encouraged by Goicoechea (2009). Thus, the individual application of low dosages of methan-sodium or dazomet (dichloropropene/methyl isothiocyanate mixtures), or in conjunction with soil amendments and/or soil solarization, would be an advisable action in olive orchards. This action is particularly interesting in treatments of well-defined focus in order to avoid problems after replanting (i.e., replacing dead trees as a consequence of the disease), as well as to limit the spreading of pathogen infective propagules throughout the plantation.

\section{Searching and exploiting sources of genetic} resistance: olive genotypes evaluation and breeding

The development of breeding programs aimed to produce resistant cultivars is likely the most economically-effective and environmentally-friendly control measure to be implemented in an integrated disease management strategy. Therefore, research efforts are aimed to find effective sources of VWO resistance in different countries where olive is a relevant commodity. Obviously, new diseaseresistant genotypes must also display agronomic traits attractive from a commercial perspective. Once an agronomically-interesting and VWO-resistant genotype is identified it may be directly used to either replace dead trees in affected olive orchards, or as rootstocks to graft scions of existing cultivars, or to be incorporated as genitor in breeding programs. An important advantage in olive breeding for resistance to $V$. dahliae is the ample source of genetic variability available (Angiolillo et al. 1999; Rallo et al. 2005). Indeed, putative resistant cultivars could be identified either in genotypes preserved in different olive germoplasm banks, or in wild olives, or in progenies generated from diverse breeding programs (Rallo et al. 2005). However, significant efforts are still needed and only limited results are available (Trapero et al. 2009b). We would like to stress that for the olive/ $V$. dahliae pathosystem we use the term resistance instead of tolerance (see Robb 2007), on the basis of histopathological observations showing that infected olive plants indeed prevent, delay or restrict pathogen penetration and further proliferation in host tissues (Rodríguez-Jurado 1993; López-Escudero and BlancoLópez 2005a). That is, plant-mediated mechanisms seem to operate for hindering pathogen colonization.

The most relevant studies on the evaluation of resistance level to VWO and on the identification of resistant genotypes are summarized in Table 2 (field conditions) and Table 3 (artificial inoculations). It is important to mention that major variables to be considered when evaluating olive VWO-resistant genotypes are: 1) pathogen inoculation methods used; 2) environmental conditions; 3) virulence of the isolates assayed; and 4) pathogen inoculum density employed or present in soil.

Studies on VWO resistance under field conditions have been carried out either in experimental or in commercial olive orchards established in infested soils. It is worth mentioning that distribution and inoculum density of $V$. dahliae were unknown (or not reported) for some of these studies, whereas the presence of $\mathrm{D}$ and/or ND pathotypes was reported in others (Tables 2 and 3). These studies usually consisted of long-term observations (Wilhelm and Taylor 1965; López-Escudero and Blanco-López 2001; Martos-Moreno 2003) and, in some cases, natural infections were complemented with artificial pathogen inoculation such as root spraying before planting (Wilhelm and Taylor 1965). Overall, information so far gathered shows that most of the olive cultivars examined to date are susceptible to VWO. Moreover, these cultivars are the economically (and historically) relevant ones in their areas of cultivation: 'Hojiblanca' or 'Picual' in Spain, 'Konservolia' or 'Kalamon' in Greece, or the worldwide cultivated cultivar 'Manzanillo' (Tables 2 and 3). For instance, a long-term study aimed at investigating VWO resistance in a plantation established in a soil with high inoculum density since 1998, has provided interesting information about some cultivars (Table 2) 
Table 2 Resistance of olive genotypes/cultivars to infection caused by Verticillium dahliae in naturally-infested fields

\begin{tabular}{|c|c|}
\hline Cultivar and resistance level ${ }^{\mathrm{a}}$ & Reference \\
\hline 'Bella di Spagna' (S), 'Nocellara' (S), 'Ogliarola' (S) & Ruggieri 1946 \\
\hline $\begin{array}{l}\text { 'Manzanillo' (S), 'Redding picholine' (S), several olive dwarf rootstocks }(\mathrm{S}) \text {, } \\
\text { Olea ferruginea }(\mathrm{S}), \text { O. chrysophylla }(\mathrm{S}), \text { O. verrucosa }(\mathrm{R}) \text {, olive seedlings } \\
\text { from fruits from open pollination of } 10 \text { olive cultivars and wild olive from Russia } \\
\text { and North Africa (some progenies from 'Frantoio' or a descendant from 'Arbequina' } \\
\text { called 'Allegra' were R; progenies from 'Manzanillo', 'Chemlali', 'Mission', } \\
\text { 'Redding Picholine', 'Chetoui', 'Nevadillo' and 'Liguria' were S). Natural infestation } \\
\text { was combined with root spraying. }\end{array}$ & Wilhelm and Taylor 1965 \\
\hline 'Konservolia' (S), 'Kalamon' (S), 'Manaki' (S), 'Koutsourelia' (S), 'Matolia' (S), 'Megaritiki' (S) & Thanassoulopoulos et al. 1979 \\
\hline ‘Cornicabra' (S), 'Kilis Yaglik’ (S), ‘Saloneque’ (S), ‘Verdale’ (S), ‘Verdial de Huevar’ (S) & Caballero et al. 1980 \\
\hline 'Manzanillo’ (S), 'Mission’ (S), 'Obliza’ (S), 'Sevillano’ (S) & Wilhelm 1981 \\
\hline 'Hojiblanca' (S), 'Manzanilla' (S), 'Picual' (S) & Blanco-López et al. 1984 \\
\hline 'Dnaebli' (S), 'Henblasi' (S), 'Sourani’ (S), 'Zaeti’ (S) & Al-Ahmad and Mosli 1993 \\
\hline 'Hojiblanca' (S), 'Picual' (S) & López-Escudero et al. 2004 \\
\hline $\begin{array}{l}\text { 'Cornicabra' (ES), 'Picual' (ES), 'Picudo' (ES), 'Arbequina' (MR), } \\
\text { 'Changlot Real' (R), 'Empeltre' (R), 'Frantoio' (R) }\end{array}$ & Martos-Moreno 2003 \\
\hline
\end{tabular}

${ }^{a}$ Cultivars (the most relevant) appear ordered by their resistance level: $R$ resistant, $T$ Tolerant (according to Tjamos et al. 1985); $M R$ Moderately resistant; $M S$ Moderately susceptible, $S$ Susceptible, ES Extremely susceptible. In the studies of López-Escudero et al. 2004 and Martos-Moreno 2003, a mixture of defoliating and non-defoliating pathotypes was present in soil. In the rest of field studies no information was available

(Martos-Moreno 2003). In this study, while 'Cornicabra', 'Picual' and 'Picudo' trees were extremely susceptible, 'Arbequina' showed to be moderately resistant. However, this cultivar has been qualified as highly susceptible to $V$. dahliae D pathotype in artificial inoculations (see below) (López-Escudero et al. 2004) (Table 3). On the contrary, low DI's scored for 'Changlot Real', 'Empeltre', 'Frantoio' and 'Oblonga' trees in the same field comfirmed resistance levels earlier found for these cultivars in artificiallyinoculated plants under controlled conditions (LópezEscudero et al. 2004; Martos-Moreno et al. 2006).

One of the first known studies on the assessment of olive resistance to $V$. dahliae using artificial inoculation of $V$. dahliae is that by Hartman et al. (1971). Since then, numerous studies have employed artificial inoculation approaches to screen for resistance to VWO, predominantly assessing olive cultivars of local importance in a given olive cultivation area/country, or genotypes preserved in germoplasm collections (Table 3). These evaluations have been conducted in controlled conditions (greenhouse or growth chambers), using pathogen isolates displaying virulence representative of the study zone (i.e. D or ND), and by root-dipping or stem-injection inoculation methods. For instance, disease reaction displayed by olive cultivars upong infection with the two $V$. dahliae pathotypes is being continuously evaluated since 1994 in the Olive World Germplasm Bank (López-Escudero et al. 2004, 2007; RayaOrtega 2005; Martos-Moreno et al. 2006; Birem et al. 2009; Abo Shkeers 2010). This is a worldwide collection of olive varieties, established in 1970 in Córdoba (southern Spain), comprising more than 400 varieties (250 originating from Spain) (Caballero and Del Rio 2008b). The first important conclusion from this research program is that all cultivars so far assessed $(>100)$ were always more susceptible to D than to ND pathotype. However, the most remarkable and alarming result is that most of the agronomically- and economically-relevant olive cultivars are susceptible or extremely susceptible to the D pathotype. This is the case of Greek cultivars Kalamon, Amfissis or Konservolia, the Italian 'Ascolana' or 'Leccino', or Spanish 'Picual', 'Hojiblanca', 'Cornicabra', 'Manzanilla de Sevilla' or 'Arbequina'. On the contrary, high resistance level has been found in cultivars Empeltre, Frantoio, Oblonga and Changlot Real. These genotypes have shown a delayed disease onset, disease recovery and low percentage of dead plants, making them attractive to farmers to replace dead trees of susceptible cultivars. Moreover, the moderate susceptibility of cultivars such as Cipresino, 
Table 3 Resistance of olive genotypes/cultivars to infection caused by Verticillium dahliae upon artificial inoculations

\begin{tabular}{|c|c|c|c|}
\hline Cultivar and resistance level ${ }^{\mathrm{a}}$ & $\begin{array}{l}\text { Inoculation } \\
\text { method }\end{array}$ & $\begin{array}{l}\text { Pathogen } \\
\text { pathotype }^{\mathrm{b}}\end{array}$ & Reference \\
\hline 'Oblonga' (R), ‘Manzanillo’ (S) & & - & Hartman et al. 1971 \\
\hline 'Manzanillo' (S) & Root spraying & $\mathrm{D}$ and ND & Schnathorst and Sibbett $1971 \mathrm{~b}$ \\
\hline $\begin{array}{l}\text { ‘Coratina' (R), 'Fragivento’ (R), 'Frantoio’ (R), 'Ascolana' (S), } \\
\text { 'Cellina' (S), 'Leccino' (S) }\end{array}$ & Root dipping & - & Cirulli and Montemurro 1976 \\
\hline $\begin{array}{l}\text { 'Lianolia' (R); 'Oblonga' (R); One genotype coming from self-pollination } \\
\text { of 'Oblonga' (113) (R), 'Koroneiki' (T), 'Conservolia' (ES) }\end{array}$ & Root spraying & - & Tjamos et al. 1985 \\
\hline 'Picual' (S), 'Oblonga' (R) & Root dipping & $\mathrm{D}$ and ND & Rodríguez-Jurado 1993 \\
\hline ‘Kalamon’ (MS), ‘Amfissis’ (ES) & Stem injection & $-^{\mathrm{c}}$ & Antoniou et al. 2001 \\
\hline ‘Koroneiki’ (MR), ‘Kalamon’ (MS), ‘Amfissis’ (ES) & Stem injection & $\mathrm{D}$ and ND & Paplomatas and Elena 2001 \\
\hline $\begin{array}{l}\text { 'Empeltre' (R), 'Frantoio' (R), 'Oblonga' (R), 'Changlot Real' (R), } \\
\text { 'Cipresino' (MR), 'Koroneiki' (MR), 'Arbosana' (S), 'Ascolana } \\
\text { Tenera' (S), 'Cornicabra' (ES), 'Arbequina' (ES), 'Hojiblanca' (ES), } \\
\text { 'Ocal' (ES), 'Picual' (ES), 'Leccino' (ES), 'Picudo' (ES), 'Cobrancosa' } \\
\text { (ES), 'Manzanilla Sevilla' (ES), 'Kalogerida' (S), 'Callosina' (ES), } \\
\text { 'Chemlal de Kabilye' (ES), 'Megaritiki' (ES) }\end{array}$ & Root dipping & $\mathrm{D}$ & $\begin{array}{l}\text { López-Escudero et al. } 2004 \text { and } \\
\text { Martos-Moreno et al. } 2006\end{array}$ \\
\hline $\begin{array}{l}\text { 'Grosal de Albocafer' (R), 'Frantoio' (R), 'Kato Drys' (R), 'Manzanilla } \\
\text { Picúa' (R), 'Negrillo de Andujar' (MR), 'Maelia' (MR), 'Kiti' (MR), } \\
\text { 'Pajarera' (MR), 'Jlot' (MR), 'Koroneiki' (MR), 'Bodoquera' (MR), } \\
\text { 'Athalassa' (S), 'Figueretes' (S), 'Flasou' (S), 'Mission Nyeland' (S), } \\
\text { 'Picual' (S), 'Chalchali-1' (ES), 'Macho de Jaén' (ES), 'Mission } \\
\text { Moojeski' (ES) }\end{array}$ & Stem injection & $\mathrm{D}$ & López-Escudero et al. 2007a \\
\hline $\begin{array}{l}\text { Progenies of a number of Spanish and Italian wild olive trees } \\
\text { (all plants in some of progenies were killed or showed variable } \mathrm{S} \text {, } \\
\text { certain genotypes were } \mathrm{R} \text { ) }\end{array}$ & Root dipping & $\mathrm{D}$ and ND & Colella et al. 2008 \\
\hline $\begin{array}{l}\text { Olive seedlings from fruits from open pollination of major Spanish cultivars } \\
\text { and more than } 300 \text { fruits from wild olive collected in different areas of Spain }\end{array}$ & Root dipping & $\mathrm{D}$ & Trapero et al. $2009 b$ \\
\hline
\end{tabular}

${ }^{\text {a }}$ Cultivars (the most relevant) appear ordered by their resistance level: $R$ resistant, $T$ Tolerant (according to Tjamos et al. 1985); $M R$ Moderately resistant; $M S$ Moderately susceptible, $S$ Susceptible, ES Extremely susceptible

${ }^{\mathrm{b}}$ Verticillium dahliae pathotype used in artificial inoculations; $D$ defoliating, $N D$ non-defoliating, (-) no data available

c Defined by the authors as "very virulent"

Sevillenca and, particularly, Koroneiki, makes them an interesting alternative in situations of low inoculum potential in soil (Paplomatas and Elena 2001; MartosMoreno et al. 2006; López-Escudero et al. 2004; 2007a; Antoniou et al. 2008).

Validation and standardization of $V$. dahliae inoculation methods to provide accurately-assessed resistant plant genotypes has been an additional goal of the above-mentioned studies (Blanco-López et al. 1998; López-Escudero et al. 2004; Martos-Moreno et al. 2006; Cirulli et al. 2008; Trapero et al. 2009b). Indeed, a rapid and effective inoculation procedure is needed to effectively differentiate resistant genotypes from susceptible ones. Thus, despite root-dip inoculation (using $V$. dahliae conidia suspension) has been the most widely-used method in evaluating VWO resistance, stem injection of conidia suspensions has proved to be a valid approach. Certainly, good correlation in susceptibility/resistance responses has been found between the two inoculation methods (Blanco-López et al. 1998; López-Escudero et al. 2007a; Paplomatas and Elena 2001) (Table 3).

Evaluation of resistance from olive genotypes crossings was early carried out by Wilhelm and Taylor (1965). They reported interesting results on the VWO resistance reaction in a number of olive seedlings grown from seeds produced under open-pollination conditions, as well as from seeds collected from wild olives planted in infested fields (Table 2). Particularly, one descendant from 'Arbequina', called 'Allegra', showed high VWO resistance levels (Wilhelm 1981). Later, Tjamos et al. (1985) informed about the high level of VWO resistance of one line obtained by selfpollination of 'Oblonga' plants. More recently, the evaluation of wild olives populations as well as progenies obtained from crosses between commercial cultivars (under both controlled and field conditions) is being pursued (Cirulli et al. 2008; Colella et al. 2008; 
Trapero et al. 2009b). Overall, several wild olive genotypes showing a complete VWO resistance level at the seedling stage have been identified in these studies. Hopefully, they will constitute the first step to generate new olive varieties resistant to $V$. dahliae. In addition, ongoing studies involving pathogen inoculation of a large number of individuals from progenies produced out of parentals with different VWO resistant levels, will serve to provide relevant information about VWO resistance inheritance (Colella et al. 2008; Trapero et al. 2009b). The improvement of $V$. dahliae inoculation methods is also a remarkable achievement from these works. Thus, by using the stem-inoculation method, the disease incubation period has been considerably reduced, a consistent expression of disease symptoms was achieved, and the possibility to work with large numbers of plants, thus reducing time and space, is facilitated. On the other hand, the inoculation of very young (3-to-5 week old) olive seedlings by root dipping was successful as well, since it allowed rapid but consistent VWO symptoms expression enabling the evaluation of a large number of plants at early stages of the breeding program. This provides that pre-selected plant genotypes can pass to the next evaluation step in the program in a shorter period of time, quickly discarding genotypes displaying a susceptible response (Trapero et al. 2009b).

The use of resistant olive rootstocks is another alternative to genetically control VWO, since pathogen proliferation can be suppressed within them, hindering tissue colonization of the grafted variety. Related to this, Rodríguez-Jurado (1993) showed that VWO expression in susceptible olive cultivars may be related to a pathogen biomass threshold present in the aerial part of the plant, while the roots could serve as a pathogen reservoir. Thus, olive rootstocks with high level of resistance may serve to hamper pathogen multiplication and therefore to protect the variety grafted. For example, after artificial inoculation with a D isolate, Porras-Soriano et al. (2003) reported a reduction of VWO symptoms developed in the susceptible cultivar Cornicabra after grafting it onto a rootstock of the moderately resistant cultivar Oblonga. Under field conditions, Hartman et al. (1971) observed that scions of cv. Sevillano grafted on 'Oblonga' rootstocks did not develop VWO symptoms during an evaluation period of 16 years, suggesting that the pathogen was not transmitted through the graft. However, other combinations tested, including graftings on several Olea species and diverse $O$. europaea commercial cultivars, yielded reactions ranging from moderate to high susceptibility. Tjamos et al. (1985) also found that 'Conservolia' plants grafted onto an 'Oblonga' clone became resistant to $V$. dahliae infection. This result was based on the absence of symptoms and the failure to isolate the pathogen from plant tissue. Our longterm field observations conducted in Spain since 1998 in an experimental olive orchard established in a heavily infested (D pathotype) soil, aimed to assess the influence of different combinations of rootstocks and grafted cultivars on VWO resistance are providing preliminary results. For instance, susceptible ('Hojiblanca' and 'Lechín de Granada') or highly susceptible cultivars ('Cornicabra' and 'Picudo') grafted on 'Oblonga', 'Frantoio', 'Empeltre' and 'Changlot Real' rootstocks showed low DI (8-20\%) 12 years after plantation, whereas the same nongrafted cultivars have reached DI ranging from 73 to 84\% (López-Escudero and Blanco-López, unpublished data).

Finally, it is worth mentioning that the extrapolation of results on disease reaction of olive genotypes obtained from artificial inoculation bioassays to observations under field conditions should be made with the necessary caution. A resistant or moderatelyresistant reaction for a given olive genotype obtained upon artificial inoculation of the pathogen may be overcome by diverse environmental conditions, by the inoculum potential of the pathogen in soil and its virulence, or by different crop management practices (Blanco-López et al. 1998). Therefore, it is strongly recommended to corroborate results obtained under controlled conditions by approaches simulating field conditions and that consistently reproduce the onset and development of the disease. This would also enable to control sources of experimental variation and to use reliable information about genotypes resistance to predict risk levels. This strategy has been successfully implemented in assays performed in above-ground microplots ( $1 \mathrm{~m}$ width, $1 \mathrm{~m}$ length, 0.5 depth, nine olives per microplot) artificially-infested with MS of the D pathotype (López-Escudero and Blanco-López 2007). Indeed, this study enabled to determine the relationship between $V$. dahliae inoculum densities present in soil and VWO onset and progress in 'Picual' plants. After nearly three years after planting, no differences on final DI were found 
among microplots infested with inoculum densities ranging from 0.4 to $1 \mathrm{MS} \mathrm{g}^{-1}$ soil, reaching a mean DI of $11 \%$ (Fig. 10). Nevertheless, in microplots infested with 3 to $10 \mathrm{MS}^{-1}$ soil, percentage of wilted trees was significantly higher (mean DI of $55.5 \%$ ), suggesting that the defensive reaction in 'Picual' plants is overcome when the amount of MS in soil is above a threshold level of 1 MS per gram of soil (López-Escudero and Blanco-López 2007).

\section{The disease recovery phenomenon: a natural control tool to be exploited?}

Resistance under field conditions can be modified by the natural recovery phenomenon. This can be observed in trees which have developed symptoms during a growing season and that may eventually recuperate. This phenomenon is commonly associated to mechanisms which allow trees to overcome injury and decay (Shigo 1984; Hiemstra 1998), but it can also be activated after infections caused by vascular pathogens such as $V$. dahliae (Tippett and Shigo 1981). Indeed, Verticillium wilt recovery has been reported in diverse woody hosts (for example, Taylor and Flentje 1968; Emechebe et al. 1974; Latorre and Allende 1983; Hiemstra 1995; Cirulli et al. 1998; Goud and Hiemstra 1998), including VWO-affected trees and nursery-produced young olives under field

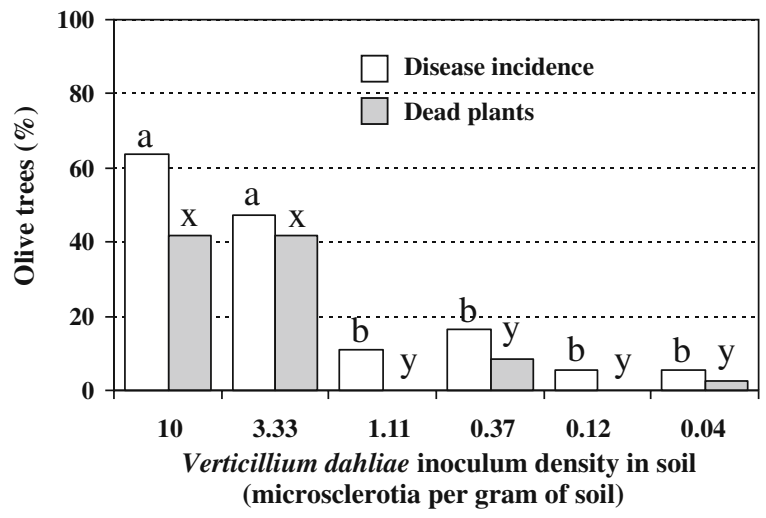

Fig. 10 Effect of inoculum density of Verticillium dahliae in soil (number of microsclerotia of a defoliating isolate) on Verticillium wilt of olive incidence (white bars) and percentage of dead plants (grey bars) for olive trees growing in artificiallyinfested microplots after two and half years after planting (valuation period from December 2000 to June 2003). For details consult López-Escudero et al. (2007). Values of bars with the same colour showing different letters are significantly different according to LSD test $(P=0.001)$ and controlled-growing conditions (Wilhelm and Taylor 1965; Vigouroux 1975; Tjamos et al. 1991; Rodríguez-Jurado et al. 1993; Mercado-Blanco et al. 2001; Levin et al. 2003b; López-Escudero and Blanco-López 2001, 2005a; Markakis et al. 2009).

Recovery is evidenced by a gradual reduction in DI and by the emission of new sprouts at the base of the trunk or under affected branches. This phenomenon has been explained as an active response by the tree. Indeed, the highly compartmentalized structure of the xylem in woody plants in combination with cambial activity producing new layers of tissue that replace old or diseased xylem facilitate plant recovery (Shigo 1984). Early steps of recovery are probably a consequence of tree responses such as occlusion of infected vessels, inactivation of the fungus in the xylem, hindrance to new infections and/or enhanced levels of certain phenolic compounds (Wilhelm and Taylor 1965; Talboys 1968; Sinclair et al. 1981; Rodríguez-Jurado 1993; Hiemstra 1995; LópezEscudero and Blanco-López 2005a; Baídez et al. 2007; Markakis et al. 2010). Since trees affected by VWO are subjected to seasonal and transient infections by the pathogen (Wilhelm and Taylor 1965; Tjamos et al. 1991), new infections seem to be necessary for a new disease cycle after recovery. This situation is particularly interesting from a disease management perspective since it may favor the implementation of effective control measures. For instance, soil solarization may be used to reduce $V$. dahliae inoculum density in soil around the tree, thus diminishing the probability of new infection events (Tjamos et al. 1991; López-Escudero and Blanco-López 2001; Saremi et al. 2006). This beneficial effect has been observed especially in young commercial olive orchards, in which soil-solarized trees frequently overcome seasonal infections by $V$. dahliae (Rodríguez-Jurado et al. 1993; López-Escudero and Blanco-López 2001; Martos-Moreno et al. 2001).

Reduction of symptoms may be a consequence of inactivation and/or elimination of the pathogen, since it is correlated with the difficulty or impossibility of a successful isolation of $V$. dahliae from affected branches that recovered (Wilhelm and Taylor 1965; RodríguezJurado 1993; Levin et al. 2003b; López-Escudero and Blanco-López 2005a), or to detect pathogen DNA in aerial tissues of infected but recovered plants (MercadoBlanco et al. 2001). These results again support that new infections are likely needed for the development of 
new symptoms, as first suggested by Wilhelm and Taylor (1965). Alternatively, the persistence of $V$. dahliae propagules within infected parts of the tree, i.e. MS produced within tracheal elements (RodríguezJurado 1993), may eventually lead to new symptoms when optimal conditions for disease development are again present. Indeed, $V$. dahliae DNA could be detected in root samples of artificially-inoculated 'Picual' plants more than 6 months after they recovered from the disease (Mercado-Blanco et al. 2001), or the pathogen could be isolated at least 1 year later (Rodríguez-Jurado 1993).

It is worth mentioning, however that the phenomenon of VWO recovery is strongly influenced by diverse critical factors such as the olive genotype susceptibility, environmental conditions, pathogen virulence, etc (López-Escudero and Blanco-López 2005a). For example, recovery strongly depends upon the virulence of the pathotype present in soil and on cultivar resistance, being more frequent when ND isolates and resistant cultivars were tested under field (López-Escudero et al. 2004; Martos-Moreno et al. 2001) or in artificial inoculation conditions (LópezEscudero and Blanco-López 2005a). Moreover, it also depended upon the resistance level of the olive cultivar examined (López-Escudero and BlancoLópez 2005a), as previously suggested by Resende et al. (1995) in cocoa (Theobroma cacao L.). In these cases, recovery could be favored by the irregular distribution, or discontinuous colonization, of the pathogen conferred by the natural resistance of the cultivar. This is particularly important since integrated disease management and risk assessment of VWO rely on, among other control measures, the use of resistant cultivars. However, this is strongly conditioned by the presence and spreading of $V$. dahliae $\mathrm{D}$ isolates to new olive orchards (López-Escudero and Blanco-López 2001; López-Escudero et al. 2004). Therefore, the complete understanding of the mechanisms underlying the natural recovery phenomenon still needs in-depth insight to be used in combination with control measures.

\section{Use of beneficial microorganisms and microbial antagonists to control VWO}

The use of biological control agents (BCAs) can be either considered as a before-planting (preventive) measure or as a post-planting (palliative) action in established orchards. It is a sustainable and environmentallyfriendly approach that could be used in combination with other control tools within the framework of an integrated disease management strategy. Thus, application of antagonistic microorganisms in pathogen-free certified olive plants during the propagation process in nurseries, to protect them from eventual $V$. dahliae infections after planting, has been proposed (Tjamos 1993; MercadoBlanco et al. 2004). It is worth mentioning that a successful biological control strategy depends on a complex and subtle balance of interactions among the pathogen, the host plant, the BCA and the environment (Fravel 1988; Weller 1988; Thomashow and Weller 1996). Therefore, the efficient use of BCAs requires of an in-depth knowledge of the physiology and ecology of the targeted systems in situ (Edwards et al. 1994). In addition, any beneficial effect that a BCA may deploy against a given phytopathogen requires of a previous and successful colonization of the target niche (rhizosphere, inner root tissues, etc.). Thus, an adequate bacterial population level is required, which is variable and highly dependent on the BCA, the plant species, and/or the specific environment (O'Sullivan and O'Gara 1992; Haas and Défago 2005). In the particular situation of root colonization by BCAs, numerous factors are dynamically interacting: water content and availability, temperature, $\mathrm{pH}$, soil type, composition of root exudates, presence of other microorganisms, host plant genotype, BCA motility, etc. (Berg et al. 2006; Costa et al. 2006). All these parameters determine how a soilresident bacterial population can be established in the rhizosphere and/or within the plant root. The contribution of each of these factors, the interactions among them and the set-up of the so-called phenomenon "rhizospheric competence" should be studied for each particular interaction (reviewed by O'Sullivan and O'Gara 1992; Lugtenberg et al. 2001; Mercado-Blanco and Bakker 2007; Raaijmakers et al. 2009).

Biological control of soil-borne pathogens of woody plants has been investigated to a lesser extent compared to herbaceous species, although examples are available in the literature (Scheffer 1990; Paul et al. 1997; Reddy et al. 1997; Utkhede et al. 2001; Ran et al. 2005). The anatomy, longevity, and/or inherent particularities of crop management of woody hosts are factors contributing to the difficulty to carry out biocontrol research of their diseases, and olive is not an exception. On the other hand, while studies on biological control of Verticillium wilts are 
available, they are again focused in herbaceous hosts and in just a small number of soil-borne fungi (i.e., Talaromyces, Trichoderma) or bacteria (i.e. Bacillus, Paenibacillus, Pseudomonas, Serratia, Streptomyces) species which have so far been demonstrated to be effective BCA against $V$. dahliae (Jordan and Tarr 1978; Leben et al. 1987; Berg et al. 1994; Madi et al. 1997; Alström 2001; Nagtzaam et al. 1998; Narisawa et al. 2002; Tjamos et al. 2004, 2005; Antonopoulos et al. 2008; Uppal et al. 2008; Erdogan and Benlioglu 2010; Meschke and Schrempf 2010). Finally, arbuscular mycorrhizal fungi (i.e. Glomus spp.) have been also investigated for their Verticillium wilt suppressive effects in different herbaceous hosts (Karagiannidis et al. 2002; Garmendia et al. 2004, 2005; Kobra et al. 2009).

Regarding biological control of VWO, indigenous Pseudomonas fluorescens and Pseudomonas putida strains originated from olive roots have been demonstrated as effective BCAs in artificial-inoculation experiments of young nursery-produced olive plants. Some of these strains showed: 1) in vitro antagonism against the ND and $\mathrm{D}$ pathotypes of $V$. dahliae in different culturing media; 2) ability to colonize and persist in the rhizosphere of young olive plants upon artificial inoculation; and 3) effective control of VWO caused by infections of the D pathotype (MercadoBlanco et al. 2004). These strains were also characterized on the ability to in vitro produce the siderophore pyoverdine, salicylic acid (SA), or hydrogen cyanide $(\mathrm{HCN})$, metabolites which have been largely studied as involved in biocontrol activity displayed by beneficial Pseudomonas spp. (reviewed by MercadoBlanco and Bakker 2007). The biocontrol capability of these strains was variable in different types of nursery-produced plants (i.e. either micropropagated or self-rooted) of the highly susceptible cv. Picual. Moreover, effective biocontrol was achieved under different culturing environments: growth-chamber (controlled) and greenhouse (semi-controlled) conditions. One of the best-performing strains was $P$. fluorescens PICF7, which in some situations reduced the disease intensity index and the final DI by $95 \%$ and $70 \%$, respectively, with regards to control (nonbacterized) plants (Mercado-Blanco et al. 2004). On the other hand, some strains displaying strong in vitro antagonism against $V$. dahliae were not so efficient in controlling the disease, a lack of correlation which has been frequently reported (Fravel 1988; Paulitz et al. 1992). Interestingly enough, a good VWO biocontrol strain was not always that one to reach highest population levels at the target niche, a situation exemplified by strain PICF7. The mechanism(s) involved in biocontrol of VWO by these Pseudomonas spp. strains have not yet been elucidated. However, some interesting findings have been recently gathered by using biotechnological and microscopy tools. Indeed, autoflorescent protein-tagging of bacterial cells, vibratome plant tissues sectioning and CLSM have been employed to demonstrate that $P$. fluorescens PICF7 endophytically colonize the intercellular spaces of the olive roots cortex (Prieto and Mercado-Blanco 2008). This poses additional advantages to be exploited in biocontrol of VWO since endophytic BCAs, such as P. fluorescens PICF7, are already adapted to colonize and persist in the ecological niche (i.e. olive roots) where their beneficial effects can be displayed. Our recent studies suggest that for an effective biocontrol of VWO, strain PICF7 should colonize intact olive roots at both superficial and endophytic levels. Moreover, bacterial root colonization should take place before $V$. dahliae gains entrance to the root interior by, for example, severe root damage (see above). Although further studies are needed to elucidate the mechanism(s) operating in the PICF7-mediated biocontrol of this disease, CLSM studies have revealed that root hairs seem to play a pivotal role in the internal colonization of the roots by PICF7, and that antagonism may be important as direct contact between PICF7 cells and $V$. dahliae hyphae has been observed (Prieto et al. 2009). Regarding to other Pseudomonas spp. as BCA for VWO, Hameed et al. (2005) informed of in vitro antagonism against $V$. dahliae of selected indigenous Pseudomonas strains from olive. However, no information on their possible biocontrol activity has been further reported.

Serratia plymuthica HRO-C48 has been also examined on its ability to suppress VWO in $V$. dahliae artificially-inoculated olive plants cv. Arbequina (Müller et al. 2007). This bacterium was isolated from oilseed rape rhizosphere, and showed in vitro antagonism against different fungal pathogens, including $V$. dahliae (Kalbe et al. 1996; Berg 2000; Erdogan and Benlioglu 2010). Diverse mechanisms have been proposed to be involved in biocontrol by HRO-C48: production of lytic enzymes such a 
chitinases and glucanases, antibiotics such as prodigyosine and pyrrolnitrin, siderophores and phytohormones (Kalbe et al. 1996; Frankowski et al. 2001; Kamensky et al. 2003). Strain HRO-C48 was shown to colonize the rhizosphere of olive plants for a prolonged period of time. However, its biocontrol performance depended on the method used for pathogen inoculation. Indeed, suppression of VWO was found when $V$. dahliae (D pathotype) was applied by soil inoculation rather than by root dipping (Müller et al. 2007).

The ubiquitous fungal genus Trichoderma has been widely used as BCAs against many soil-borne plant phytopathogenic fungi. Its biocontrol activity relies on multiple mechanisms such as competition for nutrients and space, antibiosis and mycoparasitism. Trichoderma spp. are also able to promote plant growth and activation of plant defense responses (reviewed by Howell 2003; Harman et al. 2004; Benítez et al. 2004). A commercial bioformulation of Trichoderma asperellum and T. gamsii has been tested against VWO produced by the $\mathrm{D}$ pathotype under conditions conducive for the disease (Jiménez-Díaz et al. 2009). Interestingly, biocontrol efficiency also depended on the method of pathogen inoculation in artificial inoculation experiments and controlled conditions. Thus, effectiveness and consistency of biocontrol was higher in root-dipped inoculated plants than in the case of plants transplanted to $V$. dahliae-infested soil. Suppression of VWO to a degree was also achieved by this Trichoderma spp. mixture under field conditions. However, no information was provided on the possible mechanism involved.

Endophytic fungi, which can provide diverse beneficial effects to their host plants, including enhanced resistance to diverse (a)biotic stresses (Arnold 2007; Mejía et al. 2008; Scheffer et al. 2008; Rodríguez et al. 2009b) may also represent an interesting approach for Verticillium wilts biocontrol. However, only a scarce number of studies using root endophytic fungi as BCA against $V$. dahliae have been performed (Matta and Garibaldi 1977; Narisawa et al. 2002, 2004). Regarding VWO, Martos-Moreno (2003) reported that artificial root-dipping inoculation of olive plants with a ND isolate of $V$. dahliae can protect the plant from subsequent infections by a $\mathrm{D}$ isolate. This may suggest that, among others mechanisms, an enhanced resistance could be acquired upon application of a ND isolate.
Finally, the possibility to control VWO and other soil-borne pathogens by mycorrhizal fungi has also been explored (Porras-Soriano et al. 2006). For instance, it has been shown that olive seedlings inoculated with Glomus intraradices had lower severity of infections by Phytophthora spp. than non-inoculated seedlings under controlled conditions (Guerrero 1999). However, this effect was not observed in the case of plants inoculated with $V$. dahliae (Jiménez-Díaz et al. 2009; Porras-Soriano et al. 2006).

All these studies are encouraging the use of BCAs, either at the olive propagation stage or during the first years after planting, as an effective action complementary to other disease control measures already explained: i.e., use of certified planting material, low pathogen inoculum density in soil (particularly of the D pathotype), use of tolerant/resistant olive cultivars, or the advantageous situation offered by the recovery phenomenon. An interesting perspective in VWO biocontrol is the possibility to develop combinations of different microbial agents (bioformulations), especially those involving microorganisms that have different mechanisms of action and/or can be targeted to different root niches (Whipps 2001). For instance, bioformulations which might incorporate a beneficial endophyte together with another BCA which exerts its biocontrol action on the root surface provide an interesting research field to be explored. Moreover, different biocontrol mechanisms (for instance, induction of systemic resistance triggered by an endophyte and antibiosis by a root-surface colonizer) could be operating synergistically. However, the development of commercial products that combine different BCAs still needs of in-depth studies to avoid negative interactions that may occur between the BCAs present in the bioformulation, or between them and the indigenous beneficial microflora, or between them and the target plant (Whipps 2001).

Post-planting control measures

Once an olive orchard is established the first control actions should be aimed, irrespective of whether VWO is affecting or not the plantation, to prevent the proliferation, spreading and/or new entries of $V$. dahliae propagules by applying exclusion methods. A second group of actions should be focused on the pathogen eradication to impede its 
multiplication and dispersal within and among neighboring plots. Finally, escape or evasive measures, aimed to reduce the infection efficacy of the pathogen present in the plantation, are strongly recommended (Fig. 8). This post-planting integrated disease management scenario should definitively help to avoid the onset and/or development of VWO epidemics, to reduce the increase in seasonal DI rates, to diminish symptoms severity, and to lessen the percentage of dead trees.

Whenever possible, olive orchards should be located away from the influence of $V$. dahliaesusceptible crops, since infective propagules (i.e., harbored in plant debris and soil particles) can be dispersed from neighboring plots by dominant winds, rainfall or run-off irrigation water, particularly when high slopes are present (see above). Moreover, the access of vehicles, machinery and tools previously used in infested plots and not thoroughly cleaned/ disinfested should be prevented. It is also strongly recommended to avoid the intercropping of herbaceous hosts during the first years after planting or to cultivate them in nearby plots. However, the already discussed effectiveness of some long-distance pathogen dispersal means, such as distribution by large irrigation systems, or by direct irrigation with water obtained from rivers flowing across large areas where $V$. dahliae hosts are abundantly cropped, may easily overcome the limited success of these local exclusion methods (López-Escudero et al. 2009a).

The eradication of infective $V$. dahliae propagules within a plantation can be accomplished by a number of physical, cultural, biological and chemical practices which aim to destroy pathogen inoculum sources. However, and due to their high cost, several of these methods (i.e., soil solarization or biofumigation) are usually implemented at small scale by farmers, for instance, at defined focus inside established orchards. Soils should be kept free of host weeds, what will hinder pathogen survival, multiplication and distribution. Symptomatic twigs, shoots or branches of the trees should be pruned and destroyed (burning is recommended), avoiding its spreading inside plantation. Also, in spite of its cost, fallen green leaves of infected trees should be eliminated, since they are an important inoculum source and a key factor involved in pathogen dispersal both inside and between neighboring olive orchards (Tjamos and Botseas 1987; Navas-Cortés et al. 2008).
As aforementioned, soil solarization has proved to be an effective action to eradicate soil inoculum sources of $V$. dahliae and to control Verticillium wilts of herbaceous and woody hosts. As a postplanting measure, soil solarization could be applied to small soil areas surrounding affected trees. Thus, reduction of MS viability in limited areas (focus) in the plantation where the disease has been detected and may become a serious problem can be achieved. This method does not damage the tree, and it is particularly recommended in situations of moderate inoculum potential, where it can complement the VWO natural recovery phenomenon. Moreover, it can be applied either before (to de-infest soil spots occupied by trees killed by the pathogen and that will be used to replant a new, preferable resistant, olive cultivar), or after planting (in applications to individual trees, tree lines or small areas) (Tjamos et al. 1991; López-Escudero and Blanco-López 2001; Saremi et al. 2006). An additional advantage of soil solarization is that it can be accompanied by other measures, such as organic amendment or application of BCAs which populations can even be promoted in soil after this combined action. This has been demonstrated by Tjamos and Paplomatas (1987) for the $V$. dahliae fungal antagonists Talaromyces flavus and Aspergillus terreus.

The use of organic amendments or biofumigation (Sarwar and Kirkegaard 1998; Lazarovits et al. 2000; Bhat and Subbarao 2001; Huang et al. 2006; Tsror et al. 2007) is another alternative that has been investigated for controlling soil-borne pathogens on several crops. General aspects of soil amendments to control Verticillium wilts have been recently reviewed and discussed (Goicoechea 2009, and references therein). These practices comprise the soil amendment with plant residues, green or animal manures, composted materials, plant extracts, or end-products from wastewater treatment processes, some of then potentially applicable to the particular case of VWO.

The incorporation of different organic substrates to soil can alter the physical structure of soil, increase or activate antagonistic microorganisms, and often release chemical compounds with fungicide or fungistatic activity that directly affect pathogen MS. In the case of $V$. dahliae/olive pathosystem, Wilhelm and Taylor (1965) early recommended the incorporation of sawdust to infested soils with the aim of increasing antagonistic flora and to control the disease. More 
recent studies are assessing the eradicative effects on MS exerted by amendments based on Brassicaceae (Sarwar and Kirkegaard 1998). For instance, LópezEscudero et al. (2007b) demonstrated the effectiveness of air-dried Diplotaxis virgata (Cav.) DC. debris on the eradication of $V$. dahliae MS under controlled conditions. Subsequent reduction of Verticillium wilt in cotton plants grown in pots with such amendment was also reported. Disease reduction was attributed to chemical compounds, mainly glucosinolates, resulting from the decomposition of cruciferous residues. An additional effect of this kind of debris is the anaerobic-induced environment that can favor antagonistic microflora (Goicoechea 2009, and references therein). However, under field conditions, little has been investigated about the use of some of these amendments, and available examples mainly refer to applications in herbaceous hosts. For instance, good results have been reported in reducing $V$. dahliae in soil and /or controlling Verticillium wilt in cauliflower (Subbarao and Hubbard 1999) or potato (Blok et al. 2000) by using broccoli (Brassica oleracea L.) debris.

In the particular case of VWO, Bejarano-Alcázar (2008) and López-Escudero et al. (2008) have reviewed the potential of some cultural practices involving the incorporation of different organic substrates to soils in olive plantations at southern Spain under diverse soil management systems. These authors highlighted that practices consisting in the inter-cropping and subsequent burial of pre-selected Brassicaceae species (i.e., Eruca vesicaria, Moricandia moricandioides or Sinapis alba) are being increasingly implemented by farmers. However, trials conducted so far have yielded inconsistent results, greatly varying among different locations. Moreover, some substrates potentially effective and easily applicable in olive orchards, such as olive-mill waste (Morillo et al. 2009), are currently being evaluated in relation to its efficacy against $V$. dahliae as well. Overall, however, this area of research is still waiting for in-depth and long-term studies before inferring premature conclusions on the potential (dis) advantages of some of these cultural practices in olive.

Chemical control measures against VWO have severe limitations, mainly due to the inaccessibility of most of the available active products to the vascular system and the persistence and distribution of MS in soil. Many active substances have been evaluated, particularly systemic fungicides. Despite some compounds are effective in vitro, none of them have shown successful under field conditions. Overall, studies conducted to date indicate that currentlyavailable fungicides are inefficient to control the disease (Tjamos 1993; Trapero and Blanco-López 2008). For instance, application of systemic benzimidazoles (by spraying or trunk injection) has shown to be unsuccessful (Cirulli and Montemurro 1976; Petsikos-Panayotarov 1980; Tawil et al. 1991; Gallego-Álvarez 1994). Similarly, no success was reported in VWO control of 1-year-old, root-dipped inoculated 'Picual' trees upon spraying carbendazim, prochloraz, quinosol and the mixtures carbendazim + quinosol and carbendazim + prochloraz (LópezEscudero and Blanco-López 1996). Likewise, periodical applications along 2 years with carbendazim, fosetil-Al, kresoxim-metil and potassium permanganate through the irrigation water (drip-irrigation), did not reduce the DI in an experimental plot (1.200 trees) of 'Picual' affected by VWO (Sánchez-Alcalá 2005). Interestingly though, Abu-Qamar and Al-Raddad (2001) reported that soil-drenching of 'Nabali' trees in Jordan with Cryptonol (8-hydroxyquinoline sulfate) was as effective as covering trees with a solar chamber for 15 days in suppressing VWO development.

Finally, there are some evasive methods (i.e., reduced tilling or the use of resistant cultivars) that diminish the efficacy of the inoculum present in soil to cause disease by either affecting pathogen activity, or reducing pathogen's contact with plant roots thereby limiting the infection and colonization of root tissues and disease development. However, there is still little information about the mechanisms underlying some of these actions. For instance, despite use of rational irrigation dosages and nitrogen fertilization can delay or diminish disease development, there is an important lack of information about their influence on this pathosystem. Nonetheless, the application of low doses and frequencies of irrigation are normally recommended in several crops in which $V$. dahliae causes wilt, such as cotton or olive (El-Zik 1985; Blanco-López and Jiménez-Díaz 1995; Arbogast et al. 1999).

\section{Conclusions and future perspectives}

During the last two decades VWO has become a major threat in some regions where olive is tradition- 
ally cultivated. We have described how diverse epidemiological factors have contributed to the current importance and spreading of VWO. Some of these factors are consequences of inadequate crop managing and/or plant propagation practices, some can be related to recent changes in olive cultivation systems, for example irrigation and fertilization, whereas others depend on diverse and variable environmental parameters. Moreover, these factors can interact in overlapping or synergistic ways. Many of them are not well-understood, and in-depth, longterm studies are needed.

Whilst we have gathered a significant knowledge on diversity and structure of $V$. dahliae populations infecting olive, it should be emphasized that most of this information originated from collections of isolates from diseased trees. This comprehension can be therefore considered as partial, and likely biased by the susceptibility of certain olive cultivars to be colonized by $V$. dahliae isolates showing advantageous infecting capacity over other isolates. Thus, relevant information on $V$. dahliae populations present in soil is still waiting to be uncovered.

An important concern is the nearly ubiquitous presence of highly virulent isolates (D pathotype) in some areas. Unraveling factors that contribute to spreading of these isolates may help in developing measures to reduce their dispersal to D-pathotype-free regions. One factor is the increasing inoculum density of these isolates in soil due to efficient infection and colonization of cultivated host plants. Another one is the effective dispersal of pathogen propagules that can be favored by farmer practices. In addition, effectiveness of available exclusion methods can be compromised, either because they have not been developed or implemented on time (i.e., proper administrative surveillance), or because middle or long-distance dispersal of the pathogen (i.e., distribution by irrigation water) is hindering their proper application. As a consequence, for olive orchards (or areas) severely affected by the D pathotype, only a few drastic actions can be expected, and likely with limited success.

Development of molecular detection procedures has greatly advanced the accurate and specific diagnosis of olive-infecting $V$. dahliae pathotypes. These procedures are of much help to qualify pathogen-free propagation and planting material. Detection and quantification of $V$. dahliae propagules in soil is also of highest relevance, but hampered by problems inherent to soil samples. Development of molecular tools to assess the population structure and to quantify in-soil inoculum potential of $V$. dahliae groups will help in risk assessment studies and in selection of new planting sites.

An integrated disease management strategy appears to be the only plausible framework for an effective control of VWO (Tjamos 1993; Blanco-López and Jiménez-Díaz 1995; Jiménez-Díaz et al. 1998; Tjamos and Jiménez-Díaz 1998; Trapero and Blanco-López 2008). We cannot but agree with this recommendation, and we have proposed ways to implement it throughout this review. One of the main reasons to accomplish such a holistic approach is the absence of effective curative chemical control on affected trees, or for soil disinfestation at established plantations. Moreover, none of the available control measures have been proved successful when applied individually. It should be emphasized that the most efficient and sustainable control measures are those which can be implemented before planting. Nevertheless, olive-growing areas where the disease has reached high incidence levels require a balanced implementation of after-planting control actions, including cultivation practices and biological and physical-chemical control. In these regions, like some areas in Southern Spain, increased amounts of soil inoculum and higher infection rates occur due to the polyetic nature of VWO epidemics. Moreover, to find pathogen-free soils in these areas is nearly impossible due to continuous cultivation of herbaceous $V$. dahliae hosts. However, even though this integrated strategy could be accomplished, VWO eradication in some areas seems unfeasible at present. Farmers should mainly aim at reducing the number of newly-infected trees and at diminishing VWO symptoms severity along time. Since the effectiveness of control measures largely depends on the extent of the disease in a given area, the application of an integrated strategy is particularly important in those areas where VWO is not yet a serious economic problem for the development of this commodity. A package of control actions should also be compulsory in zones where olive is becoming an economically-interesting alternative crop. Obviously, use of certified planting material along with adequate administrative surveillance to control olive trees nurseries, and selection of pathogen-free soils, are prerequisites to start successful control of VWO. 
The integrated disease management framework should be based on modern sustainable agriculture criteria (Hamblin 1995), and development of additional control actions must be solidly sustained on profound understanding of the olive- $V$. dahliae pathosystem. We have summarized research efforts to accomplish this. However, there are still important gaps to be filled. Unraveling the molecular bases of the olive- $V$. dahliae interaction, effects of biotic and abiotic factors on this pathosystem, and interactions between the host, the pathogen and potential BCAs, should provide new avenues to develop robust control tools. The same accounts to understand how traditional cultural and agronomical practices may have modified the olive agroecosystem to favor VWO spread and severity. Likewise, long-term efforts are still necessary to find sources of (and to breed for) resistance to VWO. Certainly, the proposed strategy is of interest for the integrated management of other soil-borne diseases affecting woody crops.

Acknowledgements Research on Verticillium wilt of olive by the authors is currently supported by grants AGL2007-65766 and AGL2009-07275 (Spanish Ministerio de Ciencia e Innovación, cofinanced by FEDER of the UE), P07-CVI-02624 and P08-AGR-03635 (Junta de Andalucía, Spain), and FEDERINIA RFP2009-00008-C02-01. We are deeply grateful to Drs. Peter AHM Bakker, Paul A Hoskisson, Leire Molinero, Pilar Prieto, and Luis F Roca for their critical reading of the manuscript and for interesting suggestions which improved the final version of this review. We are also in debt to Dr. Pilar Prieto for kindly providing CLSM image and to Dr. Luis F Roca for the gift of olive orchard picture. We particularly acknowledge to Dr. Miguel A Blanco-López his contribution on Verticillium wilt of olive studies, and his warm support and friendship to the authors. Our sincere apologies to colleagues whose works may have not been cited due to space limitation reasons.

Open Access This article is distributed under the terms of the Creative Commons Attribution Noncommercial License which permits any noncommercial use, distribution, and reproduction in any medium, provided the original author(s) and source are credited.

\section{References}

Abeles FB, Morgan PW, Saltviet ME (1992) Ethylene in plant biology. Academic, London

Abo Shkeers FM (2010) Evaluación de la resistencia de cultivares de olivo al patotipo defoliante de Verticillium dahliae y del contenido de etileno liberado por hojas de plantas infectadas. Msc Thesis, University of Córdoba (in Spanish)
Abu-Qamar M, Al-Raddad A (2001) Integrated control of Verticillium wilt of olive with cryptonol in combination with a solar chamber and fertilizer. Phytoparasitica 29:223-230

Al-Ahmad MA, Mosli MN (1993) Verticillium wilt of olive in Syria. Bull OEPP/EPPO Bull 23:521-529

Alström S (2001) Characteristics of bacteria form oilseed rape in relation to their biocontrol activity against Verticillium dahliae. J Phytopathol 149:57-64

Angiolillo A, Mencuccini M, Baldoni L (1999) Olive genetic diversity assessed using amplified fragment length polymorphisms. Theor Appl Genet 98:411-421

Antoniou PP, Tjamos EC, Kaltsis J, Tjamos SE (2001) Resistance evaluation to Verticillium dahliae in young olive cultivars or in root stocks of established olive orchards. 8th International Verticillium Symposium. Book of Abstracts, Córdoba, Spain, p 31

Antoniou PP, Markakis EA, Tjamos SE, Paplomatas EJ, Tjamos EC (2008) Novel methodologies in screening and selecting olive varieties and root-stocks for resistance to Verticillium dahliae. Eur J Plant Pathol 122:549-560

Antonopoulos DF, Tjamos SE, Antoniou PP, Rafeletos P, Tjamos EC (2008) Effect of Paenibacillus alvei, strain K165, on the germination of Verticillium dahliae microsclerotia in planta. Biol Control 46:166-170

Aragüés R, Puy J, Isidoro D (2004) Vegetative growth response of young olive trees (Olea europaea L., cv. Arbequina) to soil salinity and water logging. Plant Soil 258:69-80

Aragüés R, Guillén M, Royo A (2010) Five-year growth and yield response of two young olive cultivars (Olea europaea L., cvs. Arbequina and Empeltre) to soil salinity. Plant Soil 334:423-432

Arbogast M, Powelson ML, Cappaert MR, Watrud LS (1999) Response of six potato cultivars to amount of applied water and Verticillium dahliae. Phytopathology 89:782-788

Arnold AE (2007) Understanding the diversity of foliar endophytic fungi: progress, challenges, and frontiers. Fungal Biol Rev 21:51-66

Atallah ZK, Bae J, Jansky SH, Rouse DI, Stevenson WR (2007) Multiplex real-time quantitative PCR to detect and quantify Verticillium dahliae colonization in potato lines that differ in response to Verticillium wilt. Phytopathology 97:865-872

Baídez AG, Gómez P, del Río JA, Ortuño A (2007) Dysfunctionality of the xylem in Olea europaea L. plants associated with the infection process by Verticillium dahliae Kleb. Role of phenolic compounds in plant defense mechanism. J Agric Food Chem 55:3373-3377

Barbara DJ, Clewes E (2003) Plant pathogenic Verticillium species: how many of them are there? Mol Plant Pathol 4:297-305

Beckman CH (1987) The nature of wilt diseases of plant. APS, St. Paul

Bejarano-Alcázar J (2008) Efecto de las cubiertas vegetales sobre la epidemiología y control de la Verticilosis del olivo. Mercacei Mag 51:206-208 (in Spanish)

Bejarano-Alcázar J, Jiménez-Díaz RM (1997) Analysis of the spatial pattern of Verticillium dahliae in soil. 7th International Verticillium Symposium, Athens, Greece, Book of Abstracts, p 87

Bejarano-Alcázar J, Blanco-López MA, Melero-Vara JM, Jiménez-Díaz RM (1996) Etiology, importance, and 
distribution of Verticillium wilt of cotton in southern Spain. Plant Dis 80:1233-1238

Bejarano-Alcázar J, Blanco-López MA, Melero-Vara JM, Jiménez-Díaz RM (1997) The influence of Verticillium wilt epidemics on cotton yield in southern Spain. Plant Pathol 46:168-178

Bellahcene M, Fortas Z, Geiger JP, Matallah A, Henni D (2000) Verticillium wilt in olive in Algeria: geographical distribution and extent of the disease. Olivae 82:41-43

Bellahcene M, Assigbetsé K, Fortas Z, Geiger JP, Nicole M, Fernandez D (2005a) Genetic diversity of Verticillium dahliae isolates from olive trees in Algeria. Phytopathol Mediterr 44:266-274

Bellahcene M, Fortas Z, Fernandez D, Nicole M (2005b) Vegetative compatibility of Verticillium dahliae isolates from olive trees (Olea europaea L.) in Algeria. Afr J Biotechnol 4:963-967

Benítez T, Rincón AM, Limón MC, Codón AC (2004) Biocontrol mechanisms of Trichoderma strains. Int Microbiol 7:249-260

Benson DM, Ashworth LJ Jr (1976) Survival of Verticillium albo-atrum on nonsuscept roots and residues in field soil. Phytopathology 66:883-887

Berg G (2000) Diversity of antifungal and plant-associated Serratia plymuthica strains. J Appl Microbiol 88:952-960

Berg G, Knappe C, Ballin G, Seidel D (1994) Biological control of Verticillium dahliae by naturally occurring rhizosphere bacteria. Arch Phytopathol Plant Protect 29:249-262

Berg G, Opelt K, Zachow C, Lottmann J, Gotz M, Costa R, Smalla K (2006) The rhizosphere effect on bacteria antagonistic towards the pathogenic fungus Verticillium differs depending on plant species and site. FEMS Microbiol Ecol 56:250261

Bhat RG, Subbarao KV (1999) Host range specificity in Verticillium dahliae. Phytopathology 89:1218-1225

Bhat RG, Subbarao KV (2001) Reaction of broccoli to isolates of Verticillium dahliae from various hosts. Plant Dis 85:141-146

Bhat RG, Smith RF, Koike ST, Wu BM, Subbarao KV (2003) Characterization of Verticillium dahliae isolates and wilt epidemics of pepper. Plant Dis 87:789-797

Birem F, Alcántara E, Blanco-López MA, López-Escudero FJ (2009) Physiologycal differences expressed by susceptible and resistant olive cultivars inoculated with Verticillium dahliae. 10th International Verticillium Symposium, Book of Abstracts, Corfu Island, Hellas, p 71

Blanco-López MA, DeVay JE (1987) Effect of different irrigation regimes on Verticillium wilt, proline content and Leaf water potential in cotton. Proceedings VII Congress of the Mediterranean Phytopathological Union, Granada, Spain

Blanco-López MA, Jiménez-Díaz RM (1995) Una propuesta de lucha integrada contra la Verticilosis del olivo. Frutic Prof 70:52-57 (in Spanish)

Blanco-López MA, Jiménez-Díaz RM, Caballero JM (1984) Symptomatology, incidence and distribution of Verticillium wilt of olive trees in Andalucía. Phytopathol Mediterr 23:1-8

Blanco-López MA, Hiemstra J, Harris D, López-Escudero FJ, Antoniou P (1998) Selection and screening for host resistance. In: Hiemstra J, Harris D (eds) Compendium of Verticillium wilt in tree species. Ponsen \& Looijen, Wageningen, pp 51-54

Blok WJ, Lamers JG, Termorshuizen AJ, Bollen GJ (2000) Control of soilborne plant pathogens by incorporating fresh organic amendments followed by tarping. Phytopathology 90:253-259

Butterfield EJ, DeVay JE (1977) Reassessment of soil assays for Verticillium dahliae. Phytopathology 67:1073-1078

Caballero JM, Del Rio C (2008b) The olive world germplasm bank of Spain. Acta Hortic 791:31-38

Caballero JM, del Río C (2008a) Métodos de multiplicación. In: Barranco D, Fernández-Escobar R, Rallo L (eds) El cultivo del olivo, 6th edn. Junta de Andalucía and Ediciones Mundi-Prensa, Madrid, pp 93-125 (in Spanish)

Caballero JM, Pérez-Hernández J, Blanco-López MA, JiménezDíaz RM (1980) Olive, a new host of Verticillium dahliae in Spain. In: Proc 5th Cong Medit Phytopath Union. Patras, p 50

Carder JH, Barbara DJ (1991) Molecular variation and restriction fragment length polymorphism (RFLPs) within and between six species of Verticillium. Mycol Res 95:935-942

Carder JH, Morton A, Tabrett AM, Barbara DJ (1994) Detection and differentiation by PCR of subspecific groups within two Verticillium species causing vascular wilts in herbaceous hosts. In: Schots A, Dewey FM, Oliver $\mathrm{R}$ (eds) Modern assays for plant pathogenic fungi. CAB International, Oxford, pp 91-97

Castillo P, Nico AI, Navas-Cortés JA, Landa BB, Jiménez-Díaz RM, Vovlas N (2010) Plant-parasitic nematodes attacking olive trees and their management. Plant Dis 94:148-162

Chen W (1994) Vegetative compatibility groups of Verticillium dahliae from ornamental woody plants. Phytopathology 84:214-219

Cherrab M, Serrhini MN, Charest PM (2000) Characterization of Moroccan isolates of Verticillium dahliae Kleb. using RAPD markers. J Phytopathol 148:243-249

Cherrab M, Bennani A, Charest PM, Serrhini MN (2002) Pathogenicity and vegetative compatibility of Verticillium dahliae Kleb. isolates from olive in Morocco. J Phytopathol 150:703-709

Cirulli M (1981) Attualli cognizioni sulla Verticilliosi dell'olivo. Inf Fitopatol 1-2:1001-1005 (in Italian)

Cirulli M, Montemurro G (1976) A comparison of pathogenic isolates of Verticillium dahliae and sources of resistance in olive. Agriculturae Conspectus Scientificus 39:469-476

Cirulli M, Amenduni M, Paplomatas EJ (1998) Verticillium wilt of major tree hosts. Stone fruits. In: Hiemstra JA, Harris DC (eds) A compendium of Verticillium wilts in tree species. Ponsen and Looijen, Wageningen, pp 17-20

Cirulli M, Colella C, D’Arnico M, Amenduni M, Bubici G (2008) Comparison of screening methods for the evaluation of olive resistance to Verticillium dahliae Kleb. J Plant Pathol 90:714

Civantos L (2008) La olivicultura en el mundo y en España. In: Barranco D, Fernández-Escobar R, Rallo L (eds) El cultivo del olivo, 6th edn. Junta de Andalucía and Ediciones Mundi-Prensa, Madrid, pp 17-35 (in Spanish)

Colella C, Miacola C, Amenduni M, D’Amico M, Bubici G, Cirulli M (2008) Sources of Verticillium wilt resistance in 
wild olive germplasm from the Mediterranean region. Plant Pathol 57:533-539

Collado-Romero M, Mercado-Blanco J, Olivares-García C, Valverde-Corredor A, Jiménez-Díaz RM (2006) Molecular variability within and among Verticillium dahliae vegetative compatibility groups determined by fluorescent amplified fragment length polymorphism and polymerase chain reaction markers. Phytopathology 96:485-495

Collado-Romero M, Mercado-Blanco J, Olivares-García C, Jiménez-Díaz RM (2008) Phylogenetic analysis of Verticillium dahliae vegetative compatibility groups. Phytopathology 98:1019-1028

Collado-Romero M, Berbegal M, Jiménez-Díaz RM, Armengol J, Mercado-Blanco J (2009) A PCR-based "molecular tool box" for in planta differential detection of Verticillium dahliae vegetative compatibility groups infecting artichoke. Plant Pathol 58:515-526

Collado-Romero M, Jiménez-Díaz RM, Mercado-Blanco J (2010) DNA sequence analysis of conserved genes reveals hybridization events that increase genetic diversity in Verticillium dahliae. Fungal Biol 114:209-218

Collins A, Okoli CAN, Morton A, Parry D, Edwards SG, Barbara DJ (2003) Isolates of Verticillium dahliae pathogenic to crucifers are of at least three distinct molecular types. Phytopathology 93:364-376

Collins A, Mercado-Blanco J, Jiménez-Díaz RM, Olivares C, Clewes E, Barbara DJ (2005) Correlation of molecular markers and biological properties in Verticillium dahliae and the possible origins of some isolates. Plant Pathol 54:549-557

Cook RJ (1993) Alternative disease management strategies. In: Buxton DR, Shibles R, Forsberg RA, Blad BL, Asay KH, Paulsen GM, Wilson RF (eds) International Crop Science. Crop Science Society of America, Madison, pp 129-134

Costa R, Salles JF, Berg G, Smalla K (2006) Cultivation independent analysis of Pseudomonas species in soil and in the rhizosphere of field-grown Verticillium dahliae host plants. Environ Microbiol 8:2136-2149

Daayf F, Nicole M, Geiger J (1995) Differentiation of Verticillium dahliae populations on the basis of vegetative compatibility and pathogenicity on cotton. Eur J Plant Pathol 101:69-79

Dan H, Ali-Khan AT, Robb J (2001) Use of quantitative PCR diagnostics to identify tolerance and resistance to Verticillium dahliae in potato. Plant Dis 85:700-705

Datnoff LE, Rodrigues FA, Seebold KW (2007) Silicon and plant disease. In: Datnoff LE, Wade HE, Huber DM (eds) Mineral nutrition and plant disease. The American Phytopathological Society, St. Paul

Debode J, Van Poucke K, Franca SC, Höfte M, Maes M, Heungens K (2009) Quantitative detection of multiple Verticillium species in soil using real-time PCR. 10th International Verticillium Symposium. Book of Abstracts. Corfu Island, Greece, p 31

Deepak SA, Kottapalli KR, Rakwal R, Oros G, Rangappa KS, Iwahashi H, Masuo Y, Agrawal GK (2007) Real-time PCR: revolutionizing detection and expression analysis of genes. Curr Genomics 8:234-251

Dervis S, Erten L, Soylu S, Tok FM, Kurt S, Yildiz M, Soylu EM (2007) Vegetative compatibility groups in Verticillium dahliae isolates from olive in western Turkey. Eur J Plant Pathol 119:437-447

Dervis S, Kurt S, Soylu S, Erten L, Soylu EM, Yildiz M, Tok FM (2008) Vegetative compatibility groups of Verticillium dahliae from cotton in the south-eastern Anatolia region of Turkey. Phytoparasitica 36:74-83

Dervis S, Mercado-Blanco J, Erten L, Valverde-Corredor A, Pérez-Artés E (2010) Verticillium wilt of olive in Turkey: a survey on disease importance, pathogen diversity and susceptibility of relevant olive cultivars. Eur J Plant Pathol 127:287-301

DeVay JE, Pullman GS (1984) Epidemiology and ecology of diseases caused by Verticillium species, with emphasis on Verticillium wilt cotton. Phytopathol Mediterr 23:95-108

Dobinson KF, Patterson NA, White G, Grant S (1998) DNA fingerprinting and vegetative compatibility analysis indicate multiple origins for Verticillium dahliae race 2 tomato isolates from Ontario, Canada. Mycol Res 102:1089-1095

Dobinson KF, Harrington MA, Omer M, Rowe RC (2000) Molecular characterization of vegetative compatibility group 4A and 4B isolates of Verticillium dahliae associated with potato early dying. Plant Dis 84:1241-1245

Duncan DR, Himelick EB (1988) Conidial production of Verticillium dahliae as influenced by a negative pressure potential. Can J Bot 66:67-71

Easton GD, Nagle ME, Bailey DL (1969) A method of estimating Verticillium albo-atrum propagules in field soil and irrigation water. Phytopathology 59:1171-1172

Edwards SG, McKay T, Seddon B (1994) Interaction of Bacillus species with phytopathogenic fungi: methods of analysis and manipulation for biocontrol purposes. In: Blakeman JP, Williamson B (eds) Ecology of plant pathogens. CAB International, Wallingford, pp 101-118

Elena K (1999) Genetic relationships among Verticillium dahliae isolates from cotton in Greece based on vegetative compatibility. Eur J Plant Pathol 105:609-616

Elena K (2000) Vegetative compatibility among Verticillium dahliae isolates from watermelon in Greece. Phytoparasitica 28:115-120

El-Zik KM (1985) Integrated control of Verticillium wilt of cotton. Plant Dis 69:1025-1032

Emechebe AM, Leakely CLA, Banage WB (1974) Verticillium wilt of cacao in Uganda: wilt induction by mechanical vessel blockage and mode of recovery of diseased plants. East Afr Agric For J 39:337-343

Erdogan O, Benlioglu K (2010) Biological control of Verticillium wilt on cotton by the use of fluorescent Pseudomonas spp. under field conditions. Biol Control 53:39-45

Evans G, Snyder WC, Wilhelm S (1966) Inoculum increase of the Verticillium wilt fungus in cotton. Phytopathology 56:590-594

Eynck C, Koopmann B, Grunewaldt-Stoeker G, Karlovsky P, von Tiedemann A (2007) Differential interactions of Verticillium longisporum and $V$. dahliae with Brassica napus detected with molecular and histological techniques. Eur J Plant Pathol 118:259-274

Faggian R, Bulman SR, Lawrie AC, Porter IJ (1999) Specific polymerase chain reaction primers for the detection of Plasmodiophora brassicae in soil and water. Phytopathology 89:392-397 
Fahleson J, Lagercrantz U, Hu Q, Steventon LA, Dixelius C (2003) Estimation of genetic variation among Verticillium isolates using AFLP analysis. Eur J Plant Pathol 109:361371

FAO, Food and Agriculture Organization of the United Nations (2008) http://www.fao.org/corp/statistics/en/

Fernández JE, Moreno F, Cabrera F, Arrúe JL, Martín-Aranda J (1991) Drip irrigation, soil characteristics and the root distribution and root activity of olive trees. Plant Soil 133:239-251

Fradin EF, Thomma BPHJ (2006) Physiology and molecular aspects of Verticillium wilt diseases caused by $V$. dahliae and V. albo-atrum. Mol Plant Pathol 7:71-86

Frankowski J, Lorito M, Scala F, Schmid R, Berg G, Bahl H (2001) Purification and properties of two chitinolytic enzymes of Serratia plymuthica HRO-C48. Arch Microbiol 176:421-426

Fravel DR (1988) Role of antibiosis in the biocontrol of plant diseases. Annu Rev Phytopathol 26:75-91

Gallego-Álvarez FJ (1994) La Verticilosis del olivo. Control mediante inyecciones en el tronco de carbendazima. Frutic Prof 62:18-22 (in Spanish)

Gamliel A, Austerweil M, Kritzman G (2000) Non-chemical approach to soilborne pest management-organic amendments. Crop Prot 19:847-853

Garber RH, Houston B (1966) Penetration and development of Verticillium albo-atrum in cotton plants. Phytopathology 56:1121-1126

Garber RH, Presley JT (1971) Relation of air temperature to development of Verticillium wilt on cotton in the field. Phytopathology 61:204-207

García-Pedrajas MD, Bainbridge BW, Heale JB, Pérez-Artés E, Jiménez-Díaz RM (1999) A simple PCR based method for the detection of the chickpea-wilt pathogen Fusarium oxysporum f. sp. ciceris in artificial and natural soils. Eur J Plant Pathol 105:251-259

Garmendia I, Goicoechea N, Aguirreolea J (2004) Effectiveness of three Glomus species in protecting pepper (Capsicum annuum L.) against Verticillium wilt. Biol Control 31:296-305

Garmendia I, Goicoechea N, Aguirreolea J (2005) Moderate drought influences the effect of arbuscular mycorrhizal fungi as biocontrol agents against Verticillium-induced wilt in pepper. Mycorrhiza 15:345-356

Gayoso C, de la Ilarduya OM, Pomar F, de Cáceres FM (2007) Assessment of real-time PCR as a method for determining the presence of Verticillium dahliae in different Solanaceae cultivars. Eur J Plant Pathol 118:199-209

Gerik JS, Huisman OC (1988) Study of field-grown cotton roots infected with Verticillium dahliae using an immunoenzymatic staining technique. Phytopathology 78:1174-1178

Goicoechea N (2009) To what extent are soil amendments useful to control Verticillium wilt? Pest Manag Sci 65:831-839

Gómez JA, Guzmán MG, Giráldez JV, Fereres E (2009) The influence of cover crops and tillage on water and sediment yield, and on nutrient, and organic matter losses in an olive orchard on a sandy loam soil. Soil Tillage Res 106:137-144

Goud JC, Hiemstra JA (1998) Other tree species. In: Hiemstra JA, Harris DC (eds) A compendium of Verticillium wilts in tree species. Ponsen and Looijen, Wageningen, pp 37 39

Goud JC, Termorshuizen AJ (2003) Quality of methods to quantify microsclerotia of Verticillium dahliae in soil. Eur J Plant Pathol 109:523-534

Goud JC, Termorshuizen AJ, Gams W (2003) Morphology of Verticillium dahliae and $V$. tricorpus on semiselective media used for detection of $V$. dahliae in soil. Mycol Res 101:822-838

Green RJ Jr (1969) Survival and inoculum potential of conidia and microsclerotia of Verticillium albo-atrum in soil. Phytopathology 59:874-876

Guerrero M (1999) Detección y cuantificación de Phytophthora spp. en olivares afectados de podredumbre radicular. Msc Thesis University of Córdoba, Spain (in Spanish)

Haas D, Défago G (2005) Biological control of soil-borne pathogens by fluorescent pseudomonas. Nat Rev Microbiol 3:307-319

Hall R, Ly H (1972) Development and quantitative measurement of microsclerotia of Verticillium dahliae. Can J Bot 50:2097-2102

Hamblin A (1995) The concept of agricultural sustainability. In: Andrews JH, Tommerup I (eds) Advances in plan pathology, vol 11. Academy, New York, pp 1-19

Hameed K, Benzina F, Mahasneh A (2005) Indigenous fluorescent pseudomonads as biological control for olive (Olea europaea L.) wilt pathogen Verticillium dahliae in Jordan. Phytopathology 95:S39 (Abstract)

Harman GE, Howell CR, Viterbo A, Chet I, Lorito M (2004) Trichoderma species-opportunistic, avirulent plant symbionts. Nat Rev 2:43-56

Harris DC, Yang YR, Ridout MS (1993) The detection and estimation of Verticillium dahliae in naturally infested soil. Plant Pathol 42:238-250

Hartman H, Schnathorst WC, Whisler J (1971) Oblonga, clonal olive rootstock resistant to Verticillium wilt. Calif Agric $25: 12-15$

Heale JB (1988) Verticillium spp., the cause of vascular wilts in many species. Adv Plant Pathol 6:291-312

Heinz R, Platt HW (2000) Improved DNA extraction method for Verticillium detection and quantification in large-scale studies using PCR-based techniques. Can J Plant Pathol 22:117-121

Heinz R, Lee SW, Saparno A, Nazar RN, Robb J (1998) Cyclical systemic colonization in Verticillium-infected tomato. Physiol Mol Plant Pathol 52:385-396

Hiemstra JA (1995) Recovery of Verticillium-infected ash trees. Phytoparasitica 23:64-65

Hiemstra JA (1998) Some general features of Verticillium wilts in trees. In: Hiemstra JA, Harris DC (eds) A compendium of Verticillium wilts in tree species. Ponsen and Looijen, Wageningen, pp 5-11

Hiemstra JA, Harris DC (eds) (1998) A compendium of Verticillium wilts in tree species. Ponsen \& Looijen, Wageningen

Hiemstra JA, Rataj-Guranowska M (2003) Vegetative compatibility groups in Verticillium dahliae isolates from the Netherlands as compared to VCG diversity in Europe and the USA. Eur J Plant Pathol 109:827-839

Howell CR (2003) Mechanisms employed by Trichoderma species in the biological control of plant diseases: the history and evolution of current concepts. Plant Dis 87:4-10 
Hu X, Nazar RN, Robb J (1993) Quantification of Verticillium biomass in wilt disease development. Physiol Mol Plant Pathol 42:23-36

Huang J, Li H, Yuan H (2006) Effect of organic amendments on Verticillium wilt of cotton. Crop Prot 25:1167-1173

Huber DM, Thompson IA (2007) Nitrogen and plant disease. In: Datnoff LE, Wade HE, Huber DM (eds) Mineral nutrition and plant disease. APS, St. Paul, $278 \mathrm{pp}$

Huisman OC (1982) Interrelation on root growth dynamics to epidemiology of root-invading fungi. Annu Rev Phytopathol 20:303-327

Huisman OC, Ashworth LJ Jr (1974) Quantitative assessment of $V$. alboatrum in field soil: procedural and substrate improvements. Phytopathology 64:1043-1044

Ioannou N, Scheneider RW, Grogan RG (1977) Effect of oxygen, carbon dioxide and ethylene on growth, sporulation and production of microsclerotia by Verticillium dahliae. Phytopathology 67:645-650

Jiménez-Díaz RM (1998) Control de enfermedades. In: Jiménez-Díaz RM, Lamo de Espinosa J (eds) Agricultura Sostenible. Ediciones Mundi-Prensa, Madrid, Barcelona, México, DF, pp 345-375 (in Spanish)

Jiménez-Díaz RM, Tjamos EC, Cirulli M (1998) Verticillium wilt of major tree hosts. Olive. In: Hiemstra JA, Harris DC (eds) A compendium of Verticillium wilts in tree species. Ponsen and Looijen, Wageningen, pp 13-16

Jiménez-Díaz RM, Mercado-Blanco J, Olivares-García C, Collado-Romero M, Bejarano-Alcázar J, RodríguezJurado D, Giménez-Jaime A, García-Jiménez J, Armengol J (2006) Genetic and virulence diversity in Verticillium dahliae populations infecting artichoke in eastern-central Spain. Phytopathology 96:288-298

Jiménez-Díaz RM, Trapero-Casas JL, Boned J, Landa del Castillo BB, Navas-Cortés JA (2009) Avances en el control biológico de la verticilosis del olivo. Vida Rural 296:50-58 (in Spanish)

Joaquim TR, Rowe RC (1990) Reassessment of vegetative compatibility relationships among strains of Verticillium dahliae using nitrate-non-utilizing mutants. Phytopathology 80:1160-1166

Joaquim TR, Rowe RC (1991) Vegetative compatibility and virulence of strains of Verticillium dahliae from soil and potato plants. Phytopathology 81:552-558

Jordan VWL, Tarr HS (1978) Inoculum suppression of Verticillium dahliae. Ann Appl Biol 89:139-141

Kalbe C, Marten P, Berg G (1996) Strains of the genus Serratia as beneficial rhizobacteria of oilseed rape with antifungal properties. Microbiol Res 151:433-439

Kamensky M, Ovadis M, Chet I, Chernin L (2003) Soil-borne strain IC14 of Serratia plymuthica with multiple mechanisms of antifungal activity provides biocontrol of Botrytis cinerea and Sclerotinia sclerotiorum diseases. Soil Biol Biochem 35:323-331

Karagiannidis N, Bletsos F, Stavropoulos N (2002) Effect of Verticillium wilt (Verticillium dahliae Kleb.) and mycorrhiza (Glomus moseae) on root colonization, growth and nutrient uptake in tomato and eggplant seedlings. Sci Hortic 94:145-156

Karajeh MR (2006) Seed transmission of Verticillium dahliae in olive as detected by a highly sensitive nested PCR-based assay. Phytopathol Mediterr 45:15-23
Katan J (1987) Soil solarization. In: Chet I (ed) Innovative approaches to plant disease management. Wiley, New York, pp 77-105

Katan J (2000a) Physical and cultural methods for the management of soil-borne pathogens. Crop Prot 19:725-731

Katan T (2000b) Vegetative compatibility in populations of Verticillium: an overview. In: Tjamos EC, Rowe R, Heale JB, Fravel DR (eds) Advances in Verticillium: research and disease management. Proc. 7th Int Verticillium Symp. The American Phytopathological Society, St. Paul, MN, pp 69-86

Klebahn H (1913) Beiträge zur Kenntnis der Fungi Imperfecti I. Eine Verticillium-Krankheit auf Dahliaen. Mycologisches Zentralblatt 3:49-66 (in German)

Klimes A, Dobinson KF (2006) A hydrophobin gene, VDH1, is involved in microsclerotial development and spore viability in the plant pathogen Verticillium dahliae. Fungal Genet Biol 43:283-294

Klimes A, Amyotte SG, Grant S, Kang S, Dobinson KF (2008) Microsclerotia development in Verticillium dahliae: regulation and differential expression of the hydrophobin gene $\mathrm{VDH}$. Fungal Genet Biol 45:1525-1532

Klosterman SJ, Atallah ZK, Vallad GE, Subbarao KV (2009) Diversity, pathogenicity and management of Verticillium species. Annu Rev Phytopathol 47:39-62

Kobra N, Jalil K, Toubert G (2009) Effects of three Glomus species as biocontrol agents against Verticillium-induced wilt in cotton. J Plant Prot Res 49:185-189

Koike M, Fujita M, Nagao H, Oshima S (1996) Random amplified polymorphic DNA analysis of Japanese isolates of Verticillium dahliae and V. albo-atrum. Plant Dis 80:1224-1227

Korolev N, Katan T (1997) Improved medium for selecting nitrate nonutilizing (nit) mutants of Verticillium dahliae. Phytopathology 87:1067-1070

Korolev N, Katan J, Katan T (2000) Vegetative compatibility groups of Verticillium dahliae in Israel: their distribution and association with pathogenicity. Phytopathology 90:529-566

Korolev N, Pérez-Artés E, Bejarano-Alcázar J, RodríguezJurado D, Katan J, Katan T, Jiménez-Díaz RM (2001) Comparative study of genetic diversity and pathogenicity among populations of Verticillium dahliae from cotton in Spain and Israel. Eur J Plant Pathol 107:443456

Korolev N, Pérez-Artés E, Mercado-Blanco J, BejaranoAlcázar J, Rodríguez-Jurado D, Jiménez-Díaz RM, Katan T, Katan J (2008) Vegetative compatibility of cotton defoliating Verticillium dahliae in Israel and its pathogenicity to various hosts. Eur J Plant Pathol 122:603-617

Krishnamurty V, Barbara D, Price A (2001) PCR-based quantification of Verticillium dahliae in Soil. 8th International Verticillium Symposium. Book of Abstracts. Córdoba, Spain, pp 73

Lachquer K, Sedra MH (2002) Characterisation of Verticillium dahliae Kleb. isolates from Olea europaea using RAPD markers. Phytopathol Mediterr 41:170-178

Latorre BA, Allende PT (1983) Occurrence and incidence of Verticillium wilt on Chilean avocado groves. Plant Dis $67: 445-447$ 
Lazarovits G, Conn K, Tenuta M (2000) Control of Verticillium dahliae with soil amendments: efficacy and mode of action. In: Tjamos EC, Rowe RC, Heale JB, Fravel DR (eds) Advances in Verticillium research and disease management. APS, St. Paul, pp 274-291

Leben SD, Wadi JA, Easton GD (1987) Effects of Pseudomonas fluorescens on potato plant growth and control of Verticillium dahliae. Phytopathology 77:1592-1595

Leslie JF (1993) Fungal vegetative compatibility. Annu Rev Phytopathol 31:127-150

Levin AG, Lavee S, Tsror (Lahkim) L (2003a) Epidemiology of Verticillium dahliae on olive (cv. Picual) and its effect on yield under saline conditions. Plant Pathol 52:212-218

Levin AG, Lavee S, Tsror (Lahkim) L (2003b) Epidemiology and effects of Verticillium wilt on yield of olive trees (cvs. Barnea and Souri) irrigated with saline water in Israel. Phytoparasitica 31:333-343

Levin AG, Lavee S, Tsror (Lahkim) L (2007) The influence of salinity on Verticillium dahliae in stem cuttings of five olive cultivars. J Phytopathol 155:587-592

Levy J, Isaac I (1976) Colonization of host tissue of varying resistance to Verticillium dahliae. Trans $\mathrm{Br}$ Mycol Soc 67:91-94

Li KN, Rouse DI, German TL (1994) PCR primers that allow intergeneric differentiation of ascomycetes and their application to Verticillium spp. Appl Environ Microbiol 60:4324-4331

Li KN, Rouse DI, Eyestone EJ, German TL (1999) The generation of specific DNA primers using random amplified polymorphic DNA and its application to Verticillium dahliae. Mycol Res 103:1361-1368

Ligoxigakis EK, Vakalounakis DJ, Thanassoulopoulos CC (2002) Weed hosts of Verticillium dahliae in Crete: susceptibility, symptomatology and significance. Phytoparasitica 30:511518

López-Escudero FJ, Blanco-López MA (1996) Evaluación de la eficacia fungicida en el control de la Verticilosis del olivo. Libro de resúmenes del VIII Congreso Nacional de la Sociedad Española de Fitopatología. Córdoba, p 197 (in Spanish)

López-Escudero FJ, Blanco-López MA (1999) First report of transmission of Verticillium dahliae by infested manure in olive orchards in Andalucía (Southern Spain). Plant Dis 83:1178

López-Escudero FJ, Blanco-López MA (2001) Effect of a single or double soil solarization to control Verticillium wilt in established olive orchards in Spain. Plant Dis 85:489-496

López-Escudero FJ, Blanco-López MA (2005a) Recovery of young olive trees from Verticillium dahliae. Eur J Plant Pathol 113:367-375

López-Escudero FJ, Blanco-López MA (2005b) Effects of drip irrigation on population of Verticillium dahliae in olive orchards. J Phytopathol 153:238-239

López-Escudero FJ, Blanco-López MA (2005c) Isolation and morphologic characterization of microsclerotia of Verticillium dahliae isolate from soil. Biotechnology 4:296-304

López-Escudero FJ, Blanco-López MA (2007) The relationship between the inoculum density of Verticillium dahliae and the progress of Verticillium wilt of olive. Plant Dis 91:1372-1378
López-Escudero FJ, Martos-Moreno C, Blanco-López MA (2003) Análisis y significado epidemiológico de la población de Verticillium dahliae en el suelo. Servicio de publicaciones de la Universidad de Córdoba (in Spanish)

López-Escudero FJ, del Río C, Caballero JM, Blanco-López MA (2004) Evaluation of olive cultivars for resistance to Verticillium dahliae. Eur J Plant Pathol 110:79-85

López-Escudero FJ, Blanco-López MA, del Río RC, Caballero Reig JM (2007a) Response of olive cultivars to stem puncture inoculation with a defoliating pathotype of Verticillium dahliae. HortScience 42:294-298

López-Escudero FJ, Mwanza C, Blanco-López MA (2007b) Reduction of Verticillium dahliae microsclerotia viability by dried plant residues. Crop Prot 26:127-133

López-Escudero FJ, Blanco-López MA, Trapero A (2008) Influencia de las cubiertas vegetales en las enfermedades del olivar. In: Rodríguez-Lizana A, Ordóñez-Frenández R, Gil-Ribes J (eds) Cubiertas vegetales en olivar. Consejería de Agricultura y Pesca, Junta de Andalucía, pp 1001-1114 (in Spanish)

López-Escudero FJ, García-Cabello S, Blanco-López MA (2009a) Distribution of Verticillium dahliae through watering systems in irrigated olive orchards in Andalucía. 10th Int Verticillium Symposium, Book of Abstracts, Corfu Island, Hellas, p 80

López-Escudero FJ, Roca JM, Mercado-Blanco J, ValverdeCorredor A, Blanco-López MA (2009b) Effect of agronomical factors in the importance of Verticillium wilt of olive in the Guadalquivir Valley in Andalucía (Southern Spain). 10th Int Verticillium Symposium, Book of Abstracts, Corfu Island, Hellas, p 96

López-Escudero FJ, Roca LF, Trapero A, Blanco-López MA (2009c) An outbreak of Verticillium wilt in hedgerow olive orchards in Andalucía (Southern Spain). 4th European Meeting of the IOBC Working Group Integrated Protection of Olive Crops. Book of Abstracts, Córdoba, Spain, p 101

Lugtenberg BJJ, Dekkers LC, Bloemberg GV (2001) Molecular determinants of rhizosphere colonization by Pseudomonas. Annu Rev Phytopathol 39:461-490

Ma ZH, Michailides TJ (2007) Approaches for eliminating PCR inhibitors and designing PCR primers for the detection of phytopathogenic fungi. Crop Prot 26:145-161

Mace ME, Bell AA, Beckman CH (eds) (1981) Fungal wilt diseases of plants. Academic, New York

Madi L, Katan T, Katan J, Henis Y (1997) Biological control of Sclerotium rolfsii and Verticillium dahliae by Talaromyces flavus is mediated by different mechanisms. Phytopathology 87:1054-1060

Mahuku GS, Platt HW (2002) Quantifying Verticillium dahliae in soils collected from potato fields using a competitive PCR assay. Am J Potato Res 79:107-117

Mahuku GS, Platt HW, Maxwell P (1999) Comparison of polymerase chain reaction methods with plating on media to detect and identify Verticillium wilt pathogens on potato. Can J Plant Pathol 21:125-131

Manluk O, Ab-Gharbieh WI, Shaw G (1984) A check list of plant diseases in Jordan. Al-Dastour, Amman

Markakis EA, Tjamos SE, Antoniou PP, Paplomatas EJ, Tjamos EC (2009) Symptom development, pathogen 
isolation and Real-Time QPCR quantification as factors for evaluating the resistance of olive cultivars to Verticillium pathotypes. Eur J Plant Pathol 124:603-611

Markakis EA, Tjamos SE, Antoniou PP, Roussos PA, Paplomatas EJ, Tjamos EC (2010) Phenolic responses of resistant and susceptible olive cultivars induced by defoliating and nondefoliating Verticillium dahliae pathotypes. Plant Dis 94:1156-1162

Martos-Moreno C (2003) Resistencia de cultivares de olivo al aislado defoliante de Verticillium dahliae Kleb. Y reducción de la enfermedad por la infección previa con el aislado defoliante. $\mathrm{PhD}$ Thesis, University of Córdoba (in Spanish)

Martos-Moreno C, Caballero JM, del Río C, Blanco-López MA (2001) Epidemiological behavior of olive cultivars in orchard infested with mixtures of defoliating and nondefoliating isolates of Verticillium dahliae. 8th Int Verticillium Symposium, Book of Abstracts, Córdoba, Spain $\mathrm{p}$ 67

Martos-Moreno C, López-Escudero FJ, Blanco-López MA (2006) Resistance of olive cultivars to the defoliating pathotype of Verticillium dahliae. HortScience 41:13131316

Matta A, Garibaldi A (1977) Control of Verticillium wilt of tomato by preinoculation with avirulent fungi. Eur J Plant Pathol 83:457-462

McDonald BA, Linde C (2002) Pathogen population genetics, evolutionary potential, and durable resistance. Ann Rev Phytopathol 40:349-379

Mejía LC, Rojas EI, Maynard Z, Bael SV, Arnold E, Hebbar P, Samuels GJ, Robbins N, Herre EA (2008) Endophytic fungi as biocontrol agents of Theobroma cacao pathogens. Biol Control 46:4-14

Melero-Vara JM, Blanco-López MA, Bejarano-Alcázar J, Jiménez-Díaz RM (1995) Control of Verticillium wilt of cotton by means of soil solarization and tolerant cultivars in Southern Spain. Plant Pathol 44:250-260

Mercado-Blanco J, Bakker PAHM (2007) Interactions between plants and beneficial Pseudomonas spp.: exploiting bacterial traits for crop protection. Antonie Leeuwenhoek 92:367-389

Mercado-Blanco J, Rodríguez-Jurado D, Pérez-Artés E, JiménezDíaz RM (2001) Detection of the nondefoliating pathotype of Verticillium dahliae in infected olive plants by nested PCR. Plant Pathol 50:609-619

Mercado-Blanco J, Rodríguez-Jurado D, Pérez-Artés E, JiménezDíaz RM (2002) Detection of the defoliating pathotype of Verticillium dahliae in infected olive plants by nested PCR. Eur J Plant Pathol 108:1-13

Mercado-Blanco J, Collado-Romero M, Parrilla-Araujo S, Rodríguez-Jurado D, Jiménez-Díaz RM (2003a) Quantitative monitoring of colonization of olive genotypes by Verticillium dahliae pathotypes with real-time polymerase chain reaction. Physiol Mol Plant Pathol 63:91-105

Mercado-Blanco J, Rodríguez-Jurado D, Parrilla-Araujo S, Jiménez-Díaz RM (2003b) Simultaneous detection of the defoliating and nondefoliating Verticillium dahliae pathotypes in infected olive plants by duplex, nested polymerase chain reaction. Plant Dis 87:1487-1494

Mercado-Blanco J, Rodríguez-Jurado D, Hervás A, Jiménez-Díaz RM (2004) Suppression of Verticillium wilt in olive planting stocks by root-associated fluorescent Pseudomonas spp. Biol Control 30:474-486

Meschke H, Schrempf H (2010) Streptomyces lividans inhibits the proliferation of the fungus Verticillium dahliae on seeds and roots of Arabidopsis thaliana. Microb Biotechnol $3: 428-443$

Messner R, Schweigkofler W, Schweigkofler M, Berg G, Prillinger H (1996) Molecular characterization of the plant pathogen Verticillium dahliae Kleb. using RAPD-PCR and sequencing of the $18 \mathrm{~S}$ rRNA gene. J Phytopathol 144:347-354

Moraño-Moreno RJ, Bejarano-Alcázar J, Rodríguez-Jurado D (2008) Presencia de los patotipos defoliante y no defoliante de Verticillium dahliae en las aguas de riego de cultivos en Andalucía. XIV Congr Spanish Society Phytopathol, Book of Abstracts, Lugo, Spain, p 250 (in Spanish)

Morera B, Páez JI, Vega JM, Montes F (2005) Comparación de métodos de diagnóstico de Verticillium dahliae en olivo: aislamiento en medio de cultivo y PCR. Bol Sanid Veg Plagas 31:267-275 (in Spanish)

Morillo JA, Antizar-Ladislao B, Monteoliva-Sánchez M, Ramos-Cormenzana A, Russell NJ (2009) Bioremediation and biovalorisation of olive-mill waste. Appl Microbiol Biotechnol 82:25-39

Morrison TB, Weiss JJ, Wittwer CT (1999) Quantification of lowcopy transcripts by continuous SYBR Green I monitoring during amplification. Biotechniques 24:954-962

Morschel JR (1961) Recorded plant diseases in and outside Australia. Part 2 - Fruit and Edible Nut Crops. Commonwealth Department of Health Division of Plant Quarantine, Canberra p 113

Morton A, Carder JH, Barbara DJ (1995a) Sequences of the internal transcribed spacers of the ribosomal RNA genes and relationships between isolates of Verticillium alboatrum and V. dahliae. Plant Pathol 44:183-190

Morton A, Tabrett AM, Carder JH, Barbara DJ (1995b) Subrepeat sequences in the ribosomal RNA intergenic regions of Verticillium albo-atrum and $V$. dahliae. Mycol Res 99:255-266

Moukhamedov R, Hu X, Nazar RN, Robb J (1994) Use of polymerase chain reaction amplified ribosomal intergenic sequences for the diagnosis of Verticillium tricorpus. Phytopathology 84:256-259

Müller H, Tejedor-González E, Mercado-Blanco J, RodríguezJurado D, Jiménez-Díaz RM, Berg G (2007) Effect of the biological control strain Serratia plymuthica HRO-C48 on Verticillium wilt of olive trees cv. Arbequina. In: Elad Y, Ongena M, Höfte M, Haïssan Jijakli M (eds) Fundamental and practical approaches to increase biocontrol efficacy. IOBC/wprs Bulletin 30:173-177

Nagtzaam M, Bollen PM, Termorshuizen AJ (1998) Efficiency of Talaromyces flavus alone or in combination with other antagonist in controlling Verticillium dahliae in growth chamber experiments. J Phytopathol 146:165-173

Narisawa K, Kawamata H, Currah R, Hashiba T (2002) Suppression of Verticillium wilt in eggplant by some fungal root endophytes. Eur J Plant Pathol 108:103-109

Narisawa K, Usuk F, Hashiba T (2004) Control of Verticillium yellows in Chinese cabbage by the dark septate endophytic fungus LtVB3. Phytopathology 94:412-418 
Navarro C, Parra MA (2008) Plantación. In: Barranco D, Fernández-Escobar R, Rallo L (eds) El cultivo del olivo, 6th edn. Junta de Andalucía and Ediciones Mundi-Prensa, Madrid, pp 189-238 (in Spanish)

Navas-Cortés JA, Landa BB, Mercado-Blanco J, Trapero-Casas JL, Rodríguez-Jurado D, Jiménez-Díaz RM (2008) Spatiotemporal analysis of spreads of infections by Verticillium dahliae pathotypes within a high tree-density olive orchard in Southern Spain. Phytopathology 98:167-180

Nazar RN, Hu X, Schmidt J, Culham D, Robb J (1991) Potential use of PCR-amplified ribosomal intergenic sequences in the detection and differentiation of Verticillium wilt pathogens. Physiol Mol Plant Pathol 39:1-11

Nigro F, Gallone P, Romanazzi G, Schena L, Ippolito A, Salerno MG (2005) Incidence of Verticillium wilt on olive in Apulia and genetic diversity of Verticillium dahliae isolates from infected trees. J Plant Pathol 87:13-23

O'Sullivan DJ, O'Gara F (1992) Traits of fluorescent Pseudomonas spp. involved in suppression of plant root pathogens. Microbiol Rev 56:662-676

Okoli CAN, Carder JH, Barbara DJ (1994) Restriction fragment length polymorphisms (RFLPs) and the relationships of some host-adapted isolates of Verticillium dahliae. Plant Pathol 43:33-40

Paplomatas EJ, Elena K (2001) Reaction of Greek olive cultivars to the cotton defoliating strain of Verticillium dahliae. 8th International Verticillium Symposium. Book of Abstracts, Córdoba, Spain, pp 51

Paul B, Girard I, Bhatnagar T, Bouchet P (1997) Suppression of Botrytis cinerea causing grey mould disease of grape vine (Vitis vinifera) and its pectinolytic activities by a soil bacterium. Microbiol Res 152:413-420

Paulitz TC, Zhou T, Rankin L (1992) Selection of rhizosphere bacteria for biological control of Pythium aphanidermatum on hydroponically grown cucumber. Biol Control 2:226237

Pegg GF (1974) The impact of Verticillium diseases in agriculture. Phytopathol Mediterr 23:176-192

Pegg GF (1985) Life in a black hole-the microenvironment of the vascular pathogen. Trans Br Mycol Soc 68:1-20

Pegg GF, Brady BL (2002) Verticillium wilts. CAB International, Wallingford

Pennypacker BW, Leath KT (1993) Anatomical response of resistant alfalfa infected with Verticillium albo-atrum. Phytopathology 83:80-85

Pérez BA, Oriolani EJ, Otero ML, Roca MME, Becerra V, Brancher N, Matías CA, Ladux JL, Arias F, Funes C (2010) Sanitary status of olive (Olea europaea) in Argentina. 28th International Horticultural Congress (ISHS). Book of Abstracts (volume II, Symposia. Lisbon, Portugal, pp 369

Pérez-Artés E, García-Pedrajas MD, Bejarano-Alcázar J, Jiménez-Díaz RM (2000) Differentiation of cottondefoliating and nondefoliating pathotypes of Verticillium dahliae by RAPD and specific PCR analyses. Eur J Plant Pathol 106:507-517

Pérez-Artés E, Mercado-Blanco J, Ruz-Carrillo AR, RodríguezJurado D, Jiménez-Díaz RM (2005) Detection of the defoliating and nondefoliating pathotypes of Verticillium dahliae in artificial and natural soils by nested PCR. Plant Soil 268:349-356
Pérez-Jiménez F, Ruano J, Perez-Martínez P, López-Segura López-Miranda J (2007) The influence of olive oil on human health: not a question of fat alone. Mol Nutr Food Res 51:1199-1208

Perry JW, Evert RF (1983) Histopathology of Verticillium dahliae within mature roots of Russet Burbank potatoes. Can J Bot 61:3405-3421

Perry JW, Evert RF (1984) Structure of microsclerotia of Verticillium dahliae in roots of Russet Burbank potatoes. Can J Bot 62:396-401

Peters J, O’Neill T, Green K, Woodhall J, Barnes A, Lane C (2009) Detection and quantification of Verticillium dahliae and $V$. albo-atrum in soils to determine risk of Verticillium wilt in strawberry. 10th International Verticillium Symposium. Book of Abstracts. Corfu Island, Greece, pp 95

Petsikos-Panayotarov N (1980) Comportement d'um fongicide systemique apres injection dans la tronc de l'olivier afin de lutter congtre la Verticilliose. Ann Inst Phytopathol Benaki (NS) 12:227-235 (in French)

Porras-Soriano A, Soriano-Martín ML, Porras-Piedra A (2003) Grafting olive cv. Cornicabra on rootstocks tolerant to Verticillium dahliae reduces their susceptibility. Protection 22:369-374

Porras-Soriano A, Marcilla-Goldaracena I, Soriano-Martín ML, Porras Piedra A (2006) Development and resistance to Verticillium dahliae of olive plantlets inoculated with mycorrhizal fungi during the nursery period. J Agric Sci 144:151-157

Porta-Puglia A, Mifsud D (2005) First record of Verticillium dahliae on olive in Malta. J Plant Pathol 87:149

Pramateftaki PV, Antoniou PP, Typas MA (2000) The complete DNA sequence of the nuclear ribosomal RNA gene complex of Verticillium dahliae: intraspecific heterogeneity within the intergenic spacer region. Fungal Genet Biol 29:19-27

Prieto P, Mercado-Blanco J (2008) Endophytic colonisation of olive roots by the biocontrol strain Pseudomonas fluorescens PICF7. FEMS Microbiol Ecol 64:297-306

Prieto P, Navarro-Raya C, Valverde-Corredor A, Amyotte SG, Dobinson KF, Mercado-Blanco J (2009) Colonization process of olive tissues by Verticillium dahliae and its in planta interaction with the biocontrol root endophyte Pseudomonas fluorescens PICF7. Microb Biotechnol 2:499-511

Raaijmakers JM, Paulitz TC, Steinberg C, Alabouvette C, Moënne-Loccoz Y (2009) The rhizosphere: a playground and battlefield for soilborne pathogens and beneficial microorganisms. Plant Soil 321:341-361

Radišek S, Jakše J, Simončič A, Javornik B (2003) Characterization of Verticillium albo-atrum field isolates using pathogenicity data and AFLP analysis. Plant Dis 87:633638

Rallo L, Barranco D, Caballero JM, Del Rio C, Martín A, Tous J, Trujillo I (eds) (2005) Variedades de Olivo en España. Junta de Andalucía-Consejería de Agricultura y Pesca. Ministerio de Agricultura, Pesca y Alimentación. Mundi Prensa (in Spanish)

Ran LX, Liu CY, Wu GJ, Van Loon LC, Bakker PAHM (2005) Suppression of bacterial wilt in Eucalyptus urophylla by fluorescent Pseudomonas spp. in China. Biol Control 32:111-120 
Rauyaree P, Ospina-Giraldo MD, Kang S, Bhat RG, Subbarao KV, Grant SJ, Dobinson KF (2005) Mutations in VMK1, a mitogen-activated protein kinase gene, affect microsclerotia formation and pathogenicity in Verticillium dahliae. Curr Genet 48:109-116

Raya-Ortega MC (2005) Resistencia en olivo a Phytophthora spp. y Verticillium dahliae. $\mathrm{PhD}$ Thesis, University of Córdoba, Spain (in Spanish)

Reddy MS, Funk LM, Covert DC, He DN, Pedersen EA (1997) Microbial inoculants for sustainable forest. J Sustain For 5:293-306

Resende MLV, Flood J, Cooper RM (1995) Effect of methods of inoculation, inoculum density and seedling age at inoculation on the expression of resistance of cocoa (Theobroma cacao L.) to Verticillium dahliae Kleb. Plant Pathol 44:374-383

Resende MLV, Flood J, Ramsden JD, Rowan MG, Beale MH, Cooper RM (1996) Novel phytoalexins including elemental sulphur in the resistance of cocoa (Theobroma cacao L.) to Verticillium wilt (Verticillium dahliae Kleb.). Physiol Mol Plant Pathol 48:347-359

Rijkers AJM, Hiemstra JA, Bollen GL (1992) Formation of microsclerotia of Verticillium dahliae in petioles of infected ash trees. Neth J Plant Pathol 98:261-264

Robb J (2007) Verticillium tolerance: resistance, susceptibility or mutualism? Can J Bot 85:903-910

Robb J, Moukhamedov R, Hu X, Platt H, Nazar RN (1993) Putative subgroups of Verticillium albo-atrum distinguishable by PCR-based assays. Physiol Mol Plant Pathol 43:423-436

Robb J, Hu X, Platt H, Nazar R (1994) PCR assay for the detection and quantification of Verticillium species in potato. In: Schots A, Dewey FM, Oliver R (eds) Modern detection assay for plant pathogenic fungi: identification, detection and quantification. CAB International, Oxford, pp 83-90

Rodríguez E, García-Garrido JM, García PA, Campos M (2008) Agricultural factors affecting Verticillium wilt in olive orchards in Spain. Eur J Plant Pathol 122:287295

Rodríguez E, García-Garrido JM, García PA, Campos M (2009a) Large-scale epidemiological study and spatial patterns of Verticillium wilt in olive orchards in southern Spain. Crop Prot 28:46-52

Rodríguez RJ, White JE Jr, Arnold AE, Redman RS (2009b) Fungal endophytes: diversity and functional roles. New Phytol 182:314-330

Rodríguez-Jurado D (1993) Interacciones huésped-parásito en la marchitez del olivo (Olea europaea L.) inducida por Verticillium dahliae Kleb. $\mathrm{PhD}$ Thesis, University of Córdoba, Spain (in Spanish)

Rodríguez-Jurado D, Blanco-López MA, Rapoport H, JiménezDíaz RM (1993) Present status of Verticillium wilt of olive in Andalucía (southern Spain). Bull OEPP/EPPO Bull 23:513-516

Rodríguez-Lizana A, Espejo-Pérez AJ, González-Fernández P, Ordóñez-Fernández R (2008) Pruning residues as an alternative to traditional tillage to reduce erosion and pollutant dispersion in olive groves. Water Air Soil Pollut 193:165-173

Ruggieri G (1946) Una nuova malatia dell'olivo. L'Italia Agricola 83:369-372 (in Italian)
Ruggieri G (1948) Ricerche ed esperienze su una tracheoverticilliosi dell'olivo. Olivicoltora 3:6-9 (in Italian)

Sadras VO, Quiroz F, Echarte L, Escande A, Pereyra VR (2000) Effect of Verticillium dahliae on photosynthesis, leaf expansion and senescente of field-grown sunflower. Universidad de Mar del plata. INIA. Arg Ann Bot 86:1007-1015

Saeedizadeh A, Kheiri A, Okhovat M, Hoseininejad A (2003) Study on interaction between root-knot nematode Meloidogyne javanica and wilt fungus Verticillium dahliae on olive seedlings in greenhouse. Commun Agric Appl Biol Sci 68:139-43

Saeedizadeh A, Kheiri A, Okhovat SM, Zad J, Nehad SAH (2006) A study on the growth of one-year-old seedling of olive cv. Zard in the presence of two different soilborne pathogens, Meloidogyne javanica and Verticillium dahliae. Iran J Agric Sci 37:793-800

Saitou N, Nei M (1987) The neighbour-joining method: a new method for reconstructing phylogenetic trees. Mol Biol Evol 4:406-425

Sánchez-Alcalá I (2005) Evaluación de la eficacia de sustancias fungicidas para el control de la verticilosis del olivo y de la podredumbre radicular del olivo. Trabajo Profesional Fin de Carrera University of Córdoba, Spain, 211 pp (in Spanish)

Sánchez-Hernández ME, Ruiz-Dávila A, Pérez de Algaba A, Blanco-López MA, Trapero-Casas A (1998) Occurrence and aetiology of death of young olive trees in southern Spain. Eur J Plant Pathol 104:347-357

Sanei SJ, Okhoavat SM, Hedjaroude GA, Saremi H, JavanNikkhah M (2004) Olive verticillium wilt or dieback of olive in Iran. Commun Agric Appl Biol Sci 69:433-442

Sanei SJ, Okhovvat SM, Javan-Nikkhah M, Saremi H (2005) Vegetative compatibility and pathogenecity of Verticillium dahliae Kleb. isolates from olive in Iran. Commun Agric Appl Biol Sci 70:323-325

Saremi H, Amarlou A, Okhovvat SM (2006) Verticillium wilt of olive branches in Iran and its control managements with soil solarization method. Commun Agric Appl Biol Sci 71:1187-1196

Sarwar M, Kirkegaard J (1998) Biofumigation potential of Brassicas. Plant Soil 201:71-112

Saydam C, Copcu M (1972) Verticillium wilt of olives in Turkey. J Turk Phytopathol 9:235-252

Scheffer RJ (1990) Mechanisms involved in biological control of Dutch elm disease. J Phytopathol 130:265-276

Scheffer RJ, Voeten JGWF, Guries RP (2008) Biological control of Dutch Elm Disease. Plant Dis 92:192-200

Schena L, Nigro F, Ippolito A (2004a) Real-time PCR detection and quantification of soilborne fungal pathogens: the case of Rosellinia necatrix, Phytophthora nicotianae, $P$. citrophthora and Verticillium dahliae. Phytopathol Mediterr 43:273-280

Schena L, Nigro F, Ippolito A, Gallitelli D (2004b) Real-time quantitative PCR: a new technology to detect and study phytopathogenic and antagonistic fungi. Eur J Plant Pathol 110:893-908

Schnathorst WC (1981) Life cycle and epidemiology of Verticillium. In: Mace ME, Bell AA, Beckman CH (eds) Fungal wilt diseases of plants. Academic, New York, pp 81-111

Schnathorst WC, Mathre DE (1966a) Host range and differentiation of a severe form of Verticillium albo-atrum in cotton. Phytopathology 56:1155-1161 
Schnathorst WC, Mathre DE (1966b) Cross-protection in cotton with strain of Verticillium albo-atrum. Phytopathology 56:1204-1209

Schnathorst WC, Sibbett GS (1971a) T-1 Verticillium strain: major factor in cotton and olive wilt. Calif Agric 25:3-5

Schnathorst WC, Sibbett GS (1971b) The relation of strains of Verticillium albo-atrum to severity of Verticillium wilt in Gossypium hirsutum and Olea europaea in California. Plant Dis Reptr 9:780-782

Schreiber LR, Green RJ Jr (1962) Comparative survival of mycelium, conidia, and microsclerotia of Verticillium albo-atrum in mineral soil. Phytopathology 52:288-289

Sergeeva V, Spooner-Hart R (2009) Olives diseases and disorders in Australia. 4th European Meeting of the IOBC working Group Integrated Protection of Olive Crops, Book of Abstracts, Córdoba, Spain, p 30

Serrhini MN, Zeroual A (1995) Verticillium wilt in Morocco. Olivae 58:58-61

Shigo AL (1984) Compartmentalization: a conceptual framework for understanding how trees grow and defend themselves. Annu Rev Phytopathol 22:189-214

Sinclair WA, Smith KL, Larsen AO (1981) Verticillium wilt of maples: symptoms related to the movement of the pathogen in stems. Phytopathology 71:340-345

Sinclair WA, Lyon HH, Johnson WT (1987) Diseases of trees and shrubs. Comstock Publishing Associates, Cornell University Press. Ithaca and London

Snyder WC, Hansen HN, Wilhelm S (1950) New host of Verticillium albo-atrum. Plant Dis Rep 34:26-27

Strausbaugh CA (1993) Assessment of vegetative compatibility and virulence of Verticillium dahliae isolates from Idaho potatoes and tester strains. Phytopathology 83:1253-1258

Strausbaugh CA, Schroth MN, Weinhold AR, Hancock JG (1992) Assessment of vegetative compatibility of Verticillium dahliae tester strains and isolates from California potatoes. Phytopathology 82:61-68

Subbarao KV, Chassot A, Gordon TR, Hubbard JC, Bonello P, Mullin R, Okamoto D, Davis M, Koike ST (1995) Genetic relationships and cross pathogenicities of Verticillium dahliae isolates from cauliflower and other crops. Phytopathology 85:1105-1112

Subbarao KV, Hubbard JC (1999) Evaluation of broccoli residue incorporation into field soil for Verticillium wilt control in cauliflower. Plant Dis 83:124-129

Talboys PW (1968) Water deficits in vascular disease. In: Water deficits and plant growth. Vol. II: Plant water consumption and response. Academic, New York, pp 255-311

Tantaoui A, Lachqer K, Sedra MH (2002) Vegetative compatibility and pathogenicity of Verticillium dahliae isolates from olive (Olea europea). Phytopathol Mediterr 41:19-27

Tawil MZ, Halak HA, Abdón MM (1991) Introducción a la lucha contra el Verticillium dahliae del olivo. Olivae 39:36-40 (in Spanish)

Taylor JB, Flentje NT (1968) Infection, recovery from infection and resistance of apricot trees to Verticillium albo-atrum. NZ J Bot 61:417-426

Termorshuizen AJ, Davis JR, Gort G, Harris DC, Huisman OC, Lazarovits G, Locke T, Melero-Vara JM, Mol L, Paplomatas EJ, Platt HW, Powelson M, Rouse DI, Rowe RC, Tsror L (1998) Interlaboratory comparison of methods to quantify microsclerotia of Verticillium dahliae in soil. Appl Environ Microbiol 64:3846-3853

Thanassoulopoulos CC (1993) Spread of Verticillium wilt by nursery plants in olive grows in the Chalkidiki area (Greece). Bull OEPP/EPPO Bull 23:517-520

Thanassoulopoulos CC, Biris DA, Tjamos EC (1979) Survey of Verticillium wilt of olive trees in Greece. Plant Dis Rep 63:936-940

Thanassoulopoulos CC, Biris DA, Tjamos EC (1981) Weed host as inoculum source of Verticillium in olive orchards. Phytopathol Mediterr 20:164-168

Thomashow LS, Weller DM (1996) Current concepts in the use of introduced bacteria for biological disease control: mechanisms and antifungal metabolites. In: Stacey G, Keen NT (eds) Plant-microbe interactions, vol 1. Chapman and Hall, New York, pp 187-235

Tippett JT, Shigo AL (1981) Barrier zone formation: a mechanism of tree defense against vascular pathogens. IAWA Bull 2:163-168

Tjamos EC (1993) Prospects and strategies in controlling Verticillium wilt of olive. Bull OEPP/EPPO Bull 23:505512

Tjamos EC, Beckman CH (1989) Vascular wilt diseases of plants. NATO-ASI Series, Vol. H28. Springer, Berlin

Tjamos EC, Botseas D (1987) Occurrence of Verticillium dahliae in leaves of Verticillium-wilted olive trees. Can J Plant Pathol 9:86

Tjamos EC, Jiménez-Díaz RM (1998) Management of disease. In: Hiemstra JA, Harris DC (eds) A compendium of Verticillium wilts in tree species. Ponsen and Looijen, Wageningen, pp 55-57

Tjamos EC, Paplomatas EJ (1987) Effect of solarization on the survival of fungal antagonists of Verticillium dahliae. EPPO Bull 17:645-653

Tjamos EC, Paplomatas EJ (1988) Long-term effect of soil solarization in controlling verticillium wilt of globe artichokes in Greece. Plant Pathol 37:507-515

Tjamos EC, Tsougriani H (1990) Formation of Verticillium dahliae microsclerotia in partially disintegrated leaves of Verticillium affected olive trees. 5th Int Verticillium Symposium, Book of Abstracts, Leningrad, Soviet Union, p 20

Tjamos EC, Thanassoulopoulos CC, Biris DA (1985) Resistance evaluation to Verticillium dahliae olive rootstocks. Proc 3rd Nat Phytopathol Conf Hellenic Phytopathol Soc, pp 18-19

Tjamos EC, Biris DA, Paplomatas EJ (1991) Recovery of olive trees from Verticillium wilt after individual application of soil solarisation in established olive orchards. Plant Dis 75:557-562

Tjamos EC, Tsitsigiannis DI, Tjamos SE, Antoniou P, Katinakis P (2004) Selection and screening of endorhizosphere bacteria from solarised soils as biocontrol agents against Verticillium dahliae of solanaceous hosts. Eur J Plant Pathol 110:35-44

Tjamos SE, Flemetakis E, Paplomatas EJ, Katinakis P (2005) Induction of resistance to Verticillium dahliae in Arabidopsis thaliana by the biocontrol agent K-165 and pathogenesis-related proteins gene expression. Mol PlantMicrob Interact 18:555-561

Toit LJ, Derie ML, Hernandez-Perez P (2005) Verticillium wilt in spinach seed production. Plant Dis 89:4-11

Trapero A, Blanco-López MA (2008) Enfermedades. In: Barranco D, Fernández-Escobar R, Rallo L (eds) El 
cultivo de olivo. Coedición Junta de Andalucía/MundiPrensa, Madrid, pp 595-656 (in Spanish)

Trapero A, Roca LF, Moral J, López-Escudero FJ, BlancoLópez MA (2009a) Enfermedades del olivo. Phytoma 209:18-24 (in Spanish)

Trapero C, Rallo L, Blanco-López MA, López-Escudero FJ (2009b) Improvement of inoculation methods for screening olive genotypes for resistance to Verticillium dahliae. 10th Int Verticillium Symposium, Book of Abstracts, Corfu Island, Hellas, p 70

Tsai YL, Olson BH (1992) Rapid method for separation of bacterial DNA from humic substances in sediments for polymerase chain reaction. Appl Environ Microbiol 58:2292-2295

Tsror L, Levin AG (2003) Vegetative compatibility and pathogenicity of Verticillium dahliae Kleb. isolates from olive in Israel. J Phytopathol 151:451-455

Tsror L, Hazanovsky M, Mordechi-Lebiush S, Sivan S (2001) Aggressiveness of Verticillium dahliae isolates from different vegetative compatibility groups to potato and tomato. Plant Pathol 50:477-482

Tsror L, Lebiush S, Meshulam M, Erlich O, Hazanovsky M, Aharon M, Matan E, Tregerman M, Gamliel A (2007) Biofumigation for the control of soilborne diseases. Acta Hortic 747:389-394

Typas MA, Griffen AM, Bainbridge BW, Heale JB (1992) Restriction fragment length polymorphisms in mitochondrial DNA and ribosomal RNA gene complexes as an aid to the characterization of species and sub-species populations in the genus Verticillium. FEMS Microbiol Lett 95:157-162

Uppal AK, El Hadrami A, Adam LR, Tenuta M, Daayf F (2008) Biological control of potato wilt under controlled and field conditions using selected bacterial antagonists and plant extracts. Biol Control 44:90-100

Uremis I (2005) Determination of weed species and their frequency and density in olive groves in Hatay province of Turkey. Pak J Biol Sci 8:164-167

Utkhede RS, Sholberg PL, Smirle MJ (2001) Effects of chemical and biological treatment on growth and yield of apple trees planted in Phytophthora cactorum infested soil. Can J Plant Pathol 23:163-167

xVallad GE, Subbarao KV (2008) Colonization of resistant and susceptible lettuce cultivars by a green fluorescent proteintagged isolate of Verticillium dahliae. Phytopathology 98:871-885

Vallad GE, Bhat RG, Koike ST, Ryder EJ, Subbarao KV (2005) Weed-borne reservoirs and seed transmission of Verticillium dahliae in lettuce. Plant Dis 89:317-324
Van Bruggen AHC (1995) Plant disease severity in high-input compared to reduced-input and organic farming systems. Plant Dis 79:976-984

Vargas-Machuca R, Martin C, Galindez W (1987) Recovery of Verticillium dahliae from weed plants in farmers' fields in Peru. Plant Dis 71:756-758

Vigouroux A (1975) Verticillium dahliae, agent d'un dépérissement de l'olivier en France. Ann Phytopathol 7:37-44 (in French)

Volossiouk T, Robb EJ, Nazar RN (1995) Direct DNA extraction for PCR-mediated assays of soil organisms. Appl Environ Microbiol 61:3972-3976

Weller DM (1988) Biological control of soilborne plant pathogens in the rhizosphere with bacteria. Annu Rev Phytopathol 26:379-407

Whipps JM (2001) Microbial interactions and biocontrol in the rhizosphere. J Exp Bot 52:487-511

Wilhelm S (1955) Longevity of the Verticillium wilt fungus in the laboratory and field. Phytopathology 45:180-181

Wilhelm S (1981) Sources and genetics of host resistance in field and fruit crops. In: Mace ME, Bell AA, Beckman CH (eds) Fungal wilt diseases of plants. Academic, New York, pp 299-376

Wilhelm S, Taylor JB (1965) Control of Verticillium wilt of olive through natural recovery and resistance. Phytopathology 55:310-316

Xiao CL, Subbarao KV (2000) Effects of irrigation and Verticillium dahliae on Cauliflower root and shoot growth dynamics. Phytopathology 90:995-1004

Xiao CL, Subbarao KV, Schulbach KF, Koike ST (1998) Effects of crop rotation and irrigation on Verticillium dahliae microsclerotia in soil and wilt in cauliflower. Phytopathology 88:1046-1055

Yildiz A, Doğan MN, Boz Ö, Benlioğlu S (2009) Weed host of Verticillium dahliae in cotton fields and characterization of V. dahliae isolates from weeds. Phytoparasitica 37:171-178

Zachos DG (1963) La verticilliose de l'oliver en Gréce. Ann Inst Phytopathol Benaki (NS) 5:105-107 (in French)

Zeise K, von Tiedemann A (2002) Application of RAPD-PCR for virulence type analysis within Verticillium dahliae and V. longisporum. J Phytopathol 150:557-563

Zhengjun X, Achar PN, Benkang G (1998) Vegetative compatibility groupings of Verticillium dahliae from cotton in mainland China. Eur J Plant Pathol 104:871-876

Zhou L, Hu Q, Johansson A, Dixelius C (2006) Verticillium longisporum and $V$. dahliae: infection and disease in Brassica napus. Plant Pathol 55:137-144

Zohary D, Spiegel-Roy P (1975) Beginnings of fruit growing in the old world. Science 187:319-327 